\title{
WestVirginiaUniversity
}

THE RESEARCH REPOSITORY @ WVU

Graduate Theses, Dissertations, and Problem Reports

2006

\section{Carbon fiber reinforced latex modified concrete for bridge deck overlays}

Dony Cherian Oommen

West Virginia University

Follow this and additional works at: https://researchrepository.wvu.edu/etd

\section{Recommended Citation}

Oommen, Dony Cherian, "Carbon fiber reinforced latex modified concrete for bridge deck overlays" (2006). Graduate Theses, Dissertations, and Problem Reports. 4254.

https://researchrepository.wvu.edu/etd/4254

This Thesis is protected by copyright and/or related rights. It has been brought to you by the The Research Repository @ WVU with permission from the rights-holder(s). You are free to use this Thesis in any way that is permitted by the copyright and related rights legislation that applies to your use. For other uses you must obtain permission from the rights-holder(s) directly, unless additional rights are indicated by a Creative Commons license in the record and/ or on the work itself. This Thesis has been accepted for inclusion in WVU Graduate Theses, Dissertations, and Problem Reports collection by an authorized administrator of The Research Repository @ WVU. For more information, please contact researchrepository@mail.wvu.edu. 


\title{
Carbon Fiber Reinforced Latex Modified Concrete \\ For \\ Bridge Deck Overlays
}

\author{
Dony Cherian Oommen
}

\author{
Thesis submitted to the \\ College of Engineering and Mineral Resources \\ at West Virginia University \\ in partial fulfillment of the requirements \\ for the degree of \\ Master of Science \\ in \\ Mechanical Engineering
}

Dr. Samir N. Shoukry, MAE, Chair

Dr. Jacky Prucz, MAE

Dr. Kenneth Means, MAE

Dr. Gergis W. William, CEE

Dr. Mourad Riad, CEE
Department of Mechanical and Aerospace Engineering
Morgantown, West Virginia 2006

Keywords: Bridge Deck Overlays, Carbon Fiber, Flexure, Fracture, Latex Modified Concrete, Tension 


\section{ABSTRACT \\ Carbon Fiber Reinforced Latex Modified Concrete \\ For \\ Bridge Deck Overlays}

\section{Dony Cherian Oommen}

Latex modified concrete deck overlay systems are used nationwide. However, cracking, spalling and delamination have been observed both in the case of old and new bridge deck construction. Such problems have also been observed even before a newly constructed bridge deck has been opened to traffic.

In this investigation, the effect of reinforcing Latex Modified Concrete (LMC) with carbon fibers is examined. The study focuses on formulation of the mix design and laboratory test methods to evaluate the potential of using Carbon Fiber Reinforced Latex Modified Concrete (CFLMC) for bridge deck overlays. A tension test method of concrete was perfected during the course of this research.

At a low volume fraction of $0.15 \%$ (ratio of the volume of carbon fibers to the volume of concrete), CFLMC showed an average increase of $26 \%$ in strain to failure compared to LMC, in a direct tension test. Besides an average $17 \%$ increase in ultimate flexural strength, the stress strain curves also show an average increase of $43 \%$ in failure strain under flexure. Improvements in strain to failure or ductility have the potential to reduce cracking in overlays. Fracture tests predict the fracture toughness of CFLMC to have an average improvement of $27 \%$, compared to LMC. 


\section{ACKNOWLEDGEMENTS}

First and foremost, I would like to thank my advisor, Dr. Samir Shoukry, for his valuable guidance and support throughout my graduate education process. It was a pleasure and a unique experience working with him.

I am indebted to Dr. Mourad Riad for his advice in every step of this research.

I also thank Dr. Kenneth Means, Dr. Gergis William and Dr Jacky Prucz for being part of my advisory committee, and providing me the necessary guidance and important suggestions.

Special thanks to Doug Cutlip and Cliff Judy for help with laboratory work.

Also I would like to thank my colleagues Dhananjay, Praveen, Thomas, Musat, and Gabor for their friendship and a helping hand during these years.

I want to thank my wife, Sharon for her love, support, and encouragement. My parents and brother have always inspired me and given me prayer support for which I am ever thankful.

Finally, I thank and praise Almighty God for His marvelous ways and miracles in my life. 


\section{TABLE OF CONTENTS}

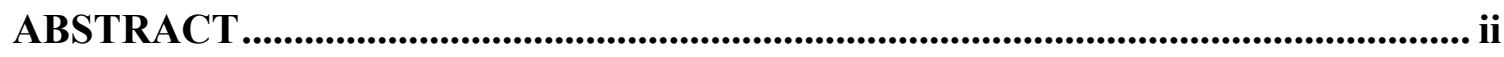

ACKNOWLEDGEMENTS .................................................................................ii

TABLE OF CONTENTS .................................................................................................. iv

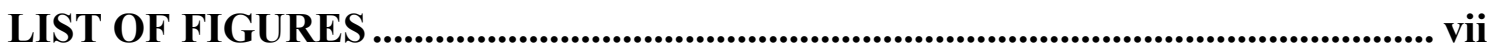

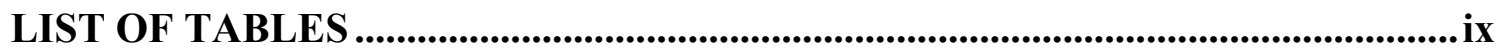

ABBREVIATION …....................................................................................................... $x$

CHAPTER ONE ................................................................................................................... 1 INTRODUCTION

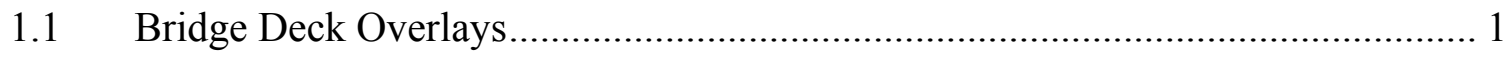

$1.2 \quad$ Need for Polymer Modification and Fiber Reinforcement..................................... 3

1.2.1 Latex Modified Concrete (LMC) ............................................................... 4

1.2.2 Carbon Fiber Reinforced Concrete …………................................................ 5

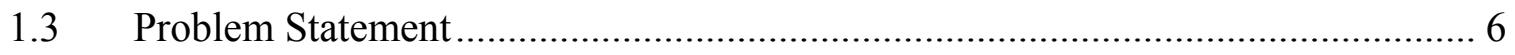

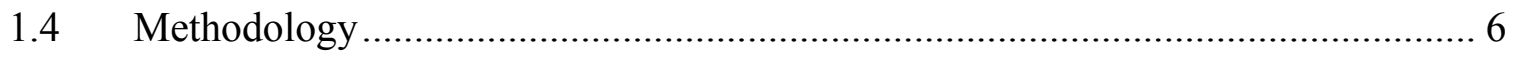

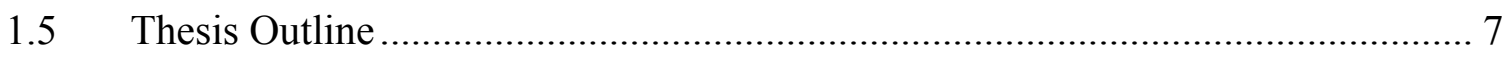

CHAPTER TWO ................................................................................................................. 8

LITERATURE REVIEW

2.1 Latex Modified Concrete ………………….............................................. 8

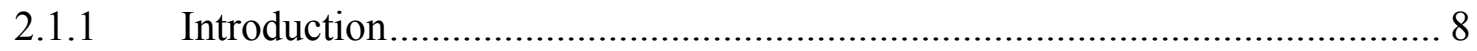

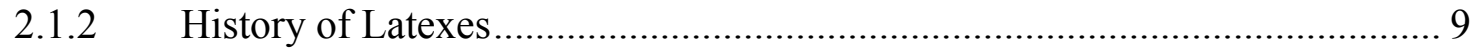

2.1.3 Types of Polymer Latexes ....................................................................... 10

2.1.4 Typical Formulation of Styrene Butadiene Latex........................................ 11

2.1.5 Principle of Latex Modification.............................................................. 12

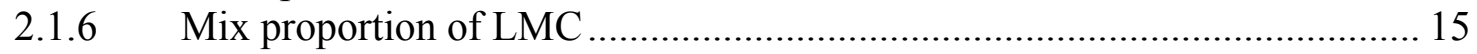

2.1.7 Placement of LMC on Bridge Decks ....................................................... 15

2.2 Carbon Fiber Reinforced Concrete ……………........................................... 17

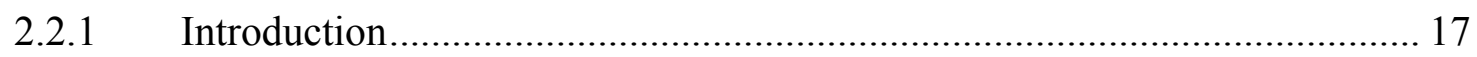

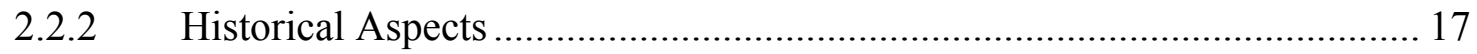

2.2.3 Principle of Fiber Modification ............................................................. 19 
2.3 Concept of Fiber Reinforcement 'and' Polymer Modification of Concrete ......... 21

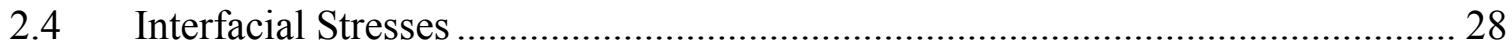

2.4.1 Interfacial Shear between Fibers and Cement Matrix................................. 28

2.4.2 Interfacial Strength between Overlay and Substrate................................ 29

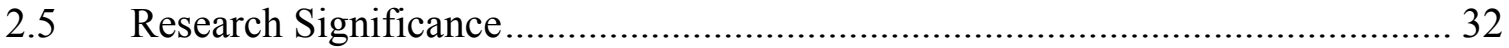

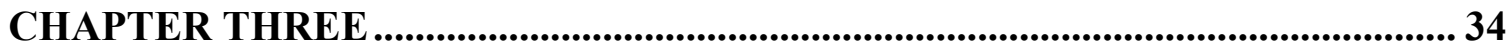

MATERIALS AND MIX PROPORTIONS

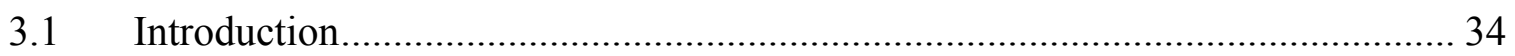

3.2 Determination of Mix Proportions................................................................. 34

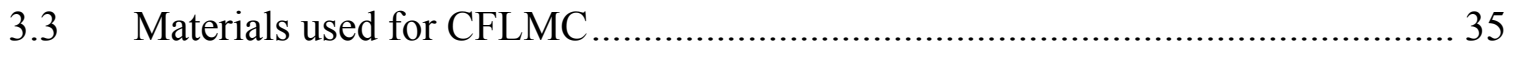

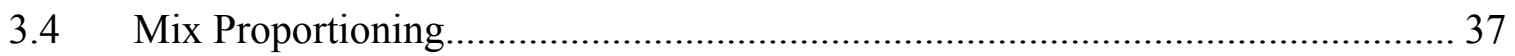

3.5 Calculation of Volume Fraction of Carbon Fibers .......................................... 39

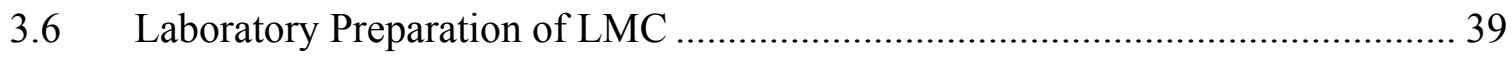

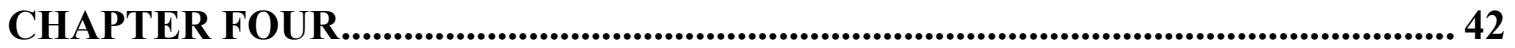
SPECIMEN PREPARATION AND TEST METHODS

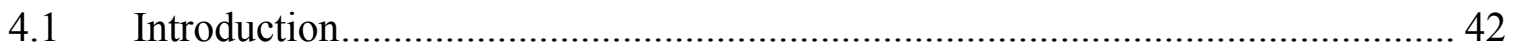

4.2 Description of Specimen Preparation and Tests Methods ................................ 43

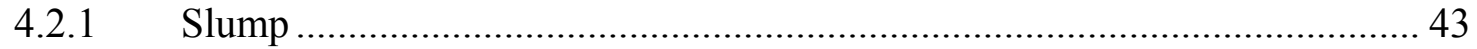

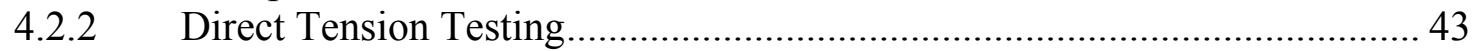

4.2.3 Four Point Loading Test .................................................................... 49

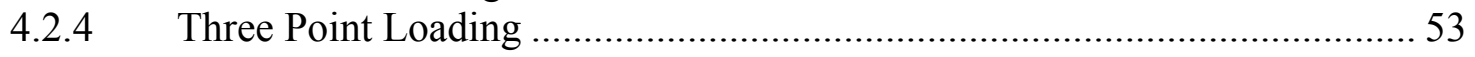

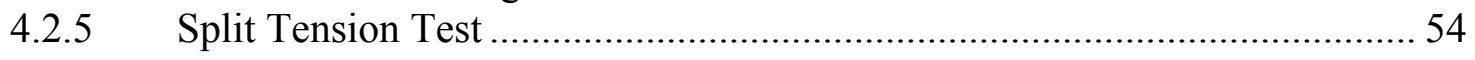

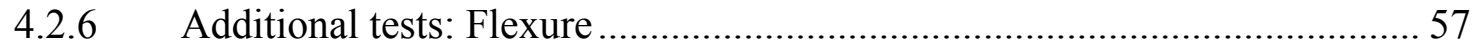

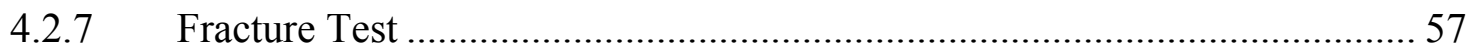

4.2.8 Split Composite Cylinder Test................................................................ 59

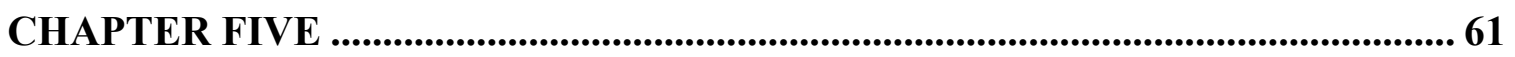
RESULTS AND ANALYSIS

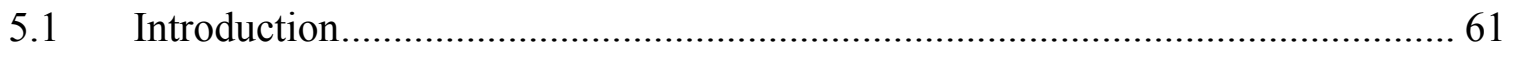

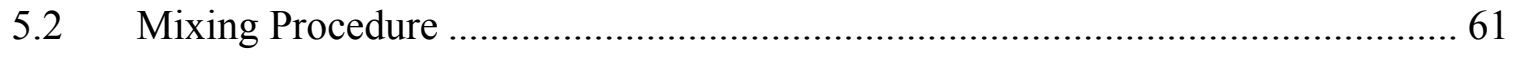

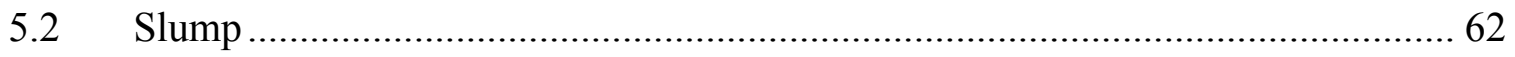

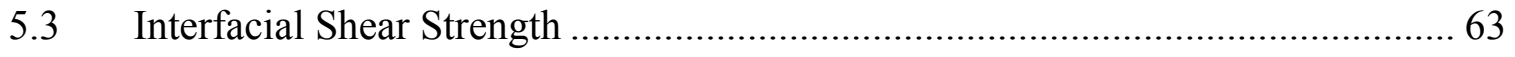




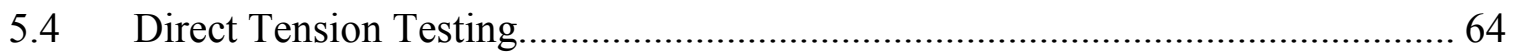

5.4.1 Theoretical Prediction of Tensile Elastic Modulus......................................... 67

5.4.2 Theoretical Prediction of Tensile Strength ..................................................... 67

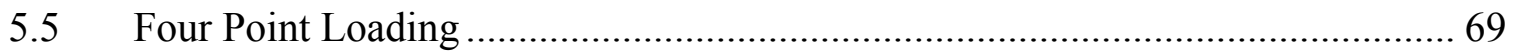

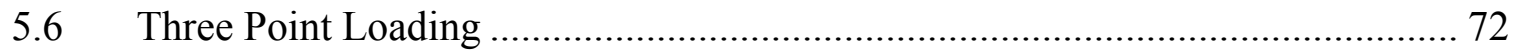

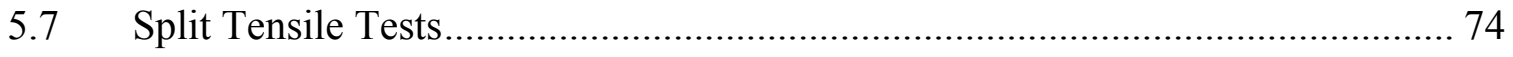

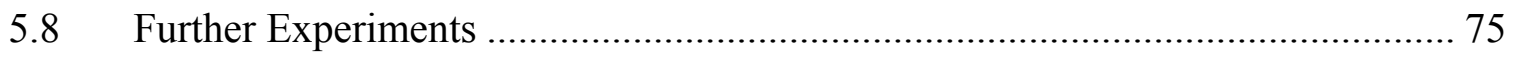

5.8.1 Four Point Loading Tests (Flexure) ........................................................ 75

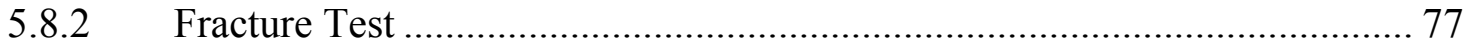

5.8.3 Split Tensile Test on Composite Cylinders .................................................. 80

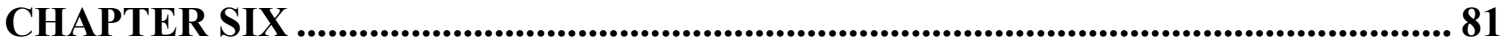
CONCLUSIONS

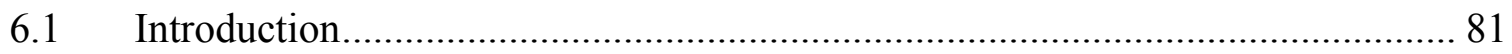

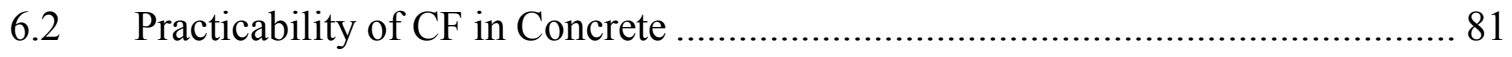

6.3 Complimentary roles of LMC and Carbon Fibers in Concrete. ........................... 81

6.4 Effect of Carbon Fibers on the Mechanical Properties of LMC ........................... 81

6.4.1 Improvements due to Carbon Fibers.......................................................... 82

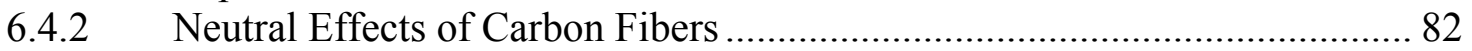

6.4.3 Disadvantages of CFLMC ………………….......................................... 82

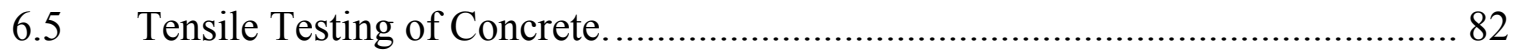

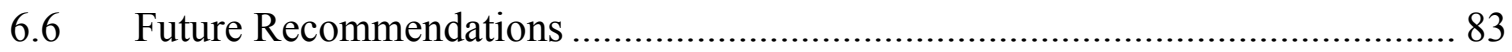

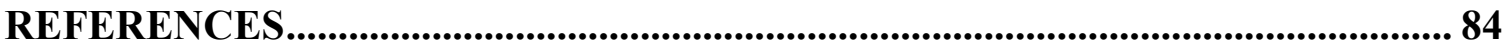

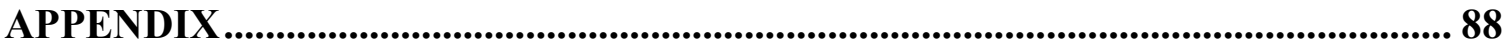




\section{LIST OF FIGURES}

Figure 1.1: Development of cracking, spalling and delamination [1] ............................. 1

Figure 1.2: Electron micrographs of LMC and PCC (magnification=12,000x) [3] ........ 4

Figure 1.3: Carbon fibers shown to arrest microcracks [10] ..................................... 5

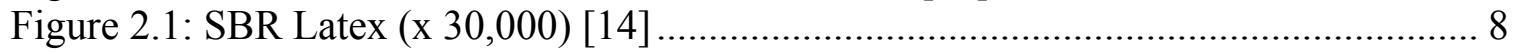

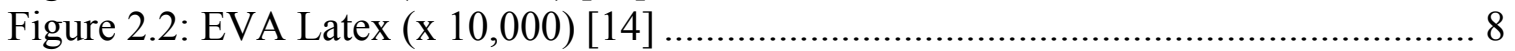

Figure 2.3: Simplified model of formation of polymer-cement co-matrix [2] ................ 12

Figure 2.4: Simplified model of process of polymer film formation on cement hydrates $[2]$

Figure 2.5: Schematic of particle size vs. fiber distribution for $40 \mathrm{~mm}$ long fibers within a $40 \mathrm{~mm}$ square [11]

Figure 2.6: Dependence of strength of carbon fiber reinforced cement on fiber content

(\% by weight of cement) [30]

Figure 2.7: Effects of water-cement ratio, polymer-cement ratio, and steel fiber volume fracture on the slump of concrete (max. aggregate size $=0.79$ in, $V_{f}=0-2 \%$, (0.01x0.022 in), $1 / \mathrm{d}=53$, PAE latex) [32].....

Figure 2.8: Load/deflection curve during flexural testing of (a) plain mortar; (b) mortar

with latex; and (c) mortar with latex and 2.2 vol.\% carbon fibers [34] .................. 25

Figure 2.9: Dependence of tensile strength on fiber content of cement pastes [39] ........ 27

Figure 2.10: Dependence of flexural strength on fiber content of cement pastes [39] .... 27

Figure 2.11: Schematic representation of a crack traveling through a composite [35] ... 28

Figure 2.12: Split tensile test to evaluate bond strength of composite cylinder .............. 30

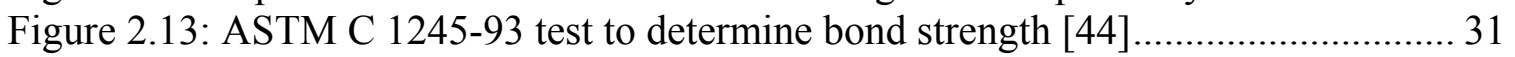

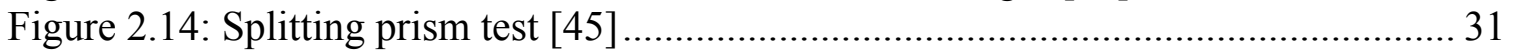

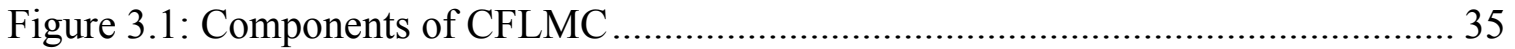

Figure 3.2: Relationship between composite strength and mixing time in a conventional

mortar mixer for carbon-fiber reinforced cements [26] .................................. 37

Figure 3.3: Slump vs CF \% (weight of cement) ...................................................... 38

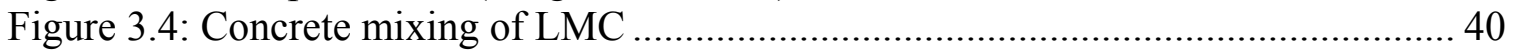

Figure 3.5: Dry mixing of carbon fibers with cement .............................................. 41

Figure 4.1: Dimensions of tensile test specimen (all dimensions in inches). .................. 44

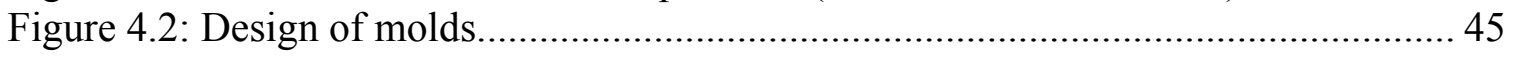

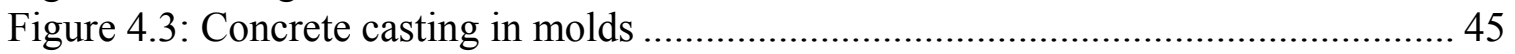

Figure 4.4: Demolding upper layer of mold ............................................................ 46

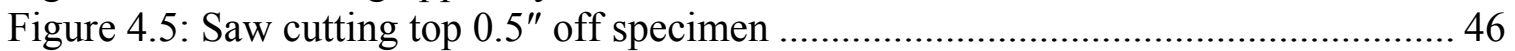

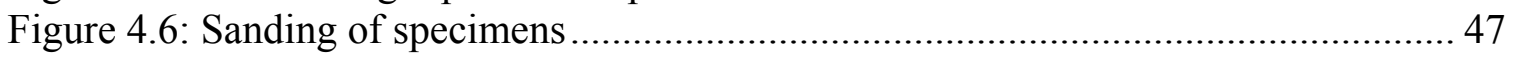

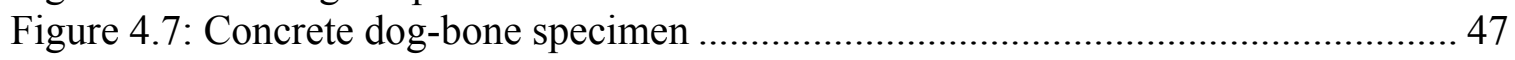

Figure 4.8: Loading arrangement for dog-bone test specimens................................... 48

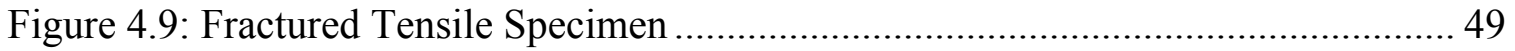

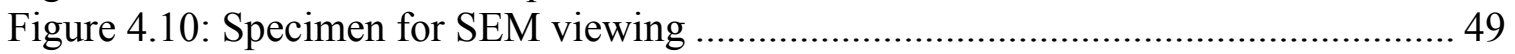

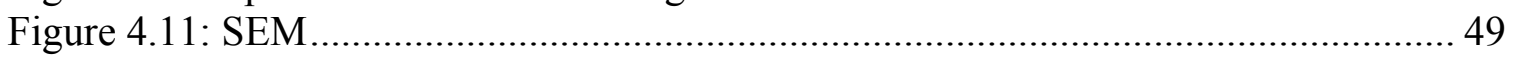

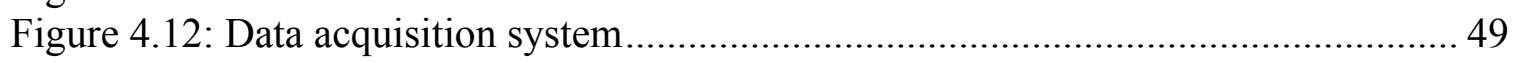

Figure 4.13: Specimen dimensions for four point loading method ............................... 50

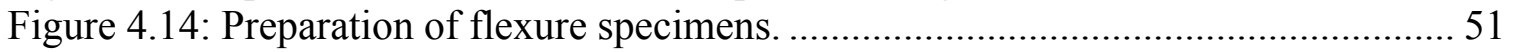

Figure 4.15: Instrumented specimen for four point loading specimen. ........................ 51

Figure 4.16: MTS 810 Hydraulic test machine .................................................... 52 


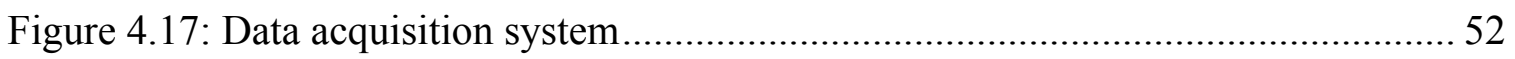

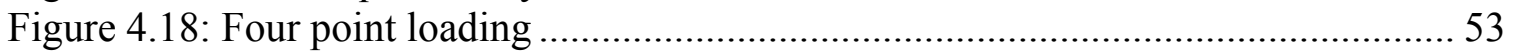

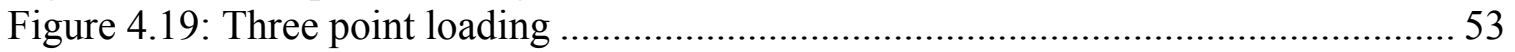

Figure 4.20: Specimen dimensions for three point loading method .............................. 54

Figure 4.21: Plastic molds for split tension test [www.globalgilson.com] ...................... 54

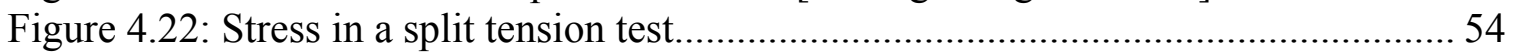

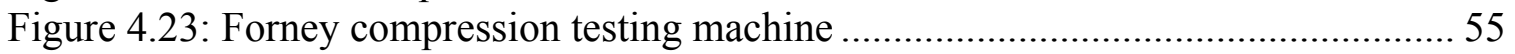

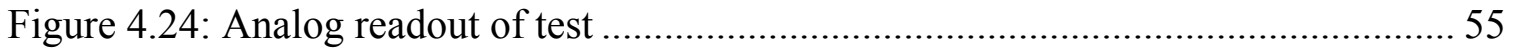

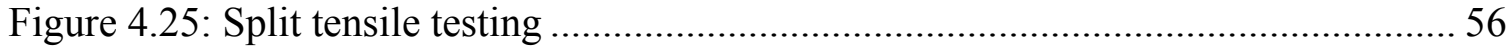

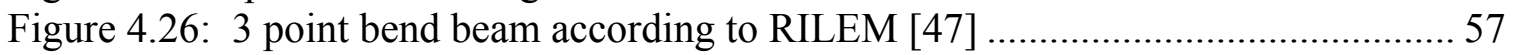

Figure 4.27: Load-displacement curve for evaluation of the fracture energy $\mathrm{G}_{\mathrm{F}}[47] \ldots \ldots .58$

Figure 4.28: Three point loading for determination of fracture energy ..........................59

Figure 4.29: Splitting tensile test of composite cylindrical specimen .............................59

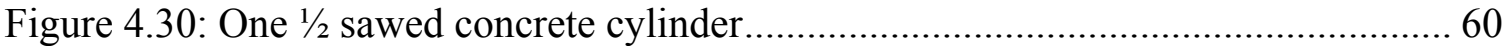

Figure 5.1: SEM photograph showing uniform fiber dispersion in concrete .................. 61

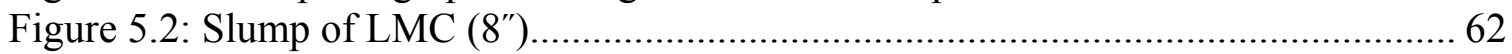

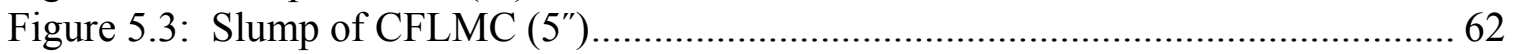

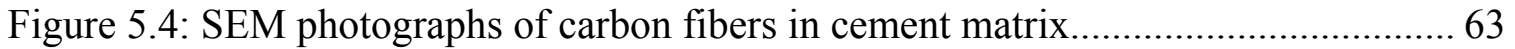

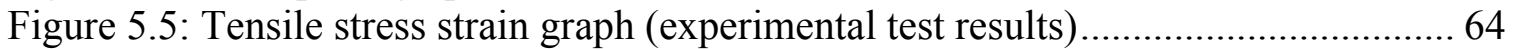

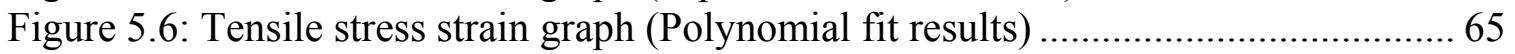

Figure 5.7: Plot of tensile modulus of elasticity (experimental test results)....................66

Figure 5.8: Plot of tensile modulus of elasticity (polynomial fit results) ........................66

Figure 5.9: Load Vs Displacement graph for four point loading.................................. 69

Figure 5.10: Stress Strain curve for four point loading (experimental test results) ......... 70

Figure 5.11: Stress Strain curve for four point loading (polynomial fit results)............... 70

Figure 5.12: Change in strain distribution and shift of neutral axis for carbon fiber-

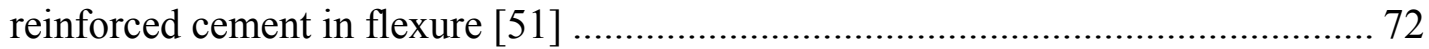

Figure 5.13: Stress Strain curve for three point loading (experimental test results)........ 72

Figure 5.14: Stress Strain curve for three point loading (polynomial fit results) ............. 73

Figure 5.15: Stress vs. Strain plot for LMC \& CFLMC specimens in four point loading

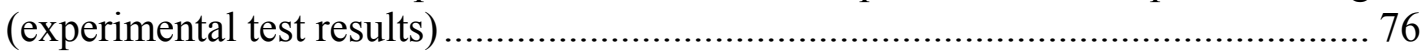

Figure 5.17: Load vs. Displacement in fracture test (experimental test results).............. 78

Figure 5.18: Load vs. Displacement in fracture test (average test results) ..................... 78

Figure 5.19: Fracture toughness vs. CF \% (by weight of cement) ................................ 79 


\section{LIST OF TABLES}

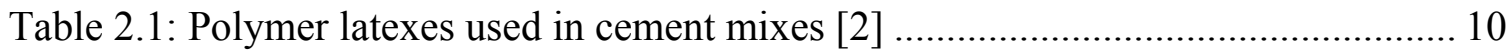

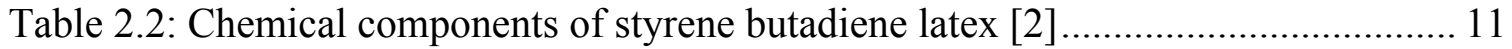

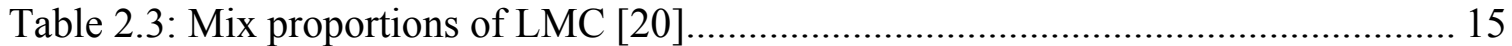

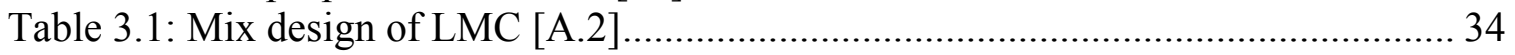

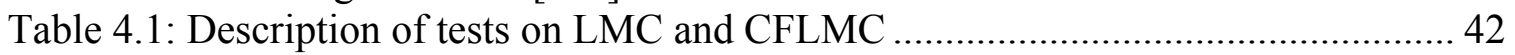

Table 4.2: Description of tests on LMC specimens with varying CF \% ........................ 43

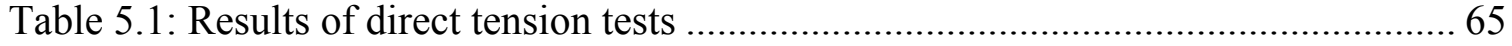

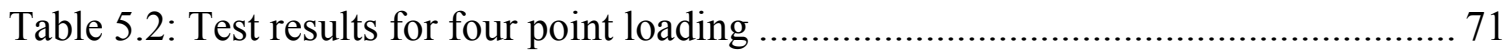

Table 5.3: Test results for three point load test....................................................... 73

Table 5.4: Test results for split tensile test ............................................................... 74

Table 5.5: Test results for four point loading test for CF\% in LMC ….......................... 77

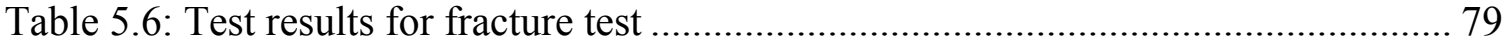

Table 5.7: Test results of split tensile test for bond strength ..................................... 80 


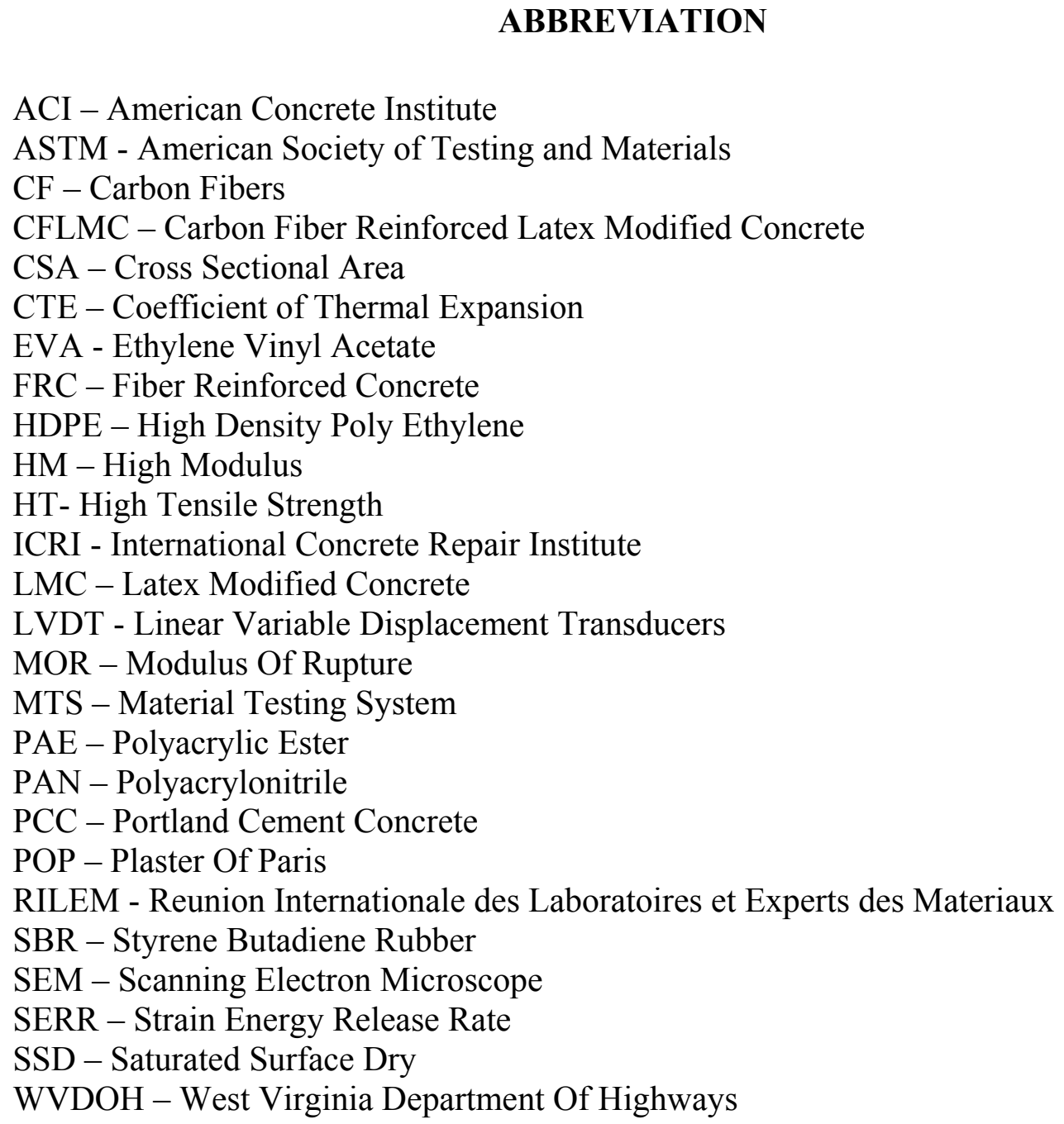

ACI - American Concrete Institute

ASTM - American Society of Testing and Materials

CF - Carbon Fibers

CFLMC - Carbon Fiber Reinforced Latex Modified Concrete

CSA - Cross Sectional Area

CTE - Coefficient of Thermal Expansion

EVA - Ethylene Vinyl Acetate

FRC - Fiber Reinforced Concrete

HDPE - High Density Poly Ethylene

HM - High Modulus

HT- High Tensile Strength

ICRI - International Concrete Repair Institute

LMC - Latex Modified Concrete

LVDT - Linear Variable Displacement Transducers

MOR - Modulus Of Rupture

MTS - Material Testing System

PAE - Polyacrylic Ester

PAN - Polyacrylonitrile

PCC - Portland Cement Concrete

POP - Plaster Of Paris

RILEM - Reunion Internationale des Laboratoires et Experts des Materiaux

SBR - Styrene Butadiene Rubber

SEM - Scanning Electron Microscope

SERR - Strain Energy Release Rate

SSD - Saturated Surface Dry

WVDOH - West Virginia Department Of Highways 


\section{CHAPTER ONE}

\section{INTRODUCTION}

\subsection{Bridge Deck Overlays}

Durability of hydraulic-cement concrete is defined as ability to resist weathering action, chemical attack, abrasion, or any other process of deterioration. Over the past 25 years, corrosion of reinforcement in concrete slabs has been a matter of serious concern regarding durability of reinforced concrete structures, especially bridge decks. Portland cement concrete is inherently alkaline $\&$ does not corrode the rebar. However, in the presence of adverse chemicals, the $\mathrm{pH}$ of concrete reduces, causing the rusting of steel. The corrosion products occupy a larger volume than the steel they replace, causing internal tensile stresses that can result in cracking, spalling and in extreme cases, delamination.
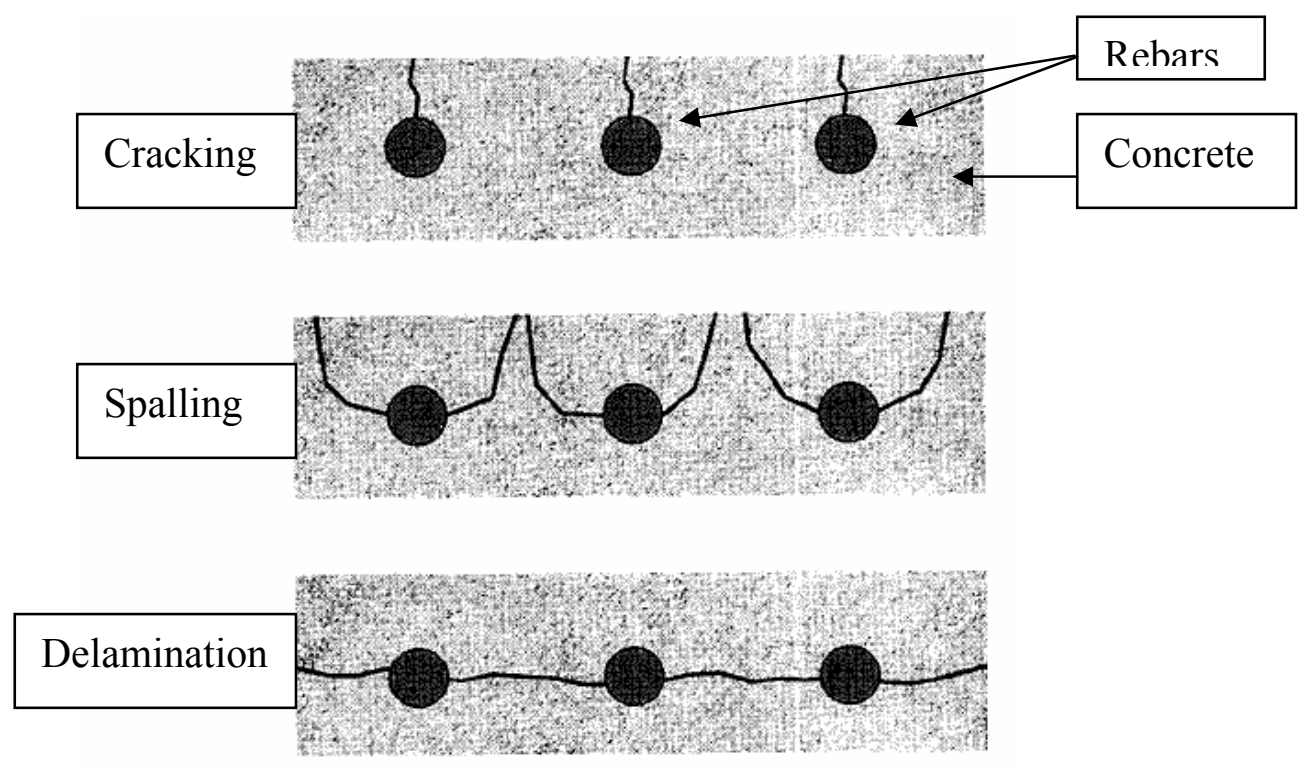

Figure 1.1: Development of cracking, spalling and delamination [1]

On bridge decks, prevention of corrosion of the reinforcing steel involves protecting the deck with overlays. An overlay is a layer of concrete or mortar, seldom thinner than 1 inch, placed on a concrete slab to restore and improve the properties of the underlying concrete. The overlay provides the necessary flooring, repair, waterproofing, 
and corrosion protection of concrete bridge decks. Concrete overlays on pavements or bridge decks can fulfill many design functions -

- Protects the underlying concrete from weather elements.

- Strengthen the structure against further deterioration due to fatigue cracking Structural overlays increase pavement thickness and reduce flexural stresses, thus increasing fatigue life.

- Improve smoothness and restore ride quality.

- Add skid resistance.

Concrete deck overlay systems are used at different locations throughout the United States. Details about the overlay materials, overlay operations, finishing, curing etc., are described in the supplemental specifications for roads and bridges [2]. Normally a 6-8 inch reinforced concrete deck is placed and then, a 2 inch overlay is applied on the reinforced concrete deck, which acts as a protective layer to the substrate. These overlays have shown to extend the life of the reinforced concrete deck, thus reducing the overall maintenance costs for the bridge structure. Overlay systems are used for new construction as well as repair of deteriorated bridge decks.

Two types of specialized concrete overlay are commonly used

1) Latex Modified Concrete: A portland cement concrete to which an approved styrene butadiene latex admixture has been added.

2) Microsilica Concrete: A portland cement concrete to which an approved microsilica admixture has been added.

Each overlay has its both advantages and limitations. Proper selection depends on many factors such as substrate concrete, local aggregate availability, construction practices, construction costs, etc. Styrene butadiene latex modified concrete (LMC) is widely used as a protection system for bridge deck overlays in US. It is estimated that over 8000 bridges are protected with LMC [3]. 
Cracking, spalling and delamination have been observed both in the case of old and new bridge deck construction. Such problems have also been observed even before a newly constructed bridge deck has been opened to traffic. Cracks are caused due to stresses caused by

1. Swelling and shrinkage stresses, mainly caused by water and water vapor phenomena

2. Thermal stresses, caused by temperature changes

3. Mechanical stresses, caused by external mechanical forces. [4]

Overlay failures have emphasized the need to develop newer materials to overcome common stresses faced by concrete bridge overlays. Today, materials are expected to provide many properties not previously available. The modern construction industry desires materials with higher early strength, elasticity, corrosion and chemical resistant, impermeability and crack resistant, without sacrificing costs, availability and workability.

\subsection{Need for Polymer Modification and Fiber Reinforcement}

Ordinary concrete has a few disadvantages such as low tensile and flexural strengths, large drying shrinkage and high permeability. It fails in a brittle manner under tensile and impact loads. These deficiencies generally result from the ease of initiation and propagation of microcracking, which usually initiate at the interface of the aggregate and the cement paste. Under external loading and environmental effects, these microcracks tend to interconnect and propagate, leading to brittle failure of concrete. Cement mortar and concrete also have disadvantages such as delayed hardening, large drying shrinkage and low chemical resistance.

Polymer modification and fiber reinforcement can overcome some of the problems faced with conventional concrete. 


\subsubsection{Latex Modified Concrete (LMC)}

Latex is a commonly used polymer modifier for concrete. Latex-modified concrete (LMC) is a portland cement concrete in which an admixture of latex is used to replace a portion of the mixing water. Latexes are generally milky fluids that are white to offwhite in color. Latex is a colloid dispersion of styrene butadiene particles suspended in water. Polymer modified portland cement concretes and mortars exhibit improved strength properties, such as flexural strength, tensile strength, fracture toughness, impermeability and abrasion resistance over similar unmodified concretes and mortars. $[5,6,7,8,9]$. Due to the inherent properties of the latex, LMC maintains good workability at lower water-cement ratios, in comparison to ordinary concrete. Lower water-cement ratio results in lower shrinkage for LMC in comparison to ordinary concrete. Latex polymer film bridges microcracks and restricts propagation [3].

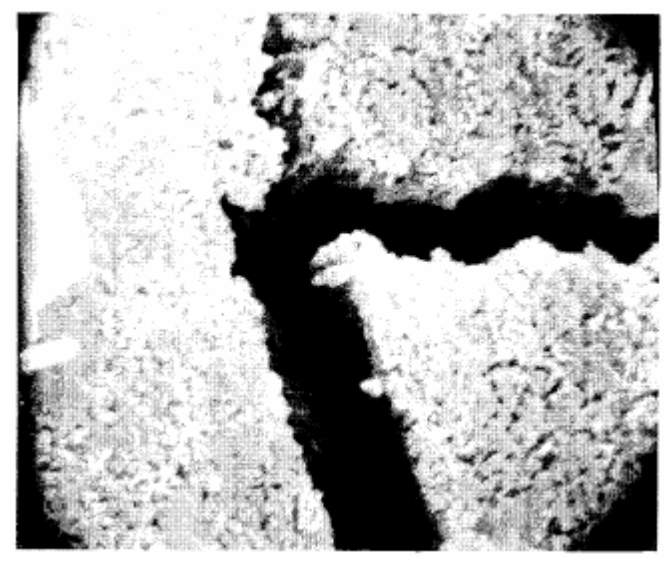

Figure 1.2 (a): Portland Cement Concrete

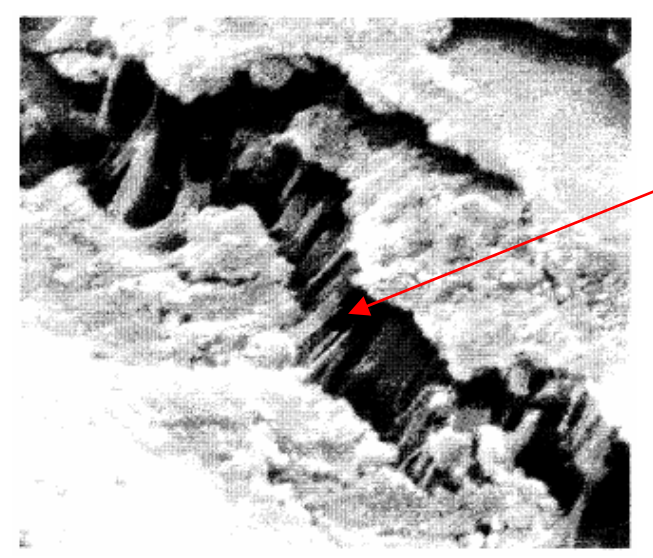

Figure 1.2 (b): Latex Modified Concrete

Figure 1.2: Electron micrographs of LMC and PCC (magnification=12,000x) [3] 


\subsubsection{Carbon Fiber Reinforced Concrete}

Fibers (glass, asbestos, steel, carbon, etc) are added to provide improved mechanical properties of inherently brittle materials like concrete. However, asbestos fibers are carcinogenic. Concrete being alkaline is deleterious to glass fibers. Steel fibers tend to rust.

Carbon fibers are inert, medically safe and as strong as steel. They are stable in the alkaline environment of concrete. They have the highest strength to density ratio among all fiber types. Earlier, the high cost of these fibers prevented their large-scale use in the construction industry. However the cost of carbon fibers have steadily declined over the years. Carbon fibers are very effective in arresting microcracks in cementitious materials [10]. Fiber reinforcement of concrete improves the tensile or flexural strength, impact strength and controls cracking and mode of failure by means of post-cracking ductility $[11,12]$.

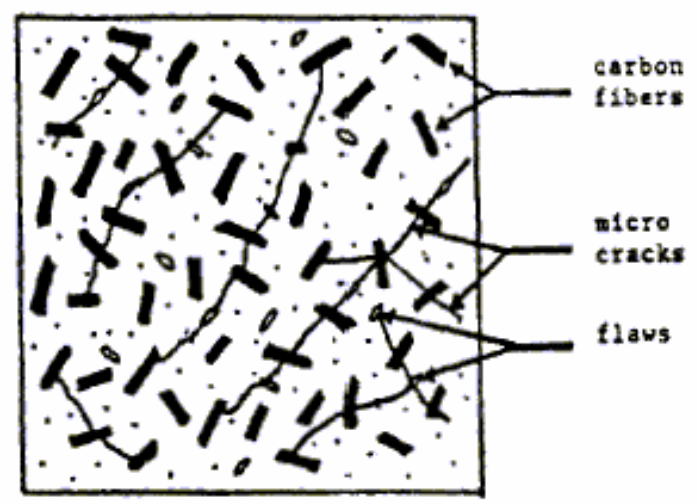

Figure 1.3: Carbon fibers shown to arrest microcracks [10]

Polymer modification and fiber reinforcement can play complimentary roles to enhance the mechanical properties of concrete. Studies have also shown that polymers helps in fiber dispersion during mixing and also better bonding to fibers, thus improving the reinforcement properties of fibers. [13] 


\subsection{Problem Statement}

Latex modified concrete overlays experience cracking, spalling and delamination. Such problems have also been observed even before a newly constructed bridge deck has been opened to traffic. Water mixed with de-icing salts can seep through these cracks causing rebar corrosion that could be detrimental to the bridge life.

\subsection{Methodology}

The objective of this research is to evaluate the potential of adding carbon fibers to latex modified concrete. It focuses on formulation of the mix design, sample preparation, and a variety of mechanical test methods to achieve improvements in the properties of CFLMC for bridge deck applications. Success of such efforts will lead to more durable bridge decks, improved repair materials and repair methods, and huge economic savings. The following experimental tests were conducted for a comparative study of LMC \& CFLMC.

Table 1.1: Experimental tests for comparison of overlays

\begin{tabular}{ll}
\multicolumn{2}{c}{ Tests } \\
\cline { 2 - 2 } & \\
Mechanical Test & Effect of CF\% \\
Slump & Slump \\
Direct Tension & 4 point loading \\
4 point Loading & Fracture Test \\
3 point Loading & Interfacial bond strength \\
Split tension &
\end{tabular}


This study will also focus on developing a practical mixing procedure of CFLMC, and analysis of the mode of failure of the CFLMC material from SEM photographs.

Such an in-depth study covering different mechanical properties should give a better understanding of the advantages and disadvantages of using CFLMC over LMC.

\subsection{Thesis Outline}

The methodology followed during this research is described in subsequent chapters and outlined as follows

Chapter two includes a thorough literature review on the principles of polymer modification and fiber reinforcement of cement/concrete. It also includes test methods and test results from similar areas of research. This section helped to identify gaps in research areas and draw an outline for the approach to testing CFLMC overlays.

Chapter three describes the sources of materials and descriptions of mix proportions and mixing methods of LMC and CFLMC.

Chapter four gives a detailed description of each of the testing methods, ASTM and ACI testing guidelines, molds used for preparing specimens, specimen instrumentation, data acquisition systems and testing equipment. A tensile testing method was developed through the course of this research. Some of the other test methods on CFLMC involved flexural loading, split tensile and fracture tests.

Chapter five presents the results and detailed analysis of each test. The results show improved ductility properties of CFLMC over LMC. With a low volume fraction of carbon fibers, the CFLMC showed greater strain to failure in tension and flexural tests.

Chapter six presents the conclusions and recommendations derived from this study. 


\section{CHAPTER TWO}

\section{LITERATURE REVIEW}

\subsection{Latex Modified Concrete}

The following paragraphs provide an insight into the different aspects of latex modified concrete (LMC) such as its history, types, chemical composition, principle of latex modification, and placement of LMC on bridge decks.

\subsubsection{Introduction}

Polymer modified concrete is prepared by mixing either a polymer or monomer in a dispersed, powdery, or liquid form with fresh concrete mixtures, and subsequent curing. In some cases, the monomer is polymerized insitu. The polymer particles are very small (0.05-5 $\mu \mathrm{m}$ in diameter) and are dispersed in water as shown in Figure $2.1 \&$ 2.2. Several types of polymer modified concretes, i.e., latex-redispersible polymer powder, watersoluble polymer, liquid resin and monomer-modified mortars and concretes are produced by using polymers and monomers. Latex modified concrete is by far the most widely used cement modifiers [14].

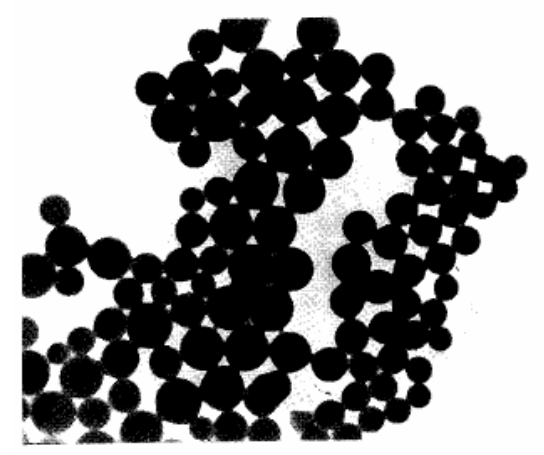

Figure 2.1: SBR Latex (x 30,000) [14]

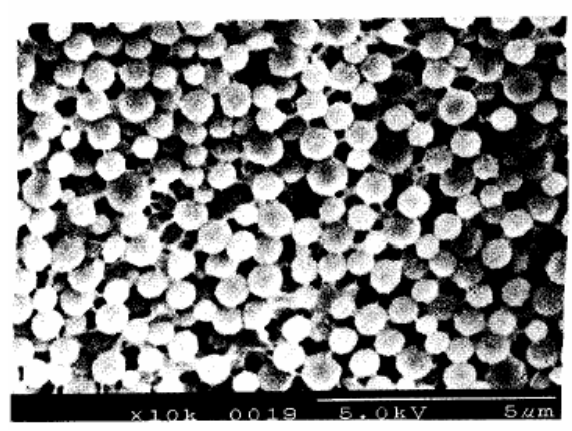

Figure 2.2: EVA Latex (x 10,000) [14] 


\subsubsection{History of Latexes}

In 1923, the patent for a latex-hydraulic cement system was issued to Cresson [5]. Natural rubber latexes were used in the patent for paving materials, with cement as the filler. The first patent with the present concept of the polymer latex-modified cement systems was published by Lefebure [15] the following year. Throughout the 1920s and 1930s, LMC using natural rubbers were developed. Bond [8] was issued a patent in 1932 for suggesting the use of synthetic rubber latexes for latex modified systems while Rodwell's [9] patent (1933) first claimed to apply synthetic resin latexes to concrete systems. In the 1940's, patents on latex modified systems with polychloroprene rubber (Neoprene) [16] latexes and polyacrylic ester latexes [7] were published. Over the years, latex modified systems have been used on bridge deck overlays, ship decks and parking garages, floorings, and as anticorrosives and adhesives. Interest was developed on the different types of natural and synthetic latexes in different parts of the world. In 1953, Geist et al [17] did a fundamental study on polyvinyl acetate modified mortar and provided valuable suggestions for later research and development of latex modified systems.

Latex modified mortar was first used as a bridge deck overlay material in 1956 [18]. The first LMC overlay was placed in West Virginia in 1961 [19]. Since the inception of latex modified portland cement for bridge repair in 1957, thousands of projects have been completed using styrene-butadiene latex [2]. 


\subsubsection{Types of Polymer Latexes}

Table 2.1 is a listing of the types of latexes that have been used or are currently being used for cement systems.

Table 2.1: Polymer latexes used in cement mixes [2]

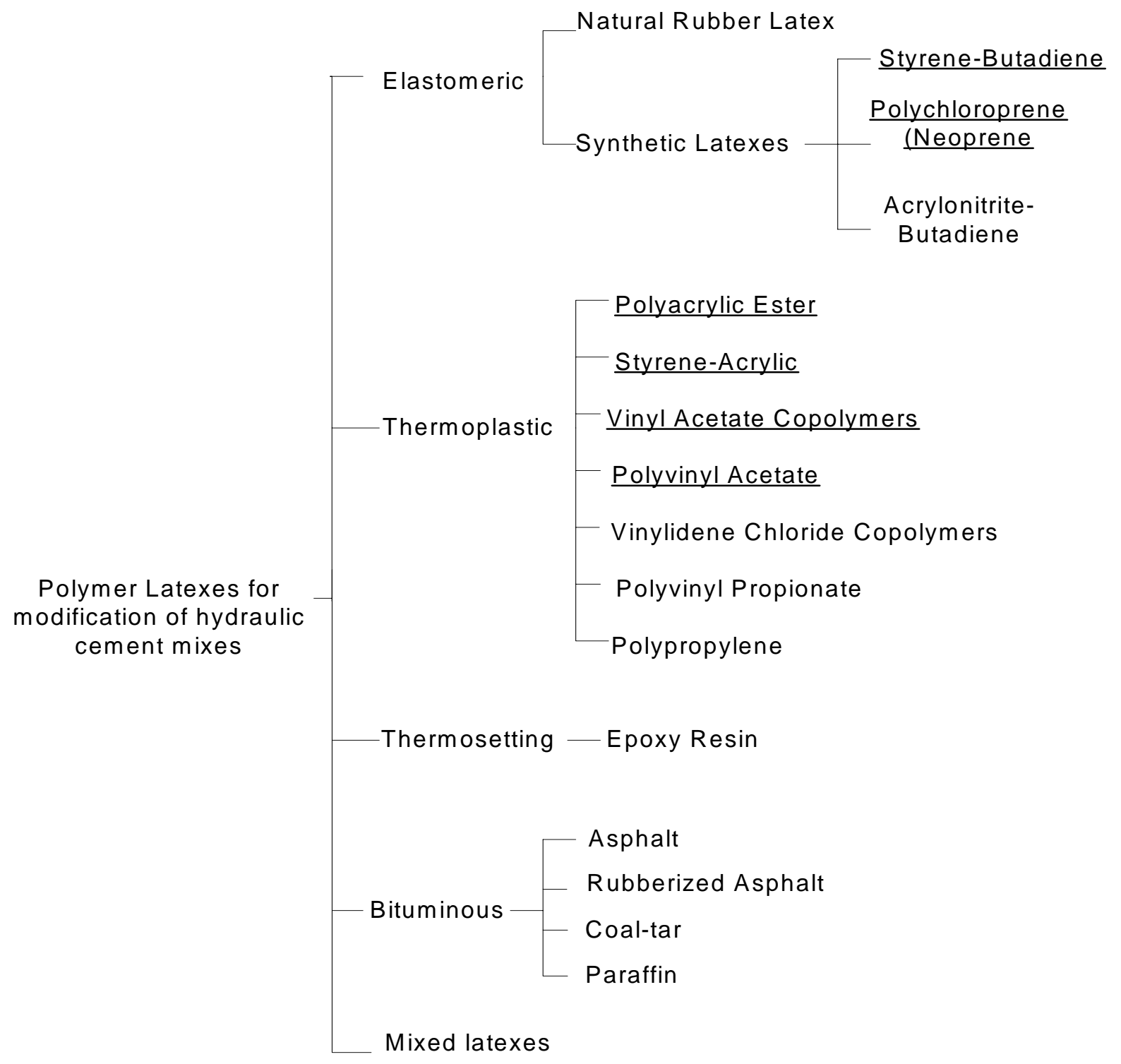

Materials that are underlined are the ones that are in general use today. Each type of polymer imparts different properties to the hydraulic cement mixture. This study will focus on styrene butadiene latex. 


\subsubsection{Typical Formulation of Styrene Butadiene Latex}

Latexes are produced by a process known as emulsion polymerization. The process involves mixing the monomer with water, a surfactant, and an initiator. The initiator generates a free radical that causes the monomer to polymerize by chain addition. Many other ingredients are used in the polymerization process and are incorporated for many reasons, such as controlling $\mathrm{pH}$, particle size, and molecular weight. Styrene to butadiene ratio of the polymer, and molecular weights have considerable influence on the properties of the cement system. [2]

Table 2.2: Chemical components of styrene butadiene latex [2]

\begin{tabular}{|c|c|}
\hline \multicolumn{2}{|c|}{ Styrene butadiene copolymer latex (parts by weight) } \\
\hline Styrene & 64 \\
\hline Butadiene & 35 \\
\hline A vinyl carboxylic acid & 1 \\
\hline Nonionic surfactant & $7^{*}$ \\
\hline Anionic surfactant & $0.1^{* *}$ \\
\hline Ammonium persulfate & 0.2 \\
\hline Water & 105 \\
\hline
\end{tabular}

*The nonionic surfactants may be nonyl phenols reacted with 20-40 molecules of ethylene oxide

** The low levels of anionic surfactant are used to control rate of polymerization

Surfactants are chemical compounds added during manufacture of the latex, which attach themselves to the surface of the latex particles. Thus, they affect the interactions of the particles themselves, as well as the interactions of the particles with portland cement. Surfactants acts as dispersants for the portland cement, thus lubricating the fresh cementitious mix and improving workability, i.e., addition of latex reduces the amount of water required for achieving the appropriate viscosity for placement of the mix. Hence LMC has a reduced water/cement ratio than conventional concrete. Latex helps also in better adhesion to the underlying concrete deck and improved flexural strength and abrasion resistance. Compounding ingredients are added to the latex for improved properties such as resistance to chemical or physical attach, e.g. bacterial protection and ultraviolet protection. 


\subsubsection{Principle of Latex Modification}

Latex modification of cement concrete is governed by cement hydration, followed by polymer film formation. In due course a co-matrix phase is formed as an end result of these processes. The co-matrix is formed according to a three step simplified model shown in figure 2.3 .

(A) Immediately after mixing.

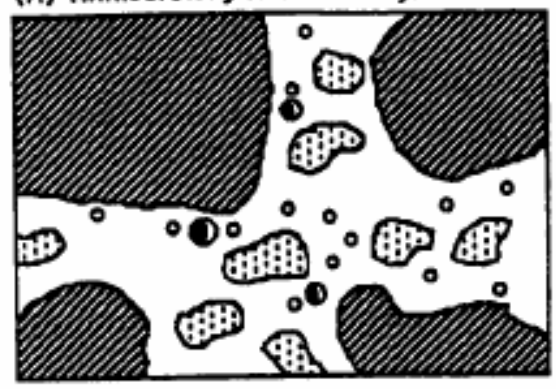

(B) First step.

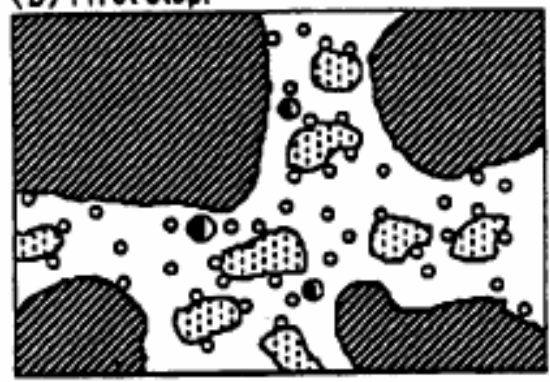

(C) Second step.

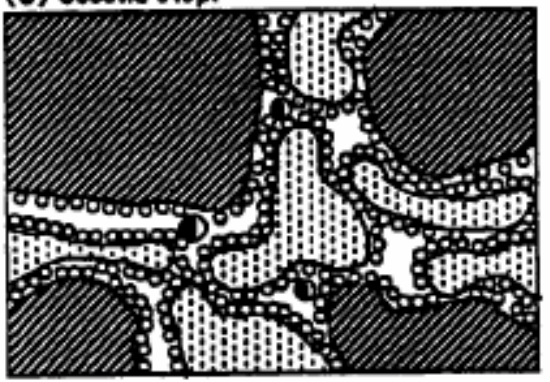

(D) Third step. (Hardened structure)
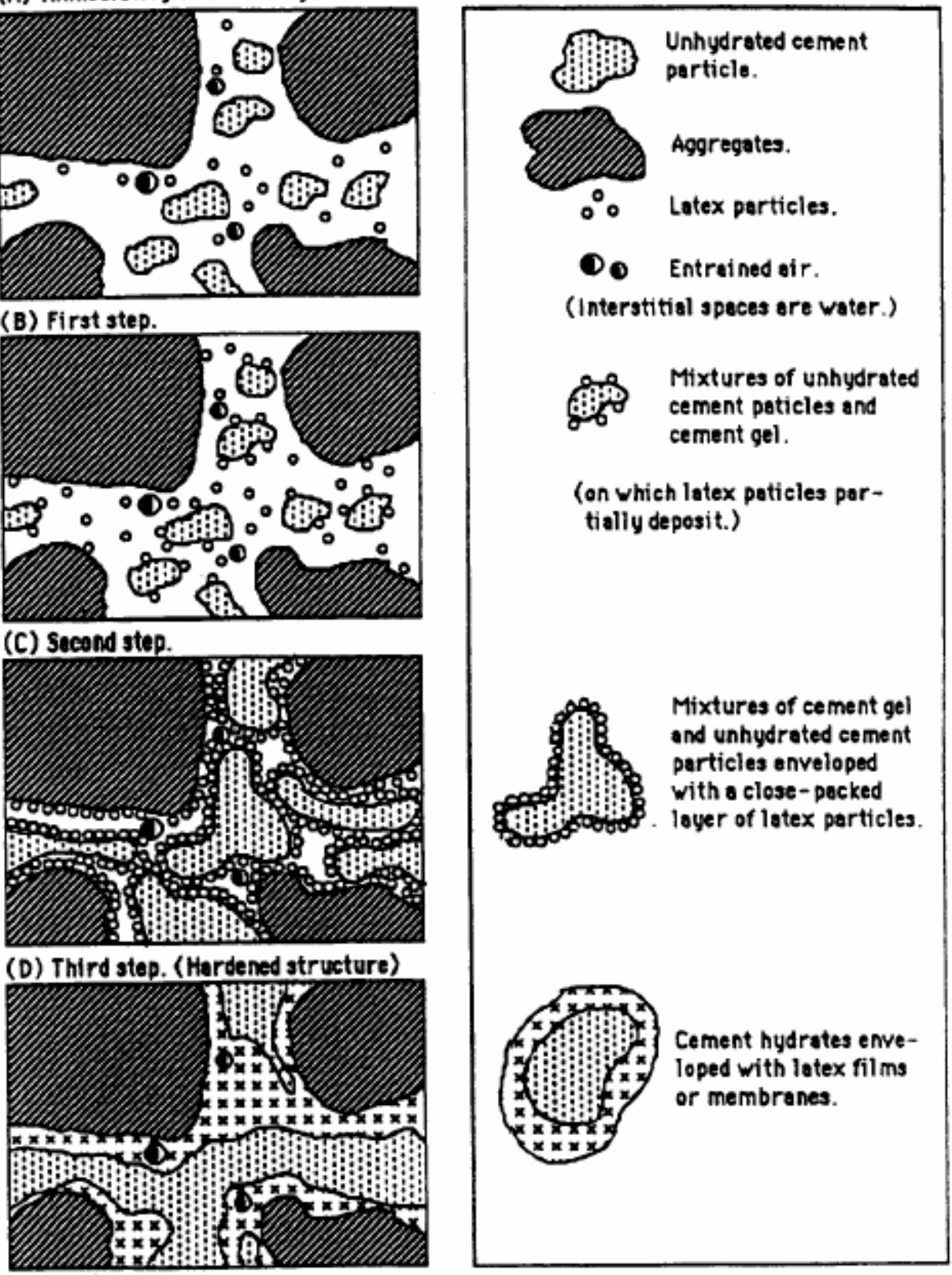

Figure 2.3: Simplified model of formation of polymer-cement co-matrix [2] 


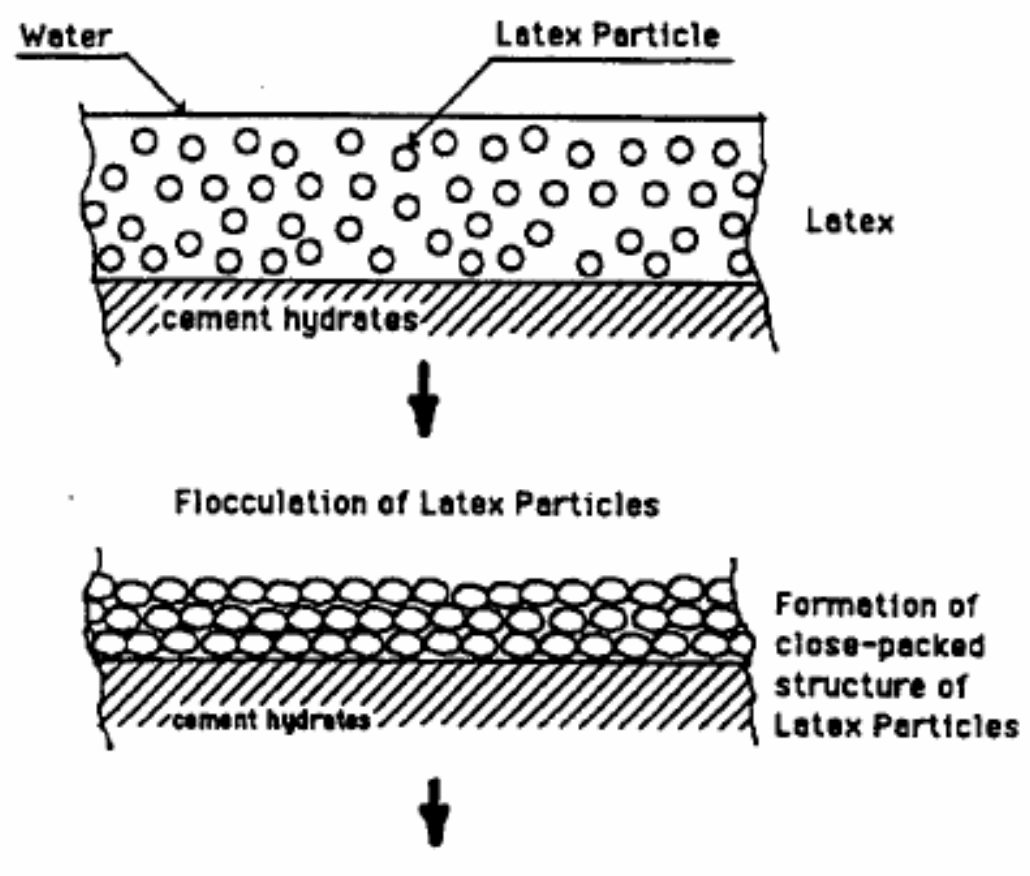

Drainage of water between porticles

Coalescence of Latex Porticles

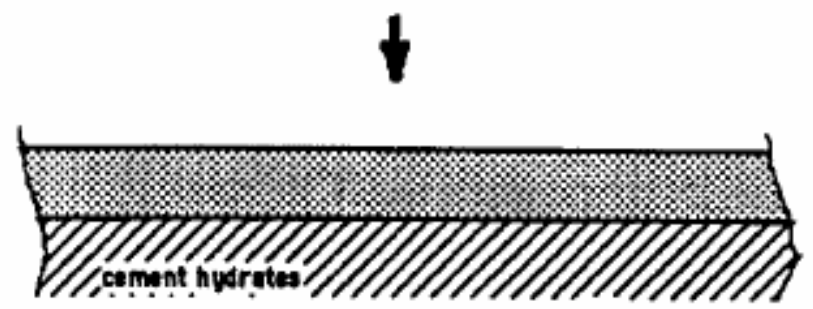

Figure 2.4: Simplified model of process of polymer film formation on cement hydrates [2]

First Step: When polymer latexes are mixed with fresh cement mortar or concrete, the polymer particles are uniformly dispersed in the cement paste phase. Cement gel is gradually formed by the cement hydration and the water phase is saturated with calcium hydroxide formed during hydration, whereas the polymer particles deposit partially on the surfaces of the cement-gel-unhydrated cement particles mixtures. (Figure 2.3). Formation of calcium hydroxide and ettringite in the contact zone between the cement hydrates and aggregates is attributed to the bond between them. 
Second Step: As the cement particles hydrate, the latex particles are generally confined in the capillary pores. Hydration proceeds, capillary water reduces and the polymer particles flocculate to form a continuous close-packed layer of polymer particles on the surfaces of the cement-gel-unhydrated cement particle mixtures This polymer layer adheres to the mixtures and the silicate layer over the aggregate surfaces. Larger pores are filled with polymer particles (typically $<100 \mathrm{~nm}$ ) rather than smaller capillary pores (with typical diameter of about $1 \mathrm{~nm}$ ).

Third step: As water is withdrawn due to cement hydration, the close-packed polymer particles on the cement hydrates coalesce into continuous films or membranes (Figure 2.4). These membranes bind the cement hydrates together to form a monolithic network in which the polymer phase interpenetrates throughout the cement hydrate phase. Such a structure acts as a matrix phase for latex-modified mortar and concrete, and the aggregates are bound by the matrix phase to the hardened mortar and concrete.

From a microscopic point of view, latex modification helps in three ways: Firstly, latex particles reduce the rate and extend of moisture movement within the cement matrix by blocking passages and capillaries within the cement matrix. Secondly the latex polymer film bridges the cracks and restricts propagation (Figure 1.2). This results in increased tensile strength and fracture toughness, compared to ordinary concrete. Finally, latexes contain reactive groups which may react with the calcium and other metallic ions in the cement, and with the silicates in the aggregates, which improve the inter particle bond and the strength of the mixture. 


\subsubsection{Mix proportion of LMC}

According the ACI 548.4-93 [20], specifications for LMC mix proportions are given below.

Table 2.3: Mix proportions of LMC [20]

\begin{tabular}{|c|c|}
\hline Cement content, minimum & $658 \mathrm{lb} / \mathrm{yd}^{3}$ \\
\hline Latex admixture, minimum & $24.5 \mathrm{gal} / \mathrm{yd}^{3}$ \\
\hline Water, maximum & $18.9 \mathrm{gal} / \mathrm{yd}^{3}$ \\
\hline Air content, maximum (ASTM C 231) & $6.5 \mathrm{percent}$ \\
\hline Slump, range & $3-8 \mathrm{in}$. \\
\hline Overlay thickness, minimum & $1 \mathrm{in}$. \\
\hline Coarse aggregate, maximum & No. 8 \\
\hline aine aggregate, range by weight, of total & $55-70 \mathrm{percent}$ \\
\hline Weight ratio, & $1.0: 2.8: 1.7$ \\
\hline saturated surface dry) & \\
\hline
\end{tabular}

\subsubsection{Placement of LMC on Bridge Decks}

A sequence of steps is followed at the work site for proper mixing, placing and curing of overlays as described below [2].

1. Surface preparation: The process involves using scarifiers, blasters (sand, water and shot), jack hammers and saws to remove the top surface of the deck and to clean the surface and achieve the required surface roughness on the bridge deck for the latex overlay to adhere well to the substrate. This is to be followed by thorough cleaning with vacuum, air or water. The prepared surface should then be thoroughly wetted for $1 \mathrm{hr}$ before placement. However, all standing water should be removed prior to placing the LMC. 
2. Mixing: Most latex modified concrete used today is mixed in a mobile mixer. The equipment is designed for accurate proportioning of ingredients with continuous mixing at the rate of 8 to $60 \mathrm{yd}^{3} / \mathrm{hr}$.

3. Placement: Usually a layer of grout (latex + cement + sand) is first applied with brooms. The LMC is later pumped or sprayed over the wetted area. Shovels and hoes are used to spread the newly placed concrete.

4. Finishing: A self-propelled rotating cylinder machine equipped with devices that will automatically and continuously spread, consolidate, and finish the plastic concrete, is used. Metal trowels, spud vibrators and tine rakes are used to apply the specified final finish.

5. Curing: Almost immediately after the surface is textured, wet burlap is applied, followed by white or clear polyethylene film. The intent is to keep the surface damp for 48 hours. After the initial damp period, the film and burlap is removed and the bridge deck overlay is allowed to air-dry. It is during the air-curing period that LMC gains most of its strength. LMC has faster curing periods and thus, LMC bridge decks are normally opened to traffic after 2 weeks. 


\subsection{Carbon Fiber Reinforced Concrete}

The following paragraphs provide an insight into the different aspects of carbon fiber reinforced concrete such as its history, and principles of fiber reinforcement in the freshly mixed and hardened state.

\subsubsection{Introduction}

Fibers (glass, asbestos, steel, carbon, etc) are added to provide improved mechanical properties of inherently brittle materials like concrete. When subjected to tension, unreinforced brittle matrices initially deform elastically. The elastic response is followed by microcracking, localized macrocracking, and finally fracture. Introduction of fibers into concrete results in post elastic property changes that range from subtle to substantial, depending upon a number of factors, include matrix strength, fiber type, fiber modulus, fiber aspect ratio, fiber strength, fiber surface bonding characteristics, fiber content, fiber orientation, and aggregate size effects. [21]

\subsubsection{Historical Aspects}

Fibers have been used since ancient times to reinforce brittle materials. Straw was used to reinforce masonry mortar and plaster. Large-scale use of asbestos fibers in cement matrices was commercialized with the invention of the Hatschek process in 1898 [21]. These fibers were typically less than $5 \mathrm{~mm}$ in length and added in high percentages ranging from 6-21\% depending on the type of application. A French patent in 1918 was based on uniformly mixing small longitudinal bodies (fibers) of iron, wood or other materials into concrete. [22]. The patent also suggested that fiber elements must be rough, or be roughened, to improve pullout resistance of fibers from concrete. However, due to the health hazards associated with asbestos, alternate fiber types were introduced throughout the 1960s and 1979s. Experimental trials and patents involved using steel reinforcements such as nails, wires, and chips to concrete. During the 1960s, studies were conducted to study the effect of steel fibers as reinforcement to concrete, in US [23]. 
Since then, substantial research has been done on steel fiber reinforcement and led to large scale industrial applications

Addition of glass fibers in concrete was attempted in the late 1950's in USSR [24]. However, these glass fibers, such as borosilicate E-glass fibers were attacked and destroyed by the alkali nature of concrete. Synthetic fibers such as nylon and polypropylene were attempted for use in concrete reinforcement, but the initial attempts were not as successful as steel or glass fibers.

Considerable research, development and applications in fiber reinforced concrete have taken place around the world. The ACI Committee 544 published a state-of-the-art report [21]. RILEM committee also published a report on fiber reinforced cement composites. [25]. Symposium proceedings such as SP-105 \& SP-124 [26, 27] provide a good summary of developments on the field of FRC. In general, the enhanced properties of fiber reinforcement to composites include tensile strength, compressive strength, elastic modulus, crack resistance, crack control, durability, fatigue life, resistance to impact and abrasion, shrinkage, expansion, thermal characteristics, and fire resistance.

Carbon fibers were developed primarily for their high strength and stiffness properties for the aerospace industries. During the early development of FRC, carbon fibers were expensive and thus had limited commercial development. However, during the recent years, the price of carbon fibers have steadily declined, leading to their commercial use gaining popularity especially in Japan and UK. Carbon fibers have high tensile strength and elastic modulus. Carbon fibers are inert, medically safe and as strong as steel. They are stable in the alkaline environment of concrete. They have the highest strength to density ratio among all fiber types. Polyacrylonitrile (PAN) based carbon fibers are manufactured by carbonizing polyacrylonitrile yarn at high temperatures while aligning the resultant graphite crystallites by a process called "hot-stretching". They are manufactured as either HM (high modulus) fibers or HT (high tensile strength) fibers. Carbon fibers can also be made from petroleum and coal pitch, which are less expensive than PAN based carbon fibers. 


\subsubsection{Principle of Fiber Modification}

The principles of fiber matrix interactions are separated studied, in the freshly mixed state and the hardened state.

\subsubsection{Fiber-Matrix Interactions in the Freshly Mixed State}

Fibers represent an addition of long slender needle like particles to a normal cement paste, mortar or concrete matrix. Some like steel are quite rigid, while glass and carbon fibers are flexible. The characteristics of the fiber-matrix combinations in the freshly mixed state depend on the type and form of the fibers, the nature and proportions of the matrix constituents, and the process used to incorporate the fibers into the matrix. Addition of fibers to paste, mortars or concrete reduces the fluidity of the mixture because of the needle-like shape and high specific area. Fibers that absorb water may cause further reduction in mixture fluidity. The greater the paste content, i.e. the volume fraction of the fluid phase within which the fibers can move and rotate, the greater the workability for any particular fiber content [28], or in other words, the greater the amount of paste needed in the mortar to produce a specified level of workability at the specified fiber content. In normally proportioned concretes the volume fraction of the fluid phase decreases with increases in the volume fraction and maximum size of the aggregate, so the volume of the space available for fibers decreases correspondingly.

In his study, Bayasi [29] recommended that aggregates should not to be used with carbon fiber cement since they may disturb the fiber distribution and increase fiber spacing. In

cement and mortars, fibers are separated by fine-grained material, which can move easily between them. However, in the case of concrete, the particle size is larger than the average fiber spacing if the fibers were uniformly distributed. This leads to bunching and greater interaction of fibers between the large aggregate particles and the effect becomes more pronounced as the volume and maximum size of the particles increases (Figure 2.5). 


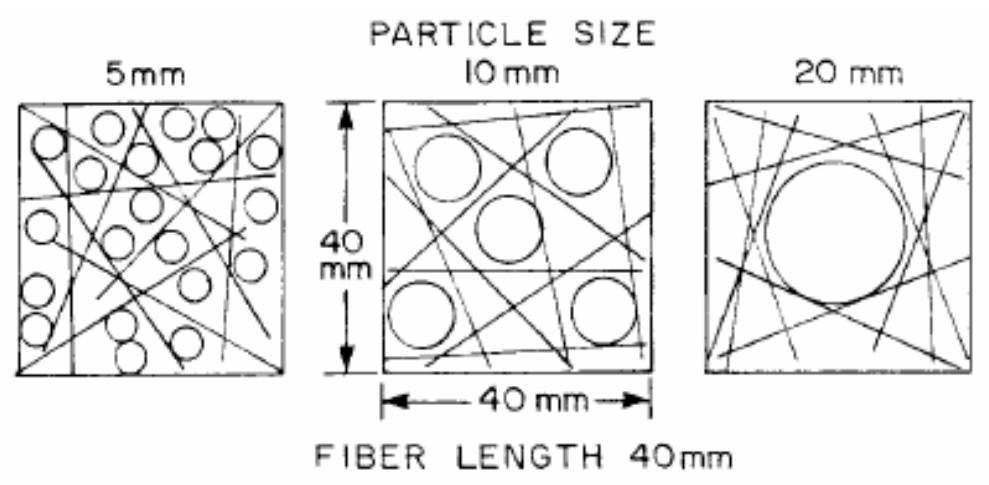

Figure 2.5: Schematic of particle size vs. fiber distribution for $40 \mathrm{~mm}$ long fibers within a $40 \mathrm{~mm}$ square [11]

\subsubsection{Fiber Matrix Interactions in the Hardened State}

Fibers in the hardened cement matrix has three important effects [11]

1) They tend to increase the stress at which the matrix starts to crack. This strengthening effect is more evident under modes of loading that induce tensile or flexural stresses

2) Depending on the type and amount of fibers, they may improve the strain capacity or ductility of the inherently brittle cementitious matrix, thus increasing its energy absorption capability or toughness characterized in general by the area under the stress-strain or load-deformation curve. Improvements in ductility are usually significant even when improvements in strength are minimal.

3) Fibers have the tendency to inhibit or modify crack development in terms of reducing crack width and average crack spacing.

These above mentioned properties depend on the intrinsic fiber properties as well as on the shear bond between the fiber and the matrix. The resistance to interfacial shear and fiber pullout may involve adhesion, friction and mechanical interlock. When the interfacial shear resistance is high enough, the fiber breaks instead of pulling out of the matrix.

The fiber must be stronger than the matrix to be effective in reinforcing concrete. The fibers are also required to withstand strains greater than the matrix cracking strains. 
Carbon fibers satisfy these criteria and theoretically offer great reinforcing potential. However, realization of full reinforcing potential depends on whether composite failure occurs by fiber pullout or fiber breakage. This research aims to study the mode of failure to understand the effectiveness of carbon fibers for reinforcing carbon fibers.

Research by Zheng and Chung, [30] have proved by using short pitch-based carbon fibers ( $0.5 \%$ by weight of cement, 0.28 vol.\% of cement mortar), together with a water reducing agent and an accelerating admixture, the compressive, tensile and flexural strengths of the carbon fiber reinforced cement mortar were found to increase by about 18-31\%, 113-164 $\%$ and $89-112 \%$, respectively, compared to the corresponding plain cement values. The ductility was also improved. The study used short carbon fibers $(3 \mathrm{~mm}$ and $5.1 \mathrm{~mm})$, and continuous fibers.

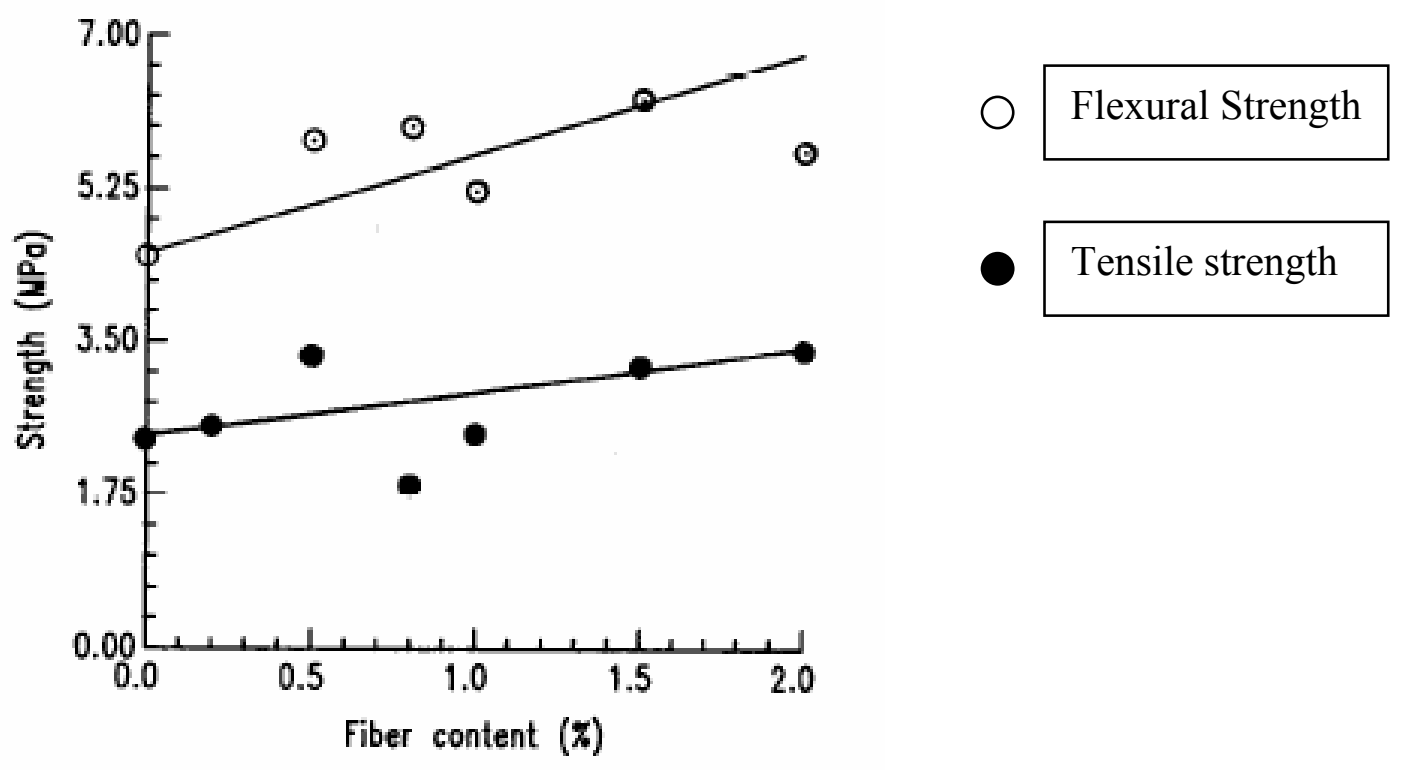

Figure 2.6: Dependence of strength of carbon fiber reinforced cement on fiber content ( $\%$ by weight of cement) [30]

\subsection{Concept of Fiber Reinforcement 'and' Polymer Modification of Concrete}

The following paragraphs describe few of the significant studies in fiber reinforced polymer modified cement by different researchers across the years, with relevance to the present study. Researches have experimented with different latexes, fiber types, volume 
fractions etc. to study the effect of the modifications on the properties of concrete. Advances such as fiber treatment and advanced test methods have also been mentioned,

During the 1980s, researchers had investigated the effects of adding steel fibers to different latexes such as styrene butadiene rubber (SBR) [31] polyacrylic ester (PAE) [32], ethylene vinyl acetate (EVA) [31] and natural rubber [33], due to workability issue arising due to steel fibers. Reinforcement by steel fibers improved the physical properties of concrete but damaged the fresh mix workability. However, latex modification of concrete helped in the dispersions of fibers. This was attributed to the effects of surfactants in the latex and helped reduce the effect of "balling" of steel fibers to some extent. . Thus polymer modification was expected to reduce the workability problems of steel fiber reinforced concrete. The graph clearly shows the major influence of polymers in increasing the slump of fiber reinforced concrete. 


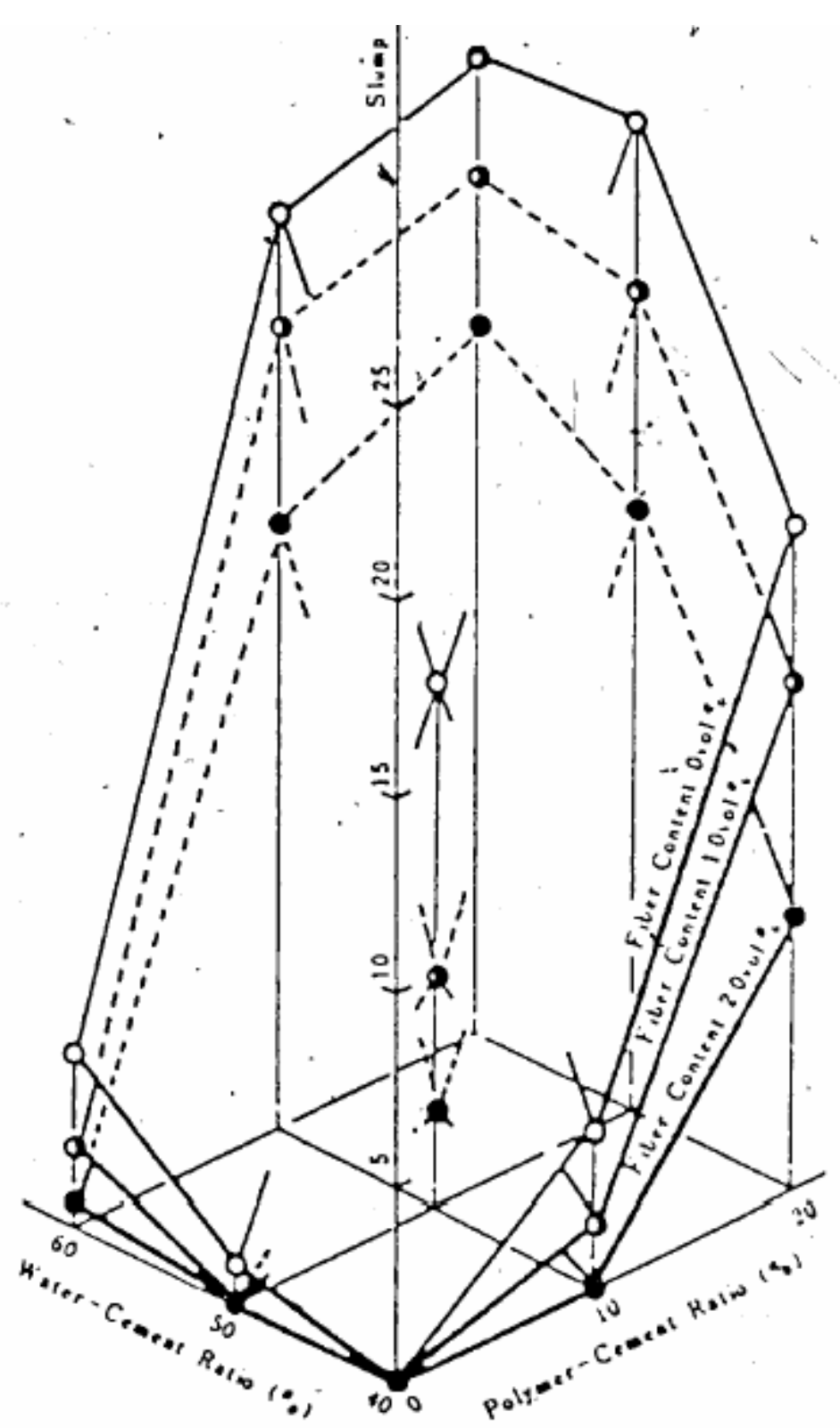

Figure 2.7: Effects of water-cement ratio, polymer-cement ratio, and steel fiber volume fracture on the slump of concrete (max. aggregate size $=0.79$ in, $V_{f}=0$ $2 \%,(0.01 x 0.022$ in $), 1 / d=53$, PAE latex) [32]

Soroushian, Aouadi and Nagi (1991) [13] investigated the effects of latex modification on performance characteristics of carbon fiber reinforced mortars. Silica fume, superplasticizer and antifoaming agent were also included in the mix. The study incorporated $3 \%$ volume fraction of $1 / 16$ in. $(1.5 \mathrm{~mm})$ pitch based carbon fibers. Latex modification was shown to increase the bonding of the cementitious matrix to carbon 
fibers. Flexural toughness was also increased through latex modification, but the effect of latex addition on flexural strength was relatively small. Latex modifications caused reductions in compressive strengths of CFRC composites, as well as reductions in water absorption, drying shrinkage and specific gravity of CFRC. The freeze thaw durability and acid resistance of carbon fiber reinforced mortar were improved with latex addition.

Yang and Chung (1992) [34] studied the effects of addition of different volume fractions of carbon fibers on the flexural and compressive strengths of latex-modified cement mortar at different curing ages of up to 28 days. An increase of $49 \%$ in the 7-day flexural strength and an increase of $33 \%$ in the 28 -day flexural strength were obtained by adding 0.37 vol. \% of carbon fibers to latex modified mortar. Relative to plain mortar, the addition of latex and fibers ( 0.37 vol. \%) caused the flexural strength to increase by $97 \%$, $65 \%$ and $54 \%$ at 7,14 and 28 days of curing, respectively. The highest flexural strength (15.3 Mpa) was attained by mortar containing latex and fibers (2.2 vol. \%) at 28 days of curing; it corresponds to a fractional strength increase of $84 \%$ relative to plain concrete at 28 days. However, at this fiber content, the compressive strength was decreased by $24 \%$ relative to latex modified mortar without fibers. Cost also increased with increasing carbon fiber content. Considering the flexural strength, compressive strength and cost, the optimum formulation of LMC containing fibers is $0.37 \mathrm{vol} . \%$. 


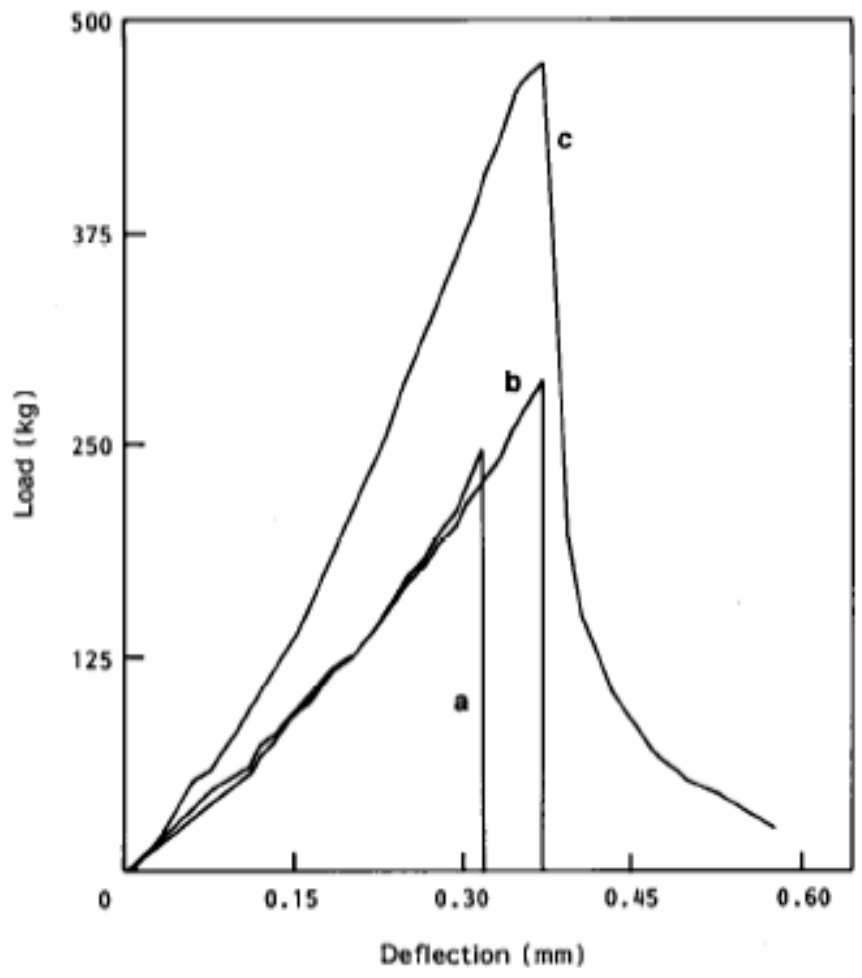

Figure 2.8: Load/deflection curve during flexural testing of (a) plain mortar; (b) mortar with latex; and (c) mortar with latex and 2.2 vol.\% carbon fibers [34]

In his dissertation, Tlili (1993) [35] studied the mechanism of joint action of steel fibers and latex polymers in concrete. Steel fibers with hooked ends 1.18 inch in length, were used for the experiment. He concluded that steel fibers and latex polymers interact favorably to produce concrete material with improved flexural strength and toughness, impact resistance, dimensional stability, freeze thaw durability and scaling resistance. Furthermore, the corrosion inhibiting effects of latex polymer modification were successfully demonstrated.

Zayat and Bayasi [36] conducted an experimental investigation onto the effects of varying latex contents on the properties of latex-modified carbon fiber reinforced cement. Carbon fibers $1 / 8$ inch $(3 \mathrm{~mm})$ were used at a volume fraction of $2 \%$. Silica fume and naphthalene formaldehyde sulfonate superplasticizer was also used. Results showed that latex increases the flexural strength and impact resistance of carbon fiber reinforced 
cement. Furthermore, lower latex contents increase tensile toughness with insignificant effects on tensile strength of carbon fiber cement.

Chen and Chung (1996) [37] conducted a comparative study of mortar reinforced with carbon, polyethylene and steel fibers and their improvement by latex addition. All fibers were $5 \mathrm{~mm}$ in length and added at a volume fraction of $0.37 \%, 0.53 \%$ and $0.35 \%$ for compressive, tensile and flexural testing respectively. Carbon fibers, though having the lowest tensile modulus, strength and elongation at break among the fiber types, gave mortar of the highest tensile strength and lowest cost; polyethylene fibers, due to their high ductility, gave mortar of the highest flexural toughness; and steel fibers gave mortar of the highest flexural strength. The tensile, compressive, and flexural strengths and flexural toughness were all increased by latex addition for any fiber type.

Fu, Lu \& Chung (1996) [38] investigated methods to increase the bond strength between carbon fibers and cement matrix. The bond strength was enhanced with polymer admixtures in the cement mix. Latex gave larger effects than methycellulose. However, the greatest bond strength was attained by ozone treatment of the fibers. This was due to the resulting oxygen-containing functional groups on the fibers helping the wettability of the fibers by the cement.

The following year in 1997, Chen, Fu and Chung [39], studied the effect of methylcellulose, silica fume and latex on the degree of dispersion of short carbon fibers in cement paste (with water-reducing agent in the amount varying from 0 to $3 \%$ by weight of cement). The nominal fiber length and monofilament diameter were $5 \mathrm{~mm}$ and $10 \mu \mathrm{m}$, respectively. The degree of dispersion was measured by the ratio of the measured volume of electrical conductivity to the calculated value. The effectiveness of the fibers in enhancing the tensile/flexural properties attained by using methylcellulose and silica fume were higher than those attained by using methylcellulose alone or latex. Methycellulose was superior to latex in giving a high degree of fiber dispersion at fiber volume fractions $<1 \%$, but latex resulted in superior tensile-flexural properties and lower content and size of air voids than methylcellulose. The flexural strength attained a 
maximum at an intermediate latex-cement ratio of 0.15 . In contrast, both flexural toughness and strength increased monotonically with increasing latex-cement ratio when fibers were absent.

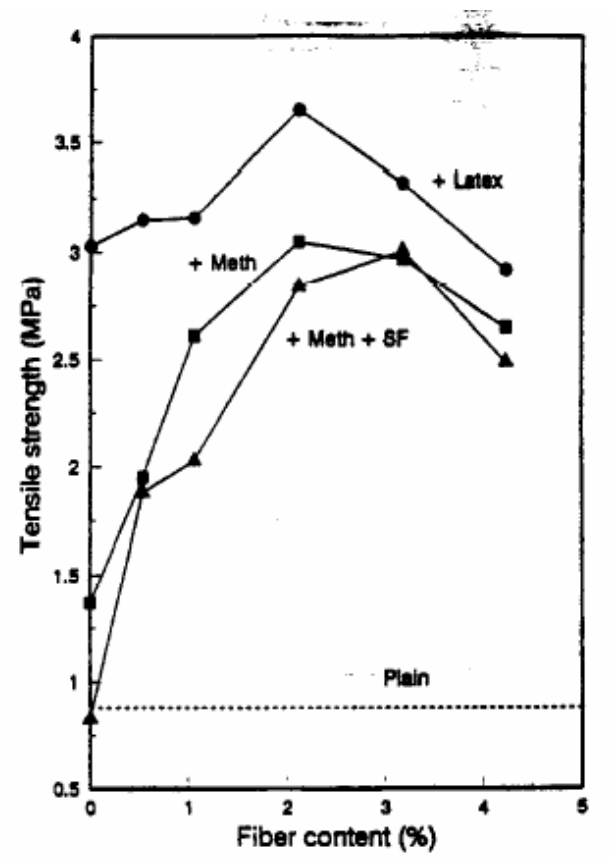

Figure 2.9: Dependence of tensile strength on fiber content of cement pastes [39]

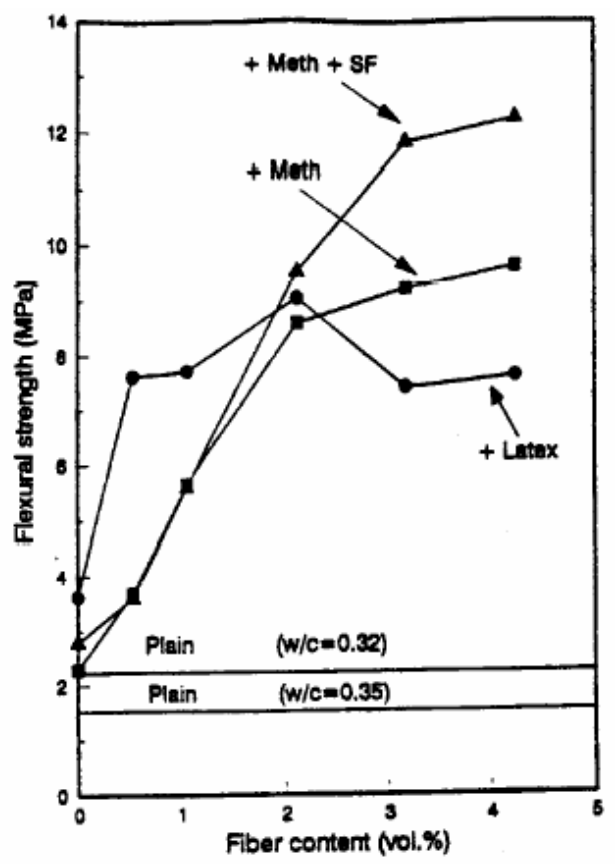

Figure 2.10: Dependence of flexural strength on fiber content of cement pastes [39]

In the same year, Zeng and Chung [40] studied the abrasion resistance of mortar by adding latex and carbon fibers. The carbon fibers used were $5 \mathrm{~mm}$ in length and added in the amount of $0.27 \%$ volume fraction. The abrasion resistance of mortar was found to be significantly improved by addition of latex ( $20 \%$ by weight of cement), and further improved by the further addition of short carbon fibers.

Cao \& Chung (2001) [42] used acrylic dispersion as an admixture for carbon fiber reinforced cement mortar. The improvements of the tensile properties (particularly strength and ductility) was more than those attained by using methylcellulose, styrene acrylic, or latex as admixtures. 
The attainment of high degree of fiber dispersion is particularly critical when fiber volume fraction is low. It was important to ensure that the fibers were distributed evenly throughout the cement matrix. Chung (2005) [42] assessed the degree of fiber dispersion by electrical resistivity and concluded that dispersion was improved by the use of admixtures such as silica fume, acrylic particle dispersion, methylcellulose solution, and silane, and fiber surface treatment (such as ozone treatment). She also concluded that acrylic particle dispersion is more effective than latex particle dispersion.

\subsection{Interfacial Stresses}

Another part of this experimental study is involved in study of interfacial strengths. These include

1. Analyzing the mode of failure in CFLMC using SEM photographs. It involves the study of interfacial shearing between the fibers and cement matrix.

2. Evaluating the tensile bond strength between the overlay and the substrate.

3. Study of interfacial stresses between overlay and substrate in field conditions.

\subsubsection{Interfacial Shear between Fibers and Cement Matrix}

If adhesive interfacial shear bond does not exist between the fiber and the matrix, no stresses can develop in the fiber. Several possible local failures in FRC are possible.

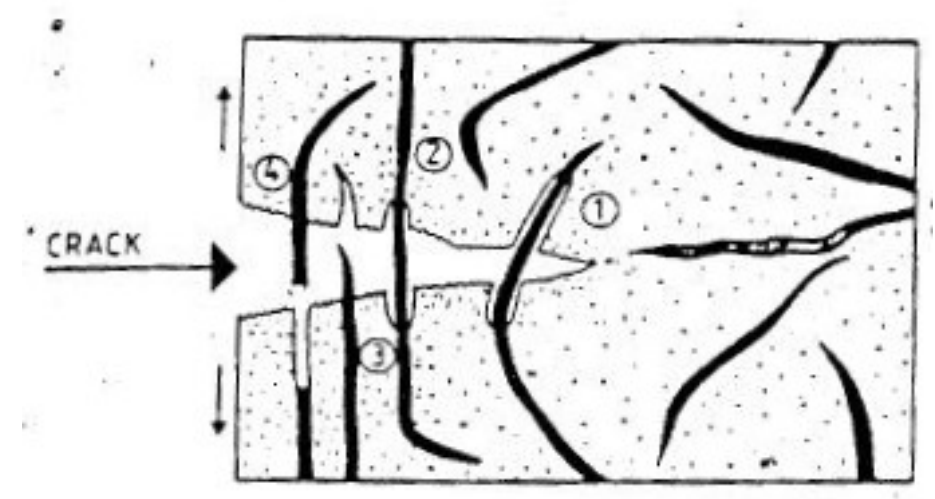

Figure 2.11: Schematic representation of a crack traveling through a composite [35] 
Even a strongly bonded fiber may pull out from the matrix before breaking if its actual embedded length relative to the plane at which cracking develops is short enough(3) If the fiber is too long, it may hold the stress for a while before breaking(2). This usually occurs when the matrix cracks initially and sufficient stress is transferred to the fiber, to enable it to be ultimately fractured. If the Poisson's ratio of the fiber is greater than the matrix, the fiber may actually reduce in cross section while being stressed, causing the fiber to debond from the sides of the matrix (1). The strain energy in the debonded length of the fiber is lost to the material and is dissipated as heat. Vice versa, when the Poisson's ratio of the fiber is less than the matrix, greater frictional shear is set up between the fiber and matrix.

Evaluation of SEM photographs will be able to determine mode of interactions between fiber and matrix, and the type of failure of the material.

\subsubsection{Interfacial Strength between Overlay and Substrate}

The interface may be considered as a two or three part system (substrate, overlay, plus possibly a bond zone), The question of how to measure this adhesive property has been a subject of numerous studies. Several tests are available to measure the bond strength. Each test has its advantages and disadvantages.

A number of requirements have been proposed for bond test methods including being able to
1) Simulate site conditions
2) Expose the bonded region to environmental conditioning
3) Induce stress states typical of service
4) Evaluate in situ bond strength and
5) Reproduce test results

But no single test method can replicate all in-service bond stress states. Nevertheless, the method should involve a stress state fairly typical of service while being sensitive to 
variation in the strength of bond. Usually, a combination of tests is usually done to effectively characterize the bond strength of the bridge deck overlay. Brief reviews of the tests that are of relevance to the proposed experiment are given below.

\subsubsection{Interfacial Bond Strength by Split Tension Test}

Ramey and Strickland [43] conducted durability tests on 3" x 6" composite cylindrical specimens to study four different repair materials. They cast composite cylinders that were one-half Portland cement concrete and one-half repair material (Fig 2.12). The tensile strength of the bond was then determined using a test similar to ASTM 496 [44]. They also tested composite prism specimens under direct shear and impact. They concluded that the splitting cylinder gave the best results, since the coefficient of variation were the smallest for the splitting cylinder specimens.

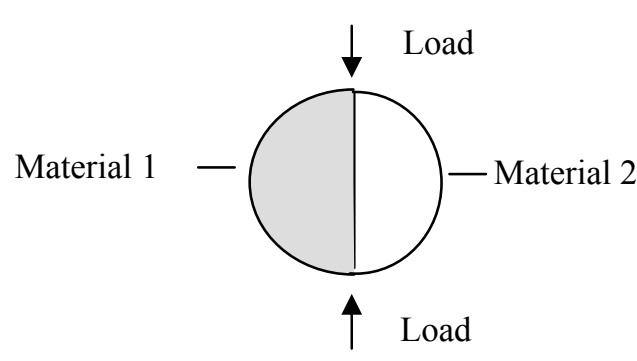

FRONT VIEW

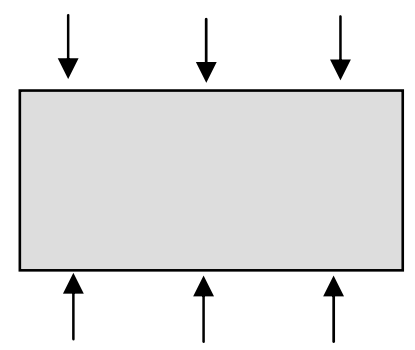

SIDE VIEW

Figure 2.12: Split tensile test to evaluate bond strength of composite cylinder

The ASTM C 1245-93 [44] gives another method to test the relative bond between layers of hardened concrete in multiple-lift forms of construction. This test method was intended to test roller-compacted concrete. However, it could be applied for all types of layered concrete construction, which involved an upper layer of concrete or mortar bonded on an underlying layer of concrete or mortar. Figure 2.13 shows the schematic diagram of the test setup. The specimens could be drilled cores from the field or could be cast in the laboratory. The bond surface is normal to the longitudinal axis at 
approximately the mid-length of the specimen. A splitting tensile stress was produced at the bond surface by point loading across its diameter at that surface.

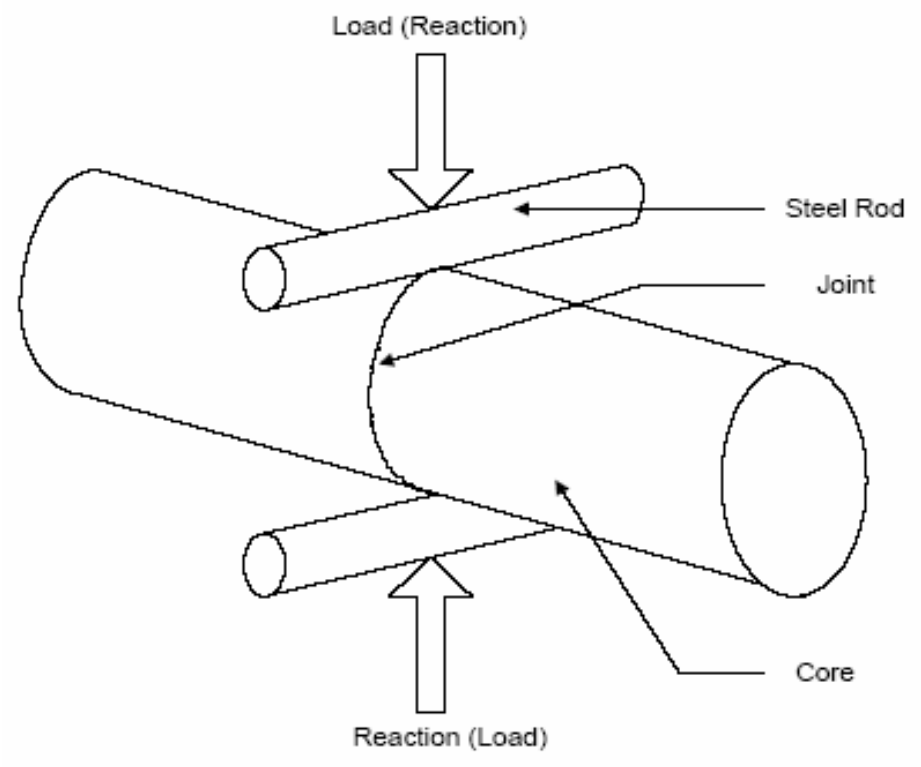

Figure 2.13: ASTM C 1245-93 test to determine bond strength [44]

Geissert et al [45] performed a splitting prism test method to evaluate concrete-toconcrete bond strength. . Comparing the test results of 3 identical series of specimens cast at different times showed good repeatability of the splitting prism test.

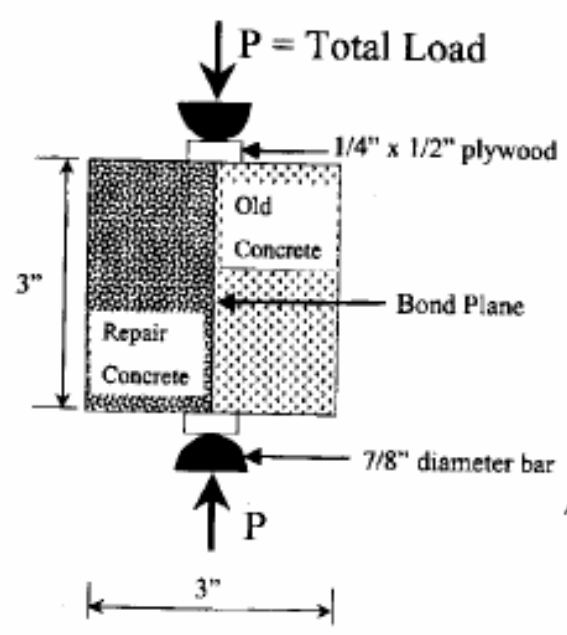

End View

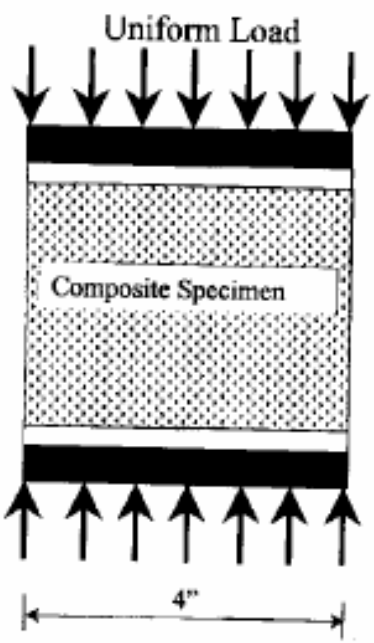

Side View

Figure 2.14: Splitting prism test [45] 


\subsection{Research Significance}

From previous published studies, gaps in research of polymer modification and fiber reinforcement is seen, as explained below.

1. There has not been any research on the effect of carbon fiber reinforcement on the properties of latex modified concrete. An optimum volume fraction of fibers is needed to design the carbon fiber reinforced latex modified concrete mix. Addition of carbon fibers improves strength, but causes loss of workability. Bridge deck applications require high workability and it was necessary to determine the volume fraction of carbon fibers to accommodate the mix within specified specification for slump. A comprehensive set of mechanical tests (tension, flexure, fracture, etc.) is required to be conducted to help us better understand the properties of CFLMC under different conditions of stress. These results will help to weigh the advantages and disadvantages of CFLMC over LMC.

2. Researchers such as Bayasi [29] did not recommend the use of aggregates in carbon fiber reinforced cement, since they could disturb fiber distribution in the matrix and increase fiber spacing. However latex has shown to improve dispersion. Thus further studies were needed to determine whether there was sufficient fiber distribution to cause significant improvement in mechanical properties in the latex modified concrete. Abrasion of fibers was also a reason for not incorporating aggregates to the cement fiber matrix. Hence this study would also investigate proper mix methods and mixing times to ensure that fibers are not degraded.

This study aims to answer the above questions with a comprehensive experimental approach. In laboratory tests, all specimens were prepared and instrumented in sets of 3 to reduce overdependence on single test results. Careful specimen preparation and testing 
methods were developed after testing of several prototypes until accurate and repeatable results were achieved. 


\section{CHAPTER THREE \\ MATERIALS AND MIX PROPORTIONS}

\subsection{Introduction}

The chapter provides description of the materials, determination of mix proportions, and mix procedure, used for study of carbon fiber reinforced latex modified concrete.

\subsection{Determination of Mix Proportions}

Typical mix design for LMC is shown in Table 3.1. Carbon fibers tend to reduce workability. Increasing the polymer/cement or water/cement ratio could overcome workability issues, but it would introduce other problems such as lower compressive strength and increased shrinkage. Hence, this research involved improving on the same mix proportion without change in the polymer/cement or water/cement ratio.

Table 3.1: Mix design of LMC [A.2]

\begin{tabular}{|c|c|c|}
\hline Material & $\begin{array}{c}\text { Gravimetric Nominal } \\
\text { proportions per cubic yard }\end{array}$ & Source \\
\hline Portland cement lbs. & 658 & Ordinary Type I cement \\
\hline$\# 8-$ SSD lbs & 1229 & Greer Limestone, WV \\
\hline Sand - SSD lbs & 1713 & $\begin{array}{c}\text { Martin Marietta } \\
\text { aggregates, OH }\end{array}$ \\
\hline Latex admix gal. & 24.5 & BASF (Styrofan@ 1186) \\
\hline Total water & 201.63 & Municipal water \\
\hline Water/Cement ratio* & 0.3064 & \\
\hline
\end{tabular}




\subsection{Materials used for CFLMC}

The main ingredients of CFLMC are shown below

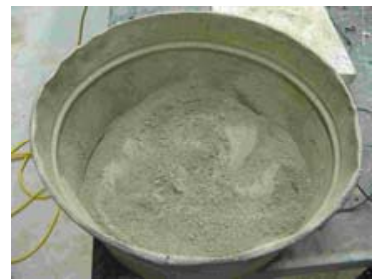

Figure 3.1 a: Cement

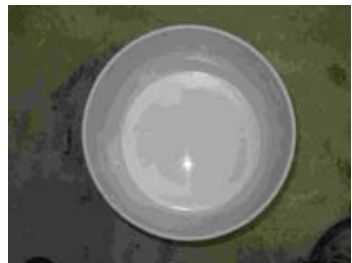

Figure 3.1 d: Latex (Styrofan 1186@)

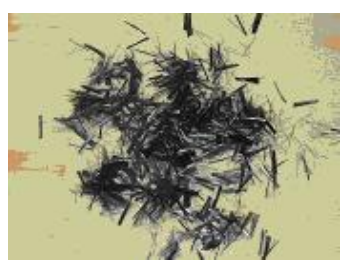

Figure 3.1 b: Carbon

Fibers (0.5 in.)

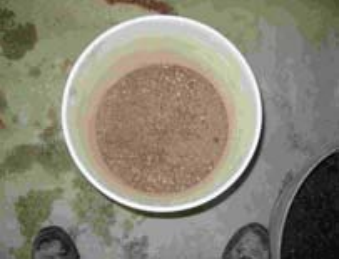

Figure 3.1 e: Fine aggregate (sand)

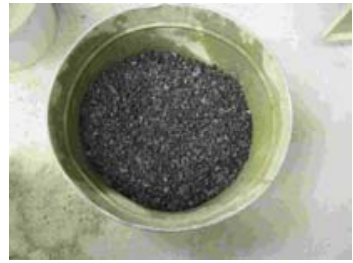

Figure 3.1 c: Coarse aggregate (\#8)

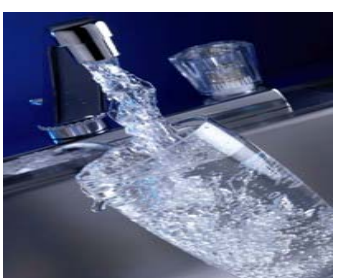

Figure 3.1 f: Water

Figure 3.1: Components of CFLMC

\section{1) Cement}

Commercially available Type I portland cement was used in this study. The cement conformed to ASTM C150 [44]. The reported bulk specific gravity of the portland cement is 3.15 .

\section{2) Carbon Fibers}

For this study, chopped carbon fibers (SIGRAFIL C with GLY coating) from SGL carbon group were used. The material is based on carbonized polyacrylonitrile (PAN) with a glycerin coating. Specifications for the fiber type are given in appendix A.3. 


\section{3) Coarse aggregate}

\#8 sized coarse aggregate for the experiment was obtained from Greer aggregates, Morgantown, WV. The aggregates conformed to ASTM C33 [44]. For preliminary calculations of water content in the aggregates, a sample of aggregates was soaked in water for 48 hours, and then oven dried to calculate the additional water in the aggregates beyond the SSD (Saturated Surface Dry) conditions. Before the actual mixing of concrete, the total quantity of aggregates required for the mix were soaked in water for 48 hours. Suitable corrections to the water added were then made to keep the water/cement ratio at 0.3064. Specifications for the coarse aggregate are given in appendix A.4.

\section{4) Fine aggregate}

The fine aggregate (sand) was supplied by Martin Marietta aggregates from their Apple grove plant. For preliminary calculations of water content in the fine aggregates, a sample of the sand was oven dried to calculate the water in the aggregates above/below the SSD (Saturated Surface Dry) conditions. The sand turned out to be below the SSD condition. Before the actual mixing of concrete, suitable corrections to the water added were then made to keep the water/cement ratio at 0.3064 . Specifications for the sand are given in appendix A.5.

\section{5) Latex admixture}

Latex from BASF, under the trade name Styrofan (C) 1186 was used for the study. Its properties are in specified in appendix A.6.

\section{6) Water}

Treated municipal (city supply) water source or other sources that comply with the physical and chemical requirements of ASTM C94 [44] could be used. 


\subsection{Mix Proportioning}

Conventional concrete mixing processes where the rotation of the mixer, shearing action of the blades, and contact with coarse aggregates subjects the fibers to considerable bending impact and abrasion. Fragile fibers are unsuitable for these processes because they sustain breakage causing loss of aspect ratio and loss of reinforcing effectiveness. Multifilament strands like glass that are not intended to separate tend to do so, and render the mixture unworkable because of increases surface area. Polypropylene fibers are intended to disperse during mixing into individual monofilaments. Insufficient mixing will fail to achieve the intended degree of separation. Optimal mixing time is necessary to achieve satisfactory workability without damage to fibers and consequent loss of reinforcement effectiveness.

Sakai [26] suggested an optimal mixing time between 2 to 3 minutes in the mixer for carbon fiber reinforced cements for increased flexural strength.

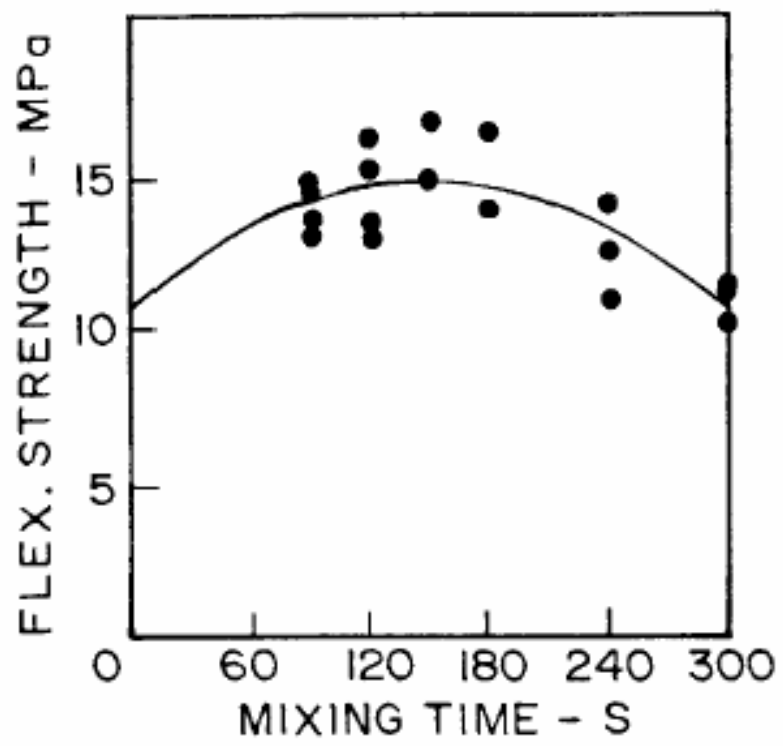

Figure 3.2: Relationship between composite strength and mixing time in a conventional mortar mixer for carbon-fiber reinforced cements [26]

Trial mixes were conducted to determine the quantity of carbon fibers to be added. A low fiber volume fraction is usually preferred, because the material cost increases, the 
workability decreases, the air void content increases, and the compressive strength decreases, as the fiber content increases. For placement on bridge deck overlays, workability was the initial concern. Hence slump was measured on different trial mixes to determine the quantity of carbon fibers that would possibly improve mechanical properties of concrete, as well as fall well within the specifications of slump required by ACI $548.4 \mathrm{r}$ (3-8 in.).

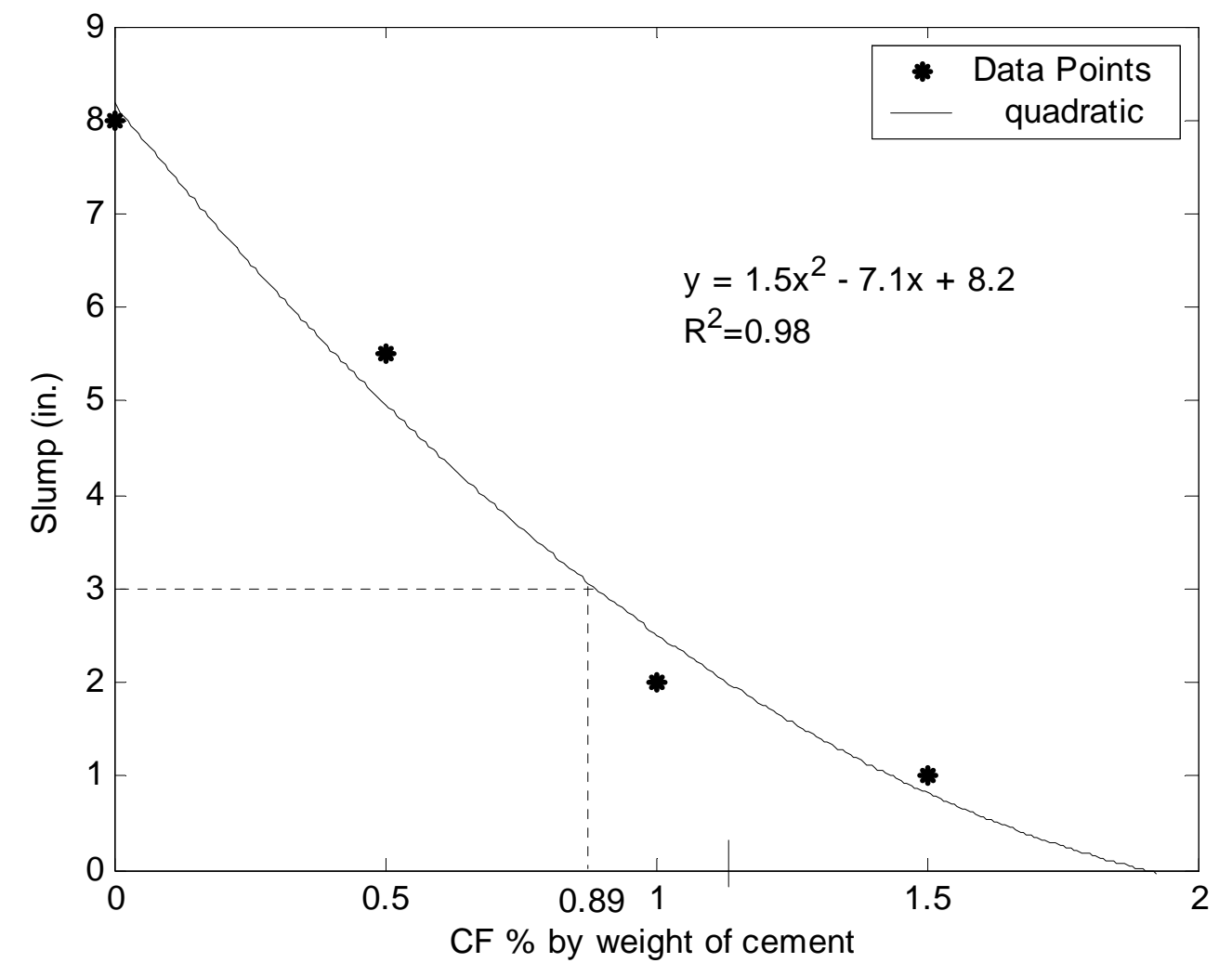

Figure 3.3: Slump vs CF \% (weight of cement)

Based on initial pilot test results, (Figure 3.3), a minimum slump of 3 inches predicted a CF percentage of 0.89 . On the safer limit, it was found feasible to add carbon fibers at 0.7 $\%$ (by weight of cement). It represented a volume fraction of $0.15 \%$. 


\subsection{Calculation of Volume Fraction of Carbon Fibers}

Expression of the carbon fiber percentage as volume fraction is required for theoretical treatment while expression in fiber weight is required for batching.

Density of the LMC mix $=144.74 \mathrm{lbs} . / \mathrm{ft}^{3}$

CF weight per cubic yard $=0.7 \%$ by weight of cement

$$
=0.007 \times 658 \mathrm{lbs} .=4.606 \mathrm{lbs}
$$

$\mathrm{CF} \%$ by weight of concrete $=($ Weight of $\mathrm{CF} /$ weight of concrete $)$ per cubic yard

$$
\begin{aligned}
& =\frac{4.606}{144.74 \times 27}=0.0011786 \\
& \approx 0.118 \% \text { by weight of concrete }
\end{aligned}
$$

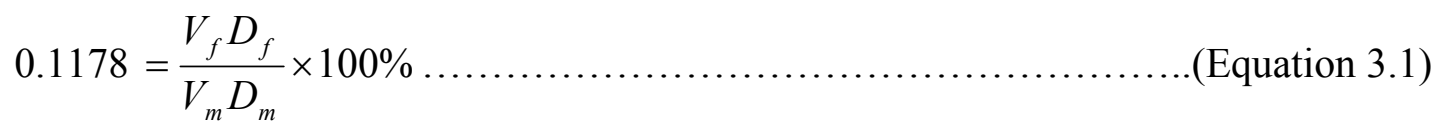

$\therefore \quad \frac{V_{f}}{V_{m}}=\frac{0.1178 \times D_{m}}{D_{f} \times 100}=\frac{0.1178 \times 144.74}{112 \times 100}$

$=0.001522$

$\therefore$ Fiber Volume fraction $\frac{V_{f}}{V_{m}}=0.15 \%$

Where

$V_{f}=$ Fiber Volume

$V_{m}=$ Matrix Volume

$D_{f}=$ Fiber Density

$D_{m}=$ Matrix Density

\subsection{Laboratory Preparation of LMC}

1) Prior to starting the rotation of the mixer, add the coarse aggregate and latex

2) Start the mixer, and let it run for $1 / 2$ minute.

3) The sand and cement were added and mixed for 1 additional minute

4) The water was later added and mixed for 2 minutes

5) Cover the top of the mixer to prevent evaporation during mixing. 
6) To eliminate segregation, deposit machine mixed LMC in the clean, damp mixing pan and remix by shovel or trowel until it appears to be uniform

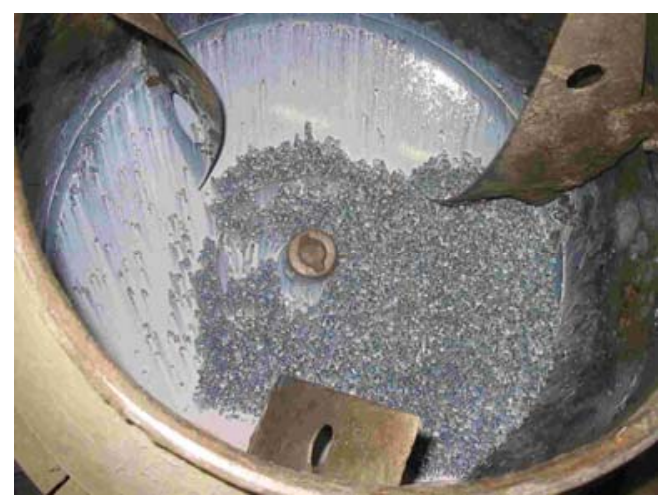

Figure 3.4: Concrete mixing of LMC

Measure the slump of the LMC batch after 5 minutes in accordance with ASTM C143 [44] and ACI 548.3r [2].

\subsection{Laboratory Preparation of CFLMC}

The technique of dispersion of carbon fibers within the concrete matrix is critical to the success of carbon fiber technology. The 'wet mix' and the 'dry mix' method of mixing carbon fibers with concrete were experimented. In the wet mix method, the fibers were initially mixed with latex and discharged into a concrete mixer. This method posed problems such as clumping of carbon fibers, or attaching of carbon fibers to the sides of the mixer itself.

In the dry mix method, carbon fibers were mixed with cement in a tabletop mixer fro about 5 minutes (Figure 3.5). This forceful mixing action caused the clumped micro fibers to separate and disperse. A SEM photograph (Figure 5.1) from the fractured surface of a cured sample, shows proper dispersion of carbon fibers within the concrete matrix. 


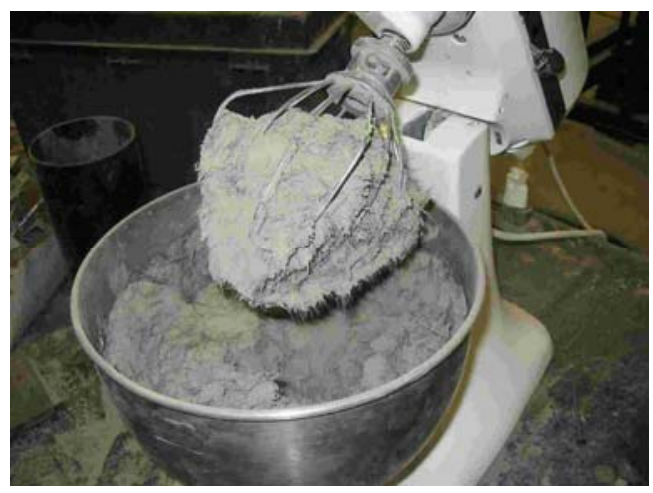

Figure 3.5: Dry mixing of carbon fibers with cement

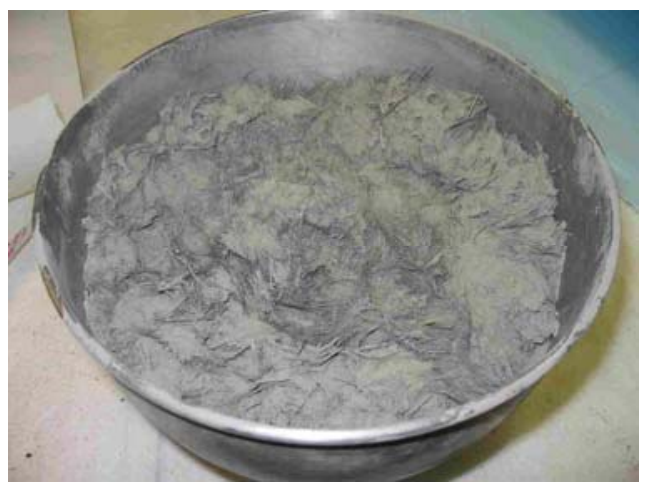

Figure 3.6: Cement and Carbon Fibers

The sequence of steps to manufacture CFLMC are given below

1) Cement and carbon fibers were dry mixed well in a tabletop mixer for about 5 minutes

2) Prior to starting the rotation of the mixer, add the coarse aggregate and latex

3) Start the mixer, and let it run for $1 / 2$ minute.

4) The sand and fiber cement were added and mixed for 1 additional minute

5) The water was added and mixed for 2 minutes

6) Cover the top of the mixer to prevent evaporation during mixing.

7) To eliminate segregation, deposit machine mixed CFLMC in the clean, damp mixing pan and remix by shovel or trowel until it appears to be uniform 


\section{CHAPTER FOUR}

\section{SPECIMEN PREPARATION AND TEST METHODS}

\subsection{Introduction}

This chapter describes in detail, the theoretical background behind each test, test specimen dimensions, specimen preparation and data acquisition systems. A brief outlook of each test method is given in Table 4.1. All specimens followed guidelines from relevant ASTM standards where applicable, and tested according to ASTM standards and ACI guidelines.

Table 4.1: Description of tests on LMC and CFLMC

\begin{tabular}{|c|c|c|c|c|c|}
\hline Sr. No & Test & $\begin{array}{c}\text { Standard } \\
\text { Test Method }\end{array}$ & $\begin{array}{l}\text { Specimen } \\
\text { dimensions }\end{array}$ & $\begin{array}{c}\text { No. of } \\
\text { specimens }\end{array}$ & Notes \\
\hline 1 & Slump & ASTM C 143 & & 1 & $\begin{array}{l}\text { Measured } 5 \\
\text { minutes } \\
\text { after mixing }\end{array}$ \\
\hline 2 & $\begin{array}{c}\text { Direct } \\
\text { Tension Test }\end{array}$ & & $\begin{array}{c}\text { Dog Bone Shaped } \\
\text { specimen with CSA } \\
1 \text { 1"x } 1 "\end{array}$ & 3 & $\begin{array}{c}\text { Loading } \\
\text { rate }= \\
0.00025 \\
\text { inch } / \mathrm{sec}\end{array}$ \\
\hline 3 & $\begin{array}{l}\text { Four point } \\
\text { Loading } \\
\text { (Flexure) }\end{array}$ & $\begin{array}{c}\text { ASTM C 78 } \\
\text { ASTM C } \\
1018\end{array}$ & $\begin{array}{c}4^{\prime \prime} \times 2 " x 16^{\prime \prime} \\
\text { Span length = } 12^{\prime \prime}\end{array}$ & 3 & $\begin{array}{c}\text { Loading } \\
\text { rate }= \\
0.00025 \\
\text { inch } / \mathrm{sec}\end{array}$ \\
\hline 4 & $\begin{array}{l}\text { Three point } \\
\text { Loading } \\
\text { (Flexure) }\end{array}$ & ASTM C 293 & $\begin{array}{c}4^{\prime \prime} \times 2 " \mathrm{x} 16^{\prime \prime} \\
\text { Span length = } 12 "\end{array}$ & 3 & $\begin{array}{l}\text { Loading } \\
\text { rate }= \\
0.00025 \\
\text { inch } / \mathrm{sec}\end{array}$ \\
\hline 5 & $\begin{array}{c}\text { Split } \\
\text { Tension Test }\end{array}$ & ASTM C 496 & $4^{\prime \prime} \times 8^{\prime \prime}$ cylinder & 3 & \\
\hline
\end{tabular}

Based on encouraging results of the flexural tests, further experiments on the effect of increasing the carbon fiber percentage to LMC were experimented in flexure and fracture. A study was also conducted to study the effect of carbon fibers on the bond strength between the overlay and concrete substrate. These tests are shown in Table 4.2. 
Table 4.2: Description of tests on LMC specimens with varying CF \%.

\begin{tabular}{|c|c|c|c|c|c|}
\hline Test & $\begin{array}{l}\text { Carbon } \\
\text { Fiber \% }\end{array}$ & $\begin{array}{c}\text { Standard } \\
\text { Test Method }\end{array}$ & $\begin{array}{c}\text { Specimen } \\
\text { Dimensions }\end{array}$ & $\begin{array}{c}\text { No. of } \\
\text { Specimens }\end{array}$ & Notes \\
\hline \multirow{4}{*}{$\begin{array}{l}\text { Four point } \\
\text { Loading } \\
\text { (Flexure) }\end{array}$} & 0 & \multirow{4}{*}{$\begin{array}{c}\text { ASTM C78 } \\
\text { ASTM C1018 }\end{array}$} & \multirow{4}{*}{$\begin{array}{c}1 " \times 3 " x 12^{\prime \prime} \\
\text { Span length =9" }\end{array}$} & 3 & \multirow{4}{*}{$\begin{array}{c}\text { Loading } \\
\text { rate }= \\
0.00025 \\
\text { inch } / \mathrm{sec}\end{array}$} \\
\hline & 0.5 & & & 3 & \\
\hline & 1.0 & & & 3 & \\
\hline & 1.5 & & & 3 & \\
\hline \multirow{4}{*}{ Fracture test } & 0 & \multirow{4}{*}{$\begin{array}{c}\text { RILEM test } \\
\text { by Hillerborg } \\
\text { et. al. }\end{array}$} & \multirow{4}{*}{$\begin{array}{c}3 " \times 3 " \times 12^{\prime \prime} \\
\text { Span length =9" }\end{array}$} & 3 & \multirow{4}{*}{$\begin{array}{c}\text { Loading } \\
\text { rate }= \\
0.00025 \\
\text { inch } / \mathrm{sec}\end{array}$} \\
\hline & 0.5 & & & 3 & \\
\hline & 1.0 & & & 3 & \\
\hline & 1.5 & & & 3 & \\
\hline \multirow{4}{*}{$\begin{array}{c}\text { Split } \\
\text { Composite } \\
\text { Cylinder test }\end{array}$} & 0 & \multirow{4}{*}{ ASTM C496 } & \multirow{4}{*}{$\begin{array}{l}4^{\prime \prime} \text { Diameter } 8 " \\
\text { long composite } \\
\text { cylinder }\end{array}$} & 3 & \\
\hline & 0.5 & & & 3 & \\
\hline & 1.0 & & & 3 & \\
\hline & 1.5 & & & 3 & \\
\hline
\end{tabular}

\subsection{Description of Specimen Preparation and Tests Methods}

\subsubsection{Slump}

Slump is the term used to describe the consistency, stiffness and workability of fresh concrete. The results of a slump test are stated in inches. The workability of concrete is affected by a number of factors: water content of the mix, mix proportions, aggregate properties, time, temperature, characteristics of the cement, and admixtures. The slump of fresh concrete properties was measured according to ASTM C 143 [44]. As per recommendations by the ACI 548.4 [20], the slump is measured 4-5 minutes after discharge from the mobile mixer.

\subsubsection{Direct Tension Testing}

Currently, there are no standard tests by ASTM that measure the stress on concrete in direct tension. After several prototype tests on concrete specimen size and preparation, loading arrangements, loading rates, gripping force etc, a successful and repeatable test method was developed in the laboratory Custom made molds were designed and 
machined to make dog bone tensile concrete specimens. Care was taken to prepare near perfect specimens with minimal eccentricities during loading. The molds were designed so as to be able to machine the top surface of the specimen for a smooth sawed surface. This was done to remove eccentricities during tensile loading. The special grip arrangement prevented preloading and eliminated any eccentricities during loading.

\subsubsection{Tensile Specimen Dimensions}

Specimen dimensions for the tensile test were specially designed taking into consideration the aggregate size, length of strain gages and width of the hydraulic test machine grips.

\section{PLAN}

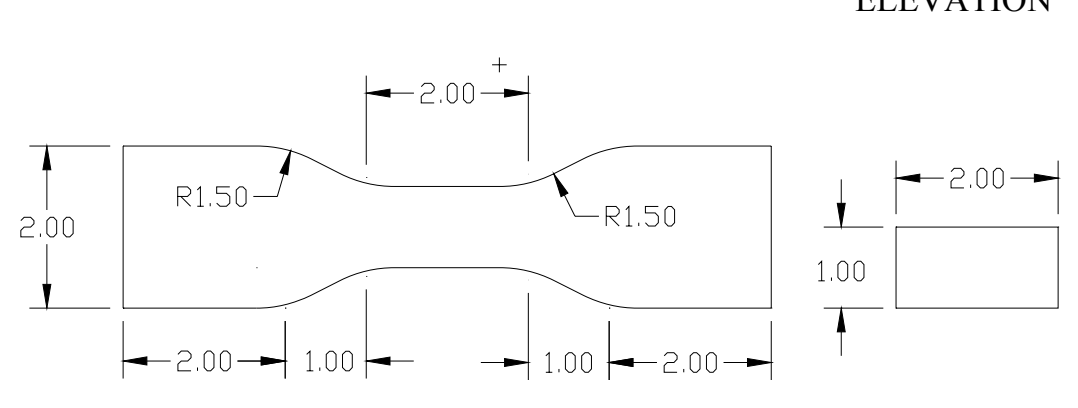

Figure 4.1: Dimensions of tensile test specimen (all dimensions in inches).

\subsubsection{Preparation of Tensile Test Specimens}

\section{Step 1: Mold Design}

Custom made molds were designed and machined to make dog bone tensile concrete specimens. The molds were designed so as to be able to machine the top surface of the specimen for a smooth sawed surface. This was done to remove eccentricities during tensile loading. The molds were made from high-density polyethylene (HDPE) materials and machined with a precision $\mathrm{CNC}$ machine. 


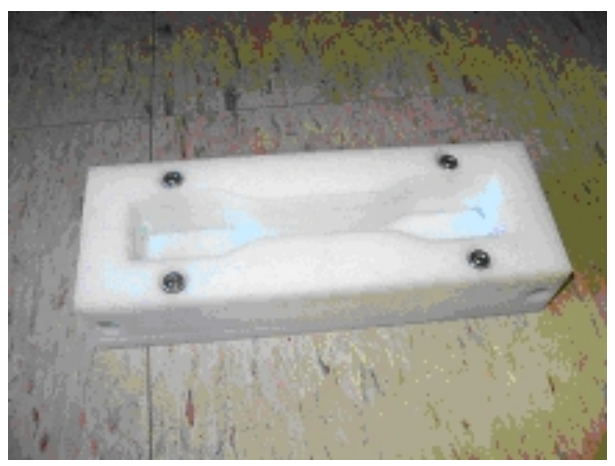

Figure 4.2: Design of molds

\section{Step 2: Casting of molds}

The molds were coated with demolding oil and concrete was cast into the molds, smoothened with a hand trowel and vibrated to ensure proper compaction and to remove air bubbles within the fresh concrete mix.

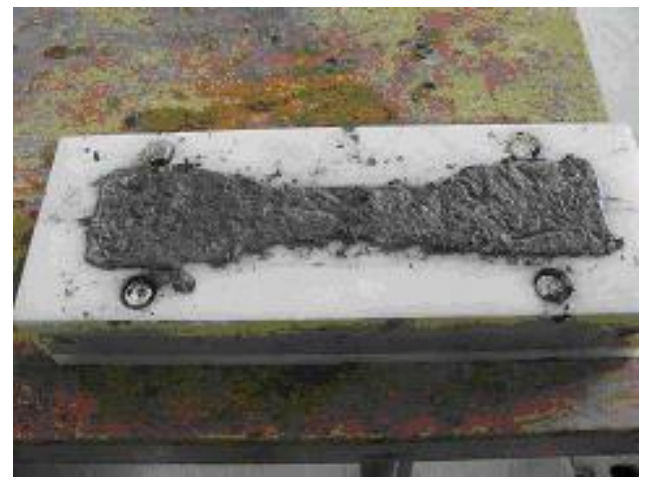

Figure 4.3: Concrete casting in molds

\section{Step 3: Curing of specimens.}

The concrete specimens were air cured for 24 hours within its mold to allow it to harden. Next the specimens were cured under water for 48 hours as per recommendations of ACI 548.3r [2], demolded, and finally air cured till the day of testing. 


\section{Step 4: Demolding of specimens}

Demolding was done on the third day of the concrete pour. The design of the mold permitted the top layer of the mold to detach, to expose $0.5^{\prime \prime}$ concrete protrusion from the mold.

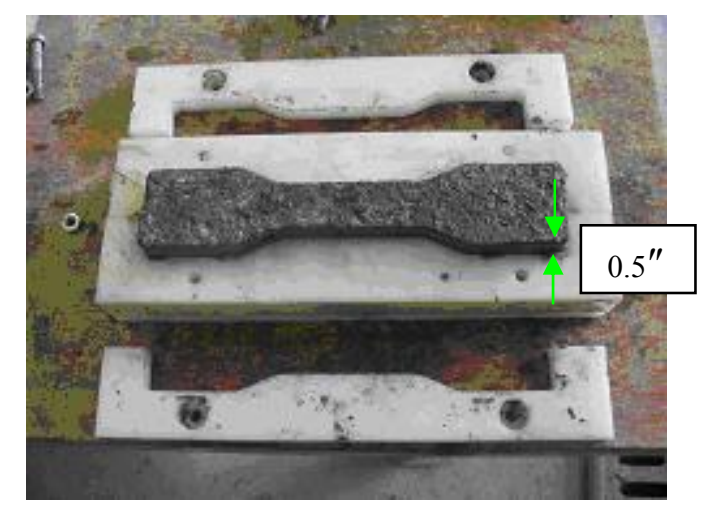

Figure 4.4: Demolding upper layer of mold

Next, the exposed surface of concrete was saw- cut with a rotary diamond tool to provide a smooth finish to the dog-bone shaped concrete specimens.

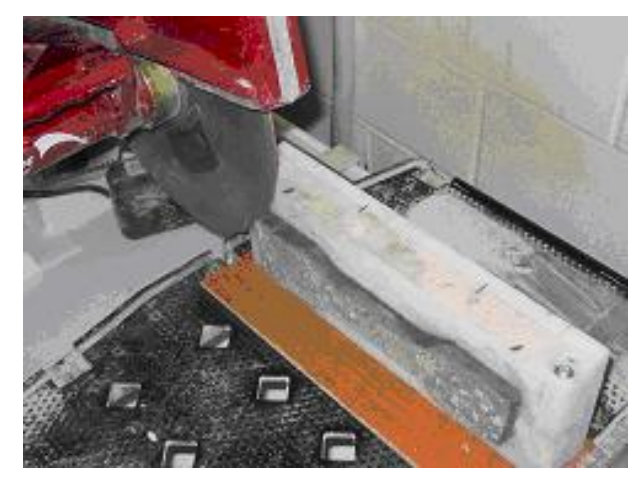

\section{Figure 4.5: Saw cutting top 0.5" off specimen}

Finally, the 1" thick dog-bone specimen could be demolded.

\section{Step 5: Sanding}

The concrete specimens were carefully sanded with a sanding machine and proper grades of sand paper, to ensure smooth and parallel surfaces. 


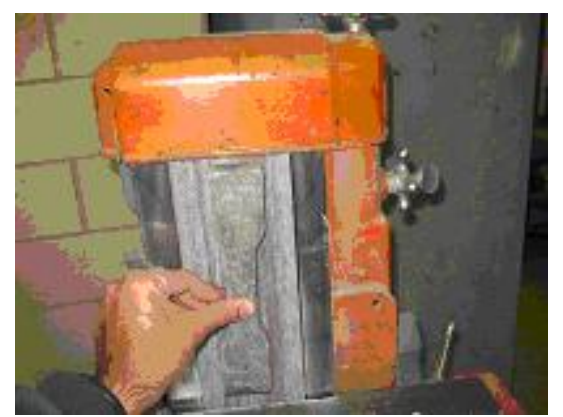

Figure 4.6: Sanding of specimens

\subsubsection{Instrumentation of Specimen and Specimen Fixtures for Testing}

During prototype testing, special grips were custom manufactured [A.12] to hold a 1" thick specimen within the gap openings of the MTS hydraulic test machine. However, the specimen tended to crack during gripping or at low tensile strengths. Due to slight imperfections in the concrete specimen, eccentric loads were induced during gripping. Hence, an arrangement had to be made to create joints at the two ends of the specimen to permit swiveling. This ensured the specimen is not preloaded or under eccentric load.

A 2" wire resistance strain gage [A.7] was attached to one face of the tension test specimen to measure strains. Four 0.25 " steel plates were attached to the grip area of the dog-bone specimen using Loctite 8500 [A.8] adhesive.

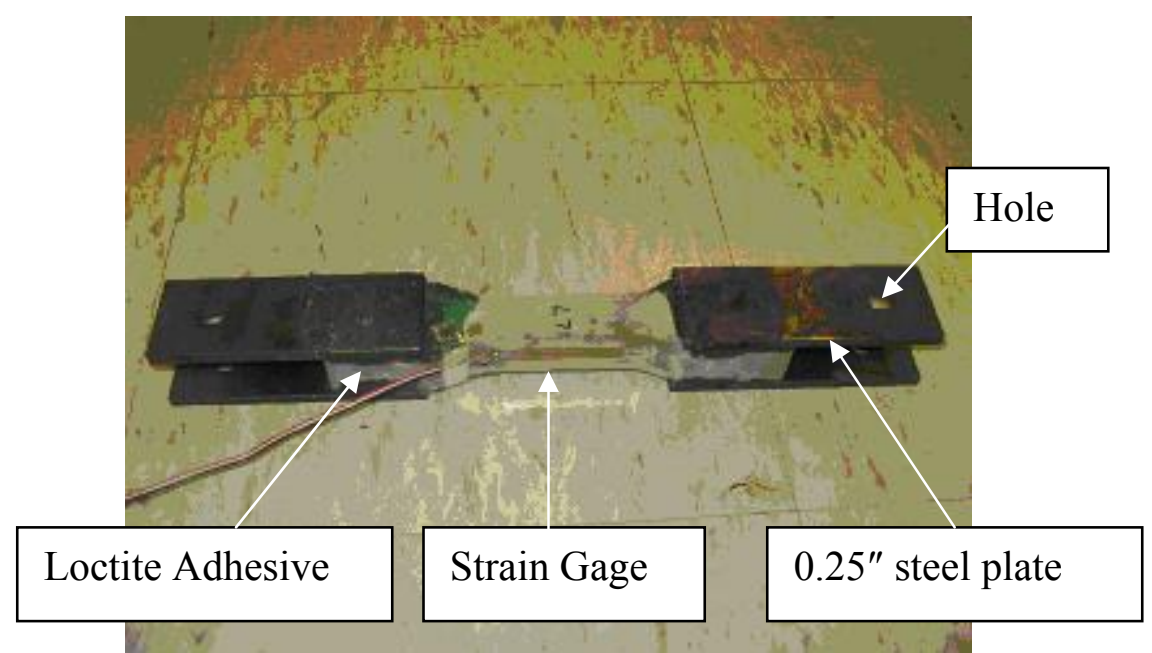

Figure 4.7: Concrete dog-bone specimen 
The steel plates have a hole drilled through, to allow a bolt to pass through. The bolt is attached to a ring fixture, which is bolted to the MTS machine (section 4.2.3.2). This unique arrangement allows for a slight swivel movement to adjust to any possible eccentricities in the specimen, or the test loading arrangements, to ensure direct tensile stresses within the specimen.

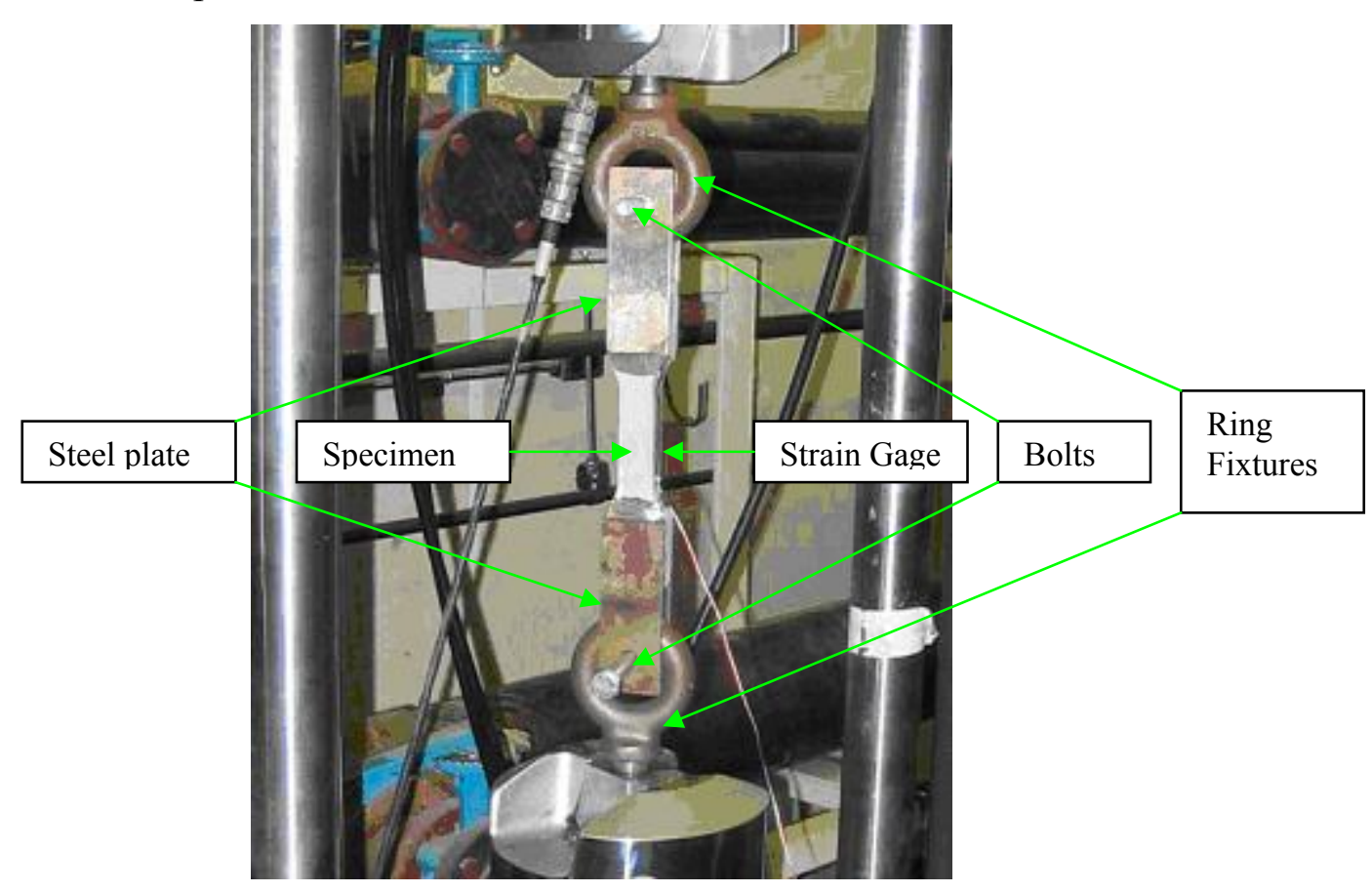

Figure 4.8: Loading arrangement for dog-bone test specimens

\subsubsection{Specimen for Scanning Electron Microscope.}

After conducting a tensile test, a thin slice of the fractured surface of concrete was cut from a CFLMC specimen for viewing under the SEM. The specimen was then cleaned and coated with a thin film of gold for properties of conductivity while viewing under the SEM. 


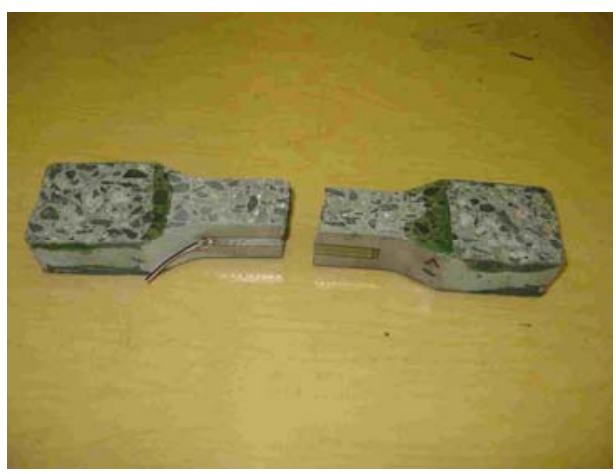

Figure 4.9: Fractured Tensile Specimen

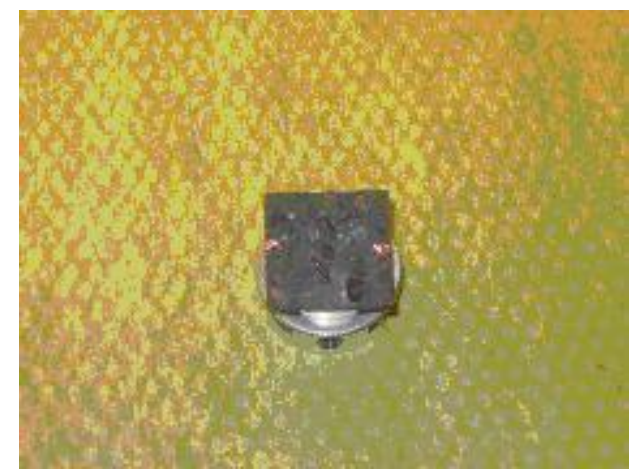

Figure 4.10: Specimen for SEM viewing

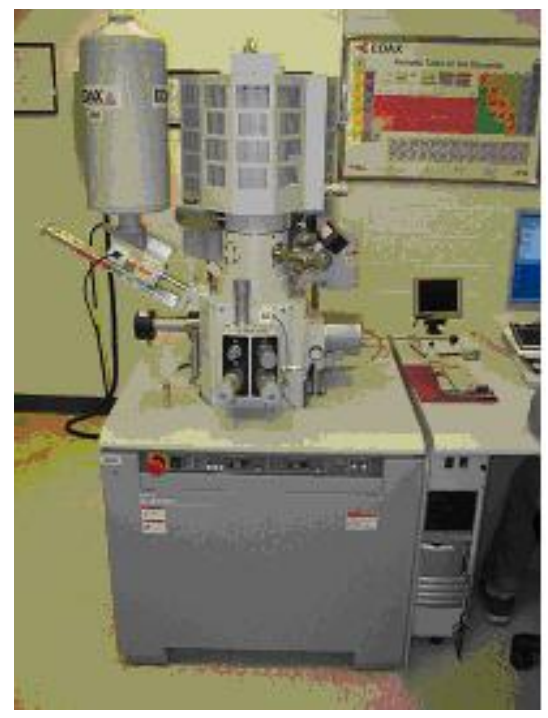

Figure 4.11: SEM

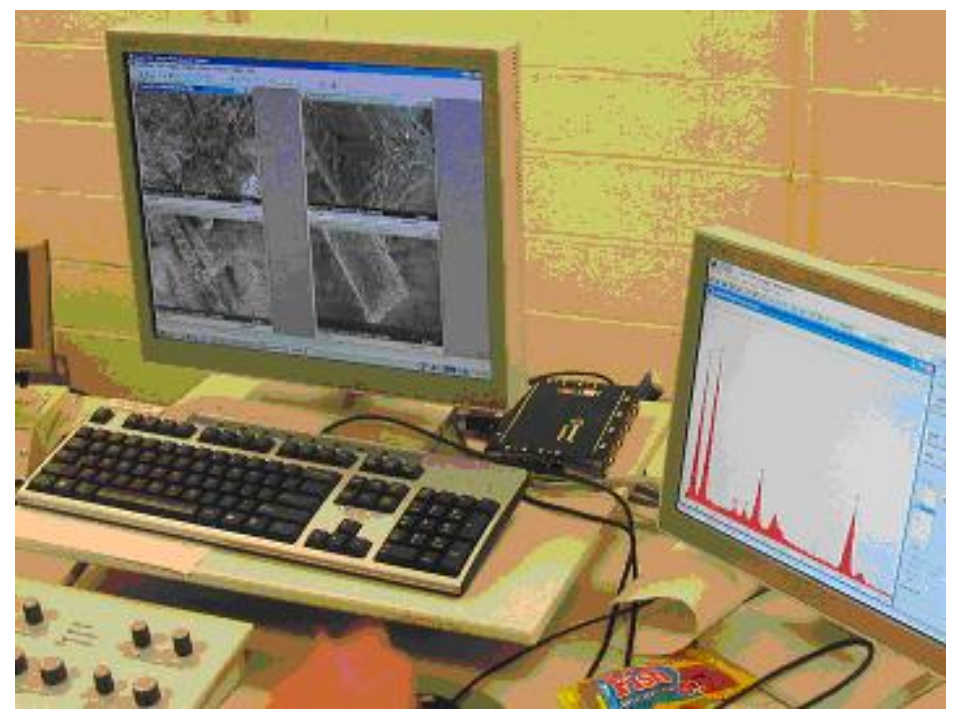

Figure 4.12: Data acquisition system

\subsubsection{Four Point Loading Test}

The flexure test method measures the behavior of materials subjected to simple beam bending. The area of uniform stress in a four point loading test exists between the inner span loading points, where half the load is applied at each third of the span length. Many applications of overlay materials subject them to flexural stresses, in addition to direct stresses. Hence, an understanding of the mechanism of strengthening in flexure is more important than studies in direct stress situations. 


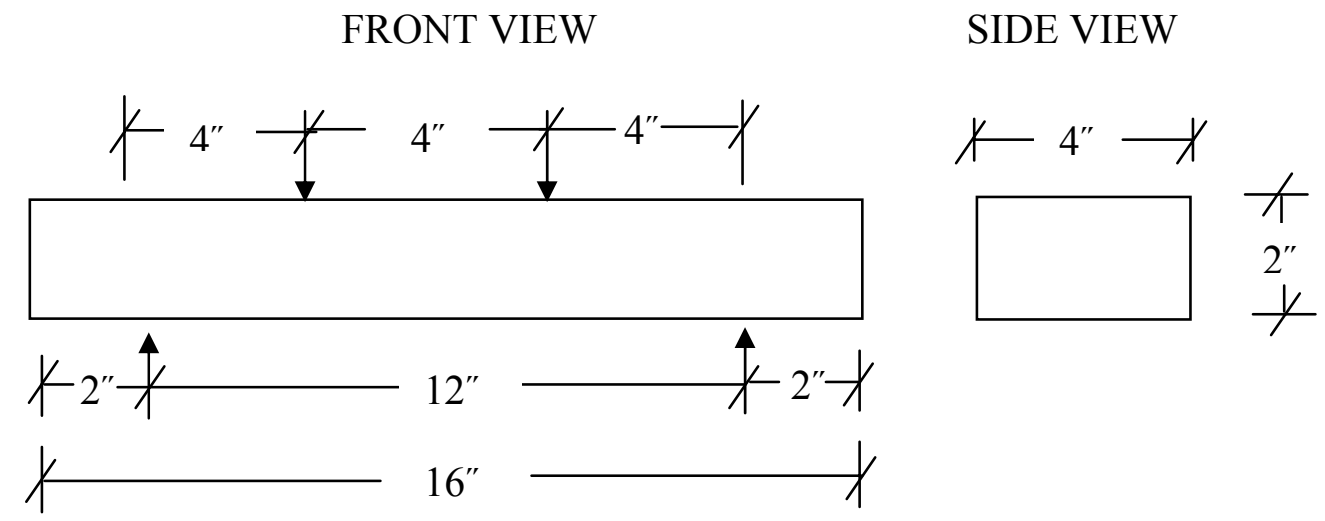

Figure 4.13: Specimen dimensions for four point loading method

Stresses were calculated from the load using the formula

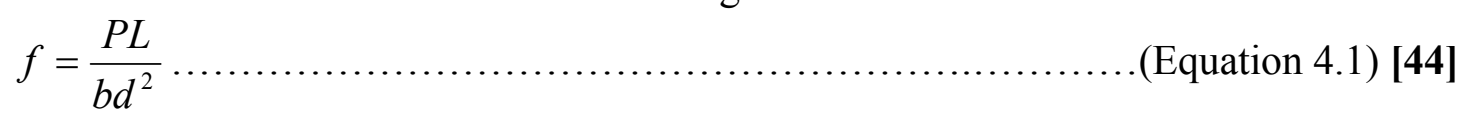

where

$\mathrm{f}=$ stress, psi

$\mathrm{P}=$ load applied, lbs

$\mathrm{L}=$ span length, in.,

$\mathrm{b}=$ average width of specimen, in.

$\mathrm{d}=$ average depth of specimen, in .

\subsubsection{Specimen Preparation}

ASTM C 78 [44] and ASTM C 1018 [44] were followed for specimen preparation with special considerations for overlay materials. The specimen dimensions were 4" 2 2"x 16 " with a span length of 12 ". Specimens were prepared in standard 4"x3"x16" steel molds with a plexiglass (acrylic) cover to achieve smooth surface finish and required thickness for the concrete specimen. Specimens were coated with demolding oil before the pour. During the pour, a vibrating rod was inserted to ensure there was no air bubbles within the concrete. 


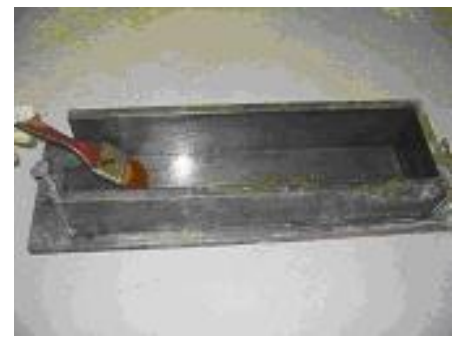

Figure 4.14 (a): Steel Mold

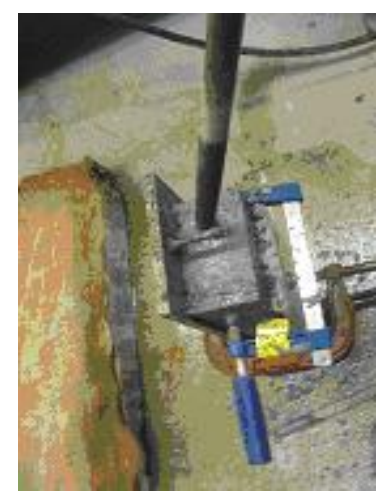

Figure 4.14 (d): Use of vibrating rod

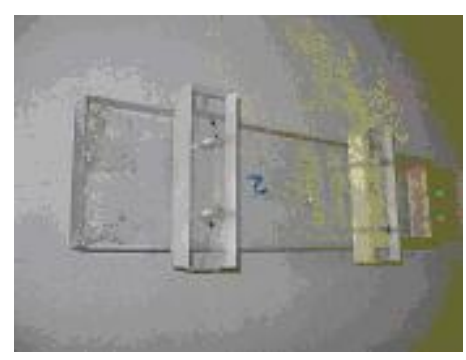

Figure 4.14 (b):

Plexiglass cover

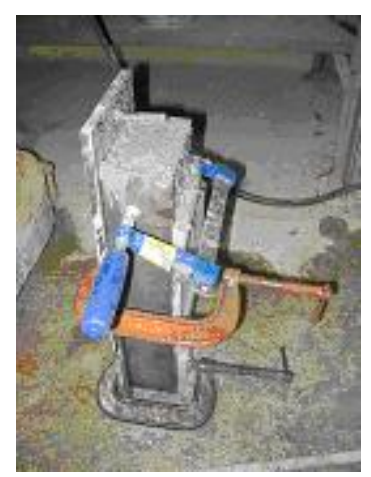

Figure 4.14 (e):

Concrete in mold

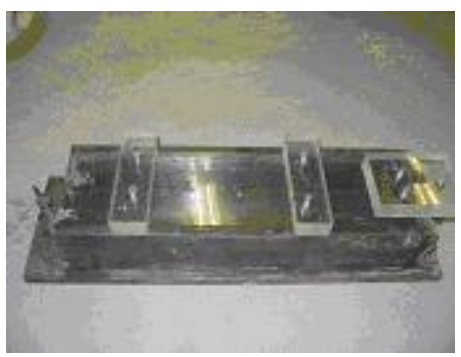

Figure 4.14 (c): Mold for flexure specimen

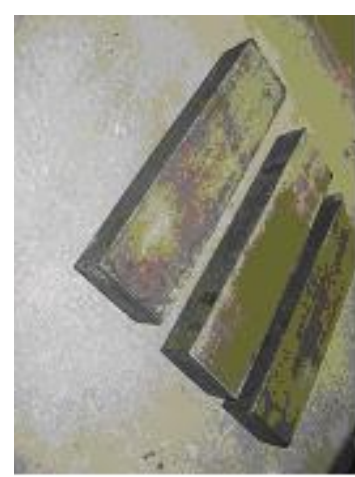

Figure 4.14 (f): Cured flexure specimen

Figure 4.14: Preparation of flexure specimens.

Once cured, the specimen was instrumented with a 2" wire resistance strain gage [A.7] on the tension side of the specimen during loading. An LVDT [A.9] was attached to the compression side of the specimen to determine the mid-point deflection of the specimen.

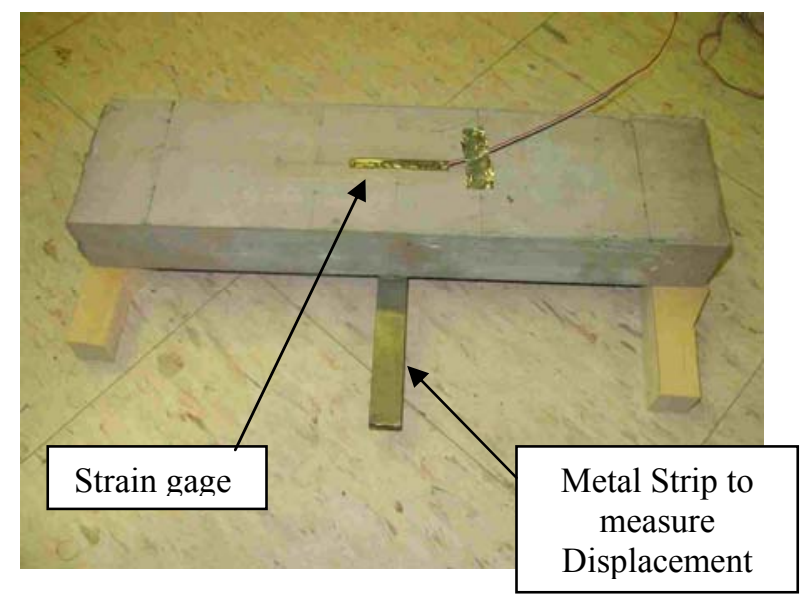

Figure 4.15: Instrumented specimen for four point loading specimen. 
Based on the favorable results from the flexural tests, additional LMC and CFLMC specimens $(\mathrm{CF} \%$ of $0.5,1.0 \& 1.5)$ with dimensions 1"x 3"x 12" (Span length =9") were prepared and tested on the $28^{\text {th }}$ day of curing, in a four point loading test.

\subsubsection{Test Setup for Four Point Loading}

For the four point loading test, an MTS -810 hydraulic material [A.10] test system is used. The machine is controlled via the 458.10 Microconsole and the 418.91 Microprofiler. Programming the Microprofiler can control the rate of loading and displacement. Vishay System 5000 data acquisition [A.11] was used to collect the data from the strain gages as well as load and displacement from the MTS hydraulic machine. Data from the Vishay instrument is downloaded to a laptop using the data acquisition card and strainsmart software. Strainsmart is a ready-to-use, Windows based software system for acquiring, reducing, presenting, and storing measurement data from strain gages, strain-gage-based transducers, thermocouples, temperature sensors, LVDT's, potentiometers, piezoelectric sensors, and other commonly used transducers. The acquired data was analyzed and plotted in Matlab.
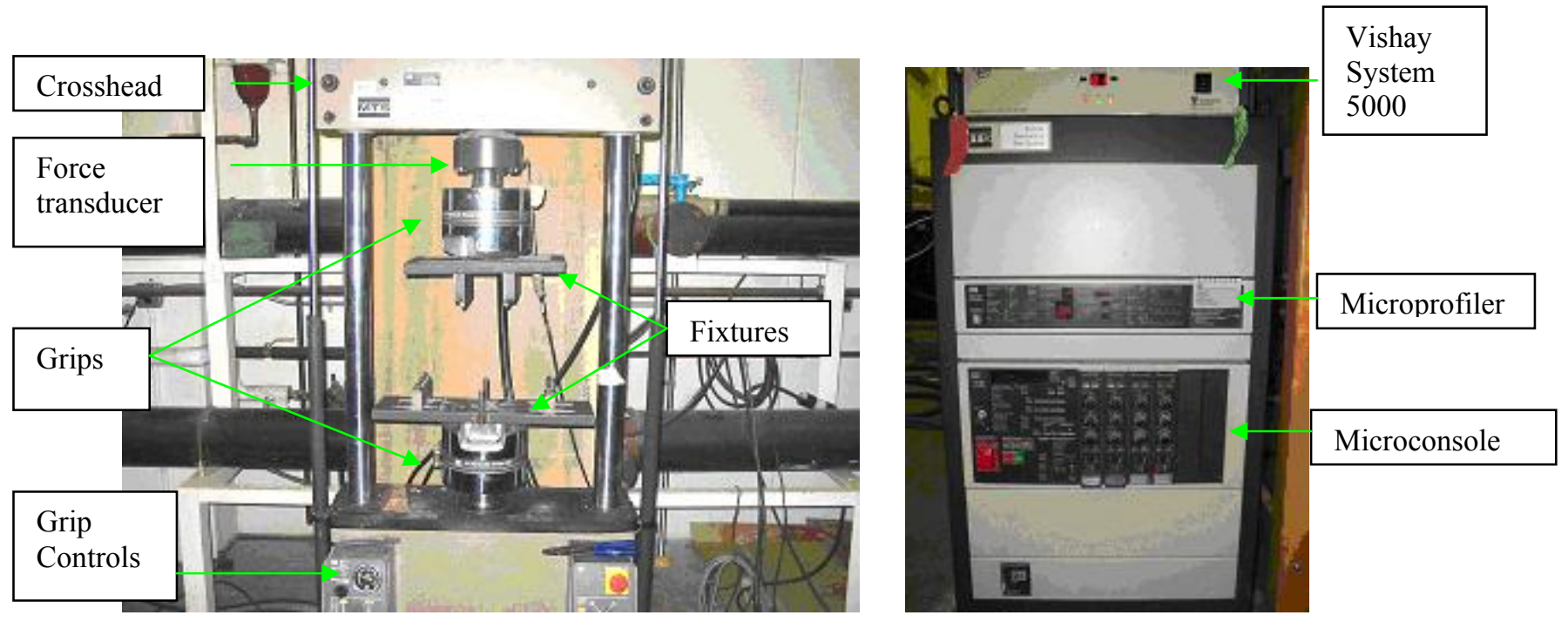

Figure 4.16: MTS 810 Hydraulic test machine

Figure 4.17: Data acquisition system 


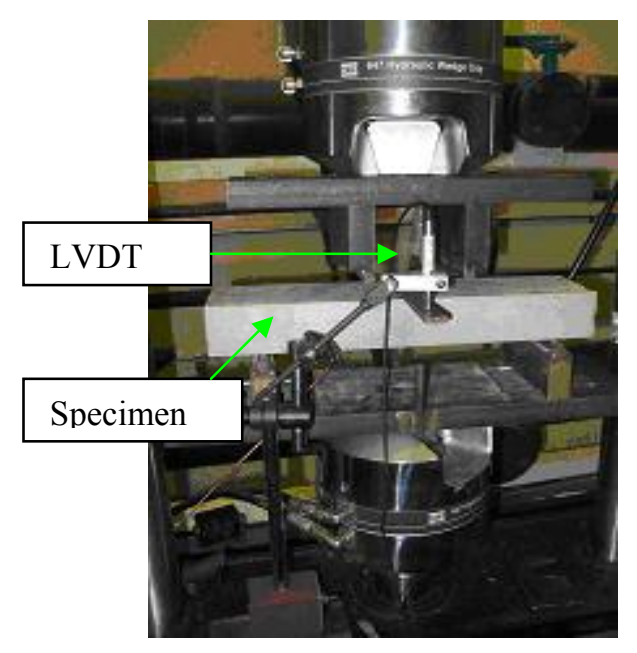

Figure 4.18: Four point loading

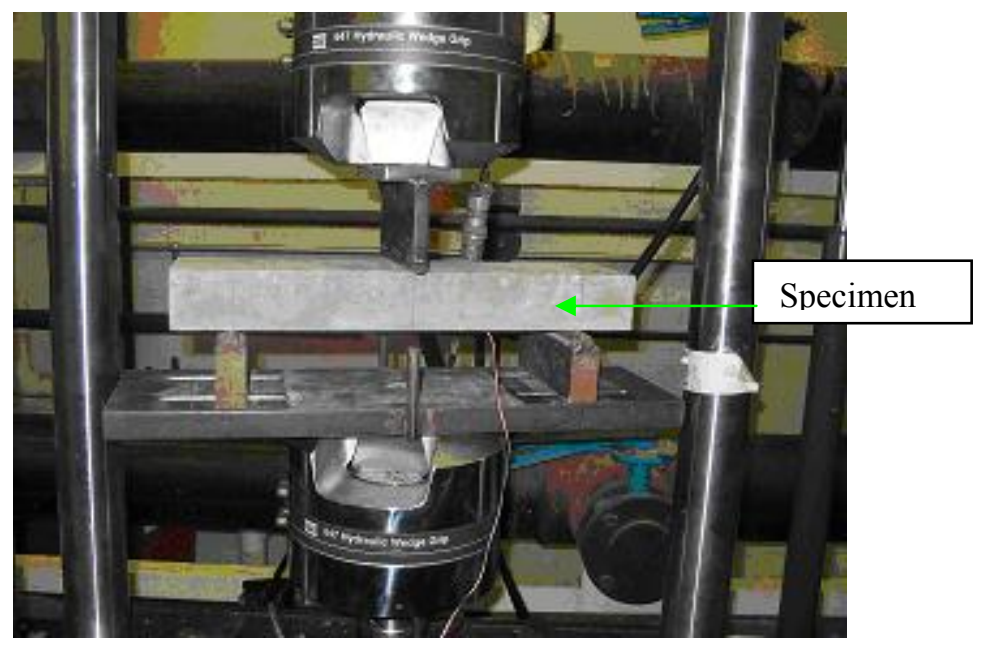

Figure 4.19: Three point loading

\subsubsection{Three Point Loading}

In a three point loading test, the area of uniform stress is quite small and concentrated under the center load. This test was conducted in addition to the third point loading to reinforce the results and conclusions obtained from the previous test. The specimens for center point loading had the same dimensions as those for the four point loading. Stresses, modulus of rupture and strains were measured during testing.

Stresses during loading are calculated from the load using the formula

$f=\frac{3 P L}{2 b d^{2}}$

where,

$\mathrm{f}=$ stress, psi

$\mathrm{P}=$ maximum applied load, lbs

$\mathrm{L}=$ span length, in.,

$\mathrm{b}=$ average width of specimen, in.

$\mathrm{d}=$ average depth of specimen, in. 


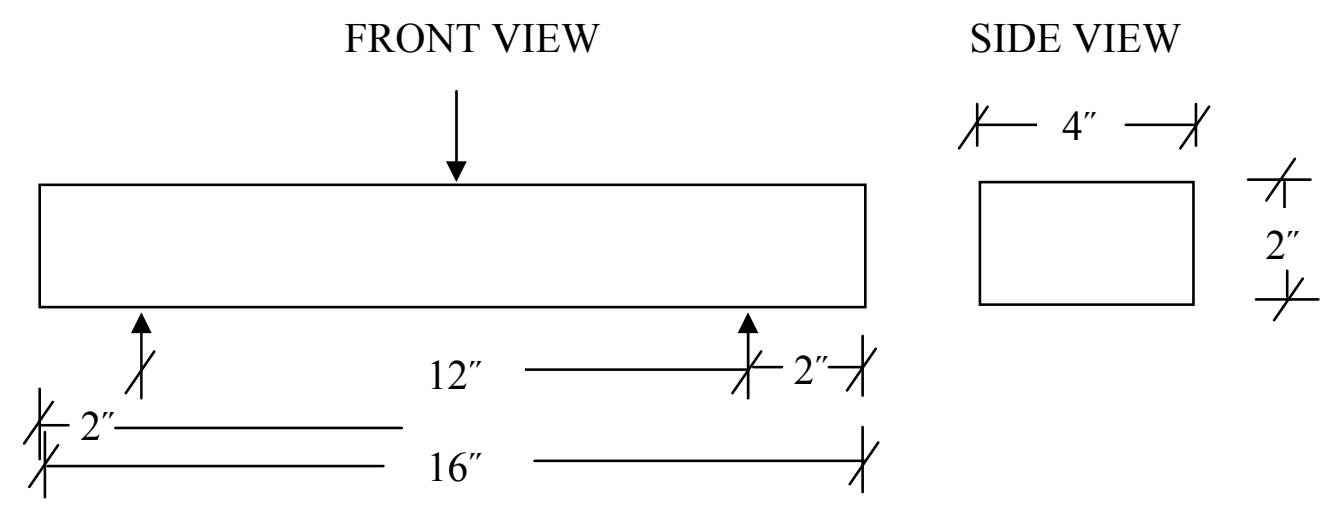

Figure 4.20: Specimen dimensions for three point loading method

\subsubsection{Split Tension Test}

Split tensile strength is a measure of a material's ability to resist a diametric compressive force. The compressive loads induce an essentially uniform tensile stress on the diametrical plane. The cylindrical material specimen is placed with its axis placed horizontally between the platens of a test machine. A relatively low and uniform rate of force is applied on the test specimen until splitting or rupture occurs. Specimens for split tension testing were prepared according to recommendations from ASTM C496 [44]. Concrete cylinder $4 "$ in diameter and 8 " long were prepared by pouring freshly mixed concrete in standard plastic molds

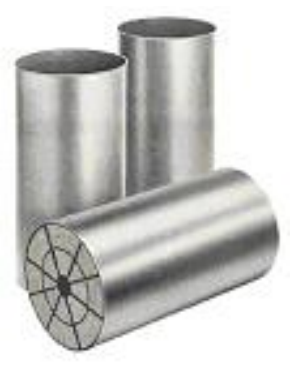

Figure 4.21: Plastic molds for split tension test [www.globalgilson.com]

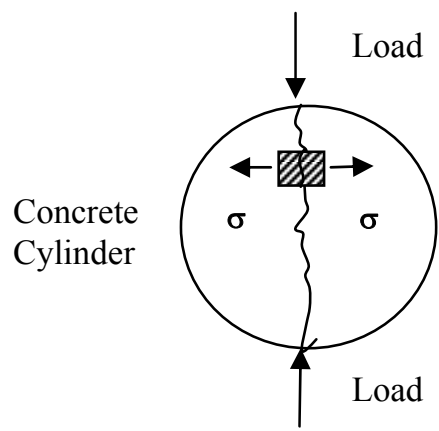

Figure 4.22: Stress in a split tension test 
Based on the load at which the cylinder split, the tensile strength $\sigma$ of the concrete is computed.

The equation is:

$\sigma=2 \mathrm{P} /(\pi \mathrm{dL})$ (Equation 4.3) [44]

where $\mathrm{P}$ is the load at which the cylinder failed

$\mathrm{d}$ is the diameter of the cylinder

and $\mathrm{L}$ is the length of the cylinder

A Forney testing machine with a capacity of 350,000 lbs was used. The rate of loading is controlled manually. The testing machine has a sensitivity of $100 \mathrm{lbs}$. Wood strips are placed between the cylinder and platen for a more uniform load distribution

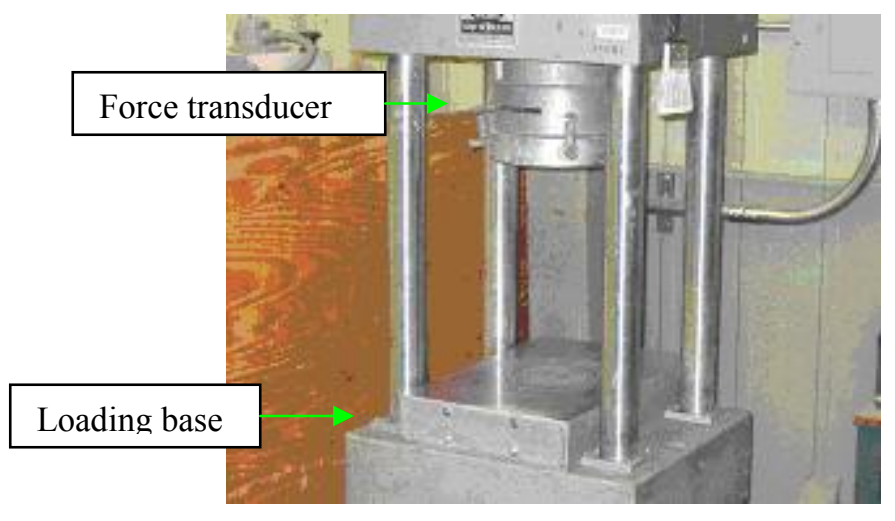

Figure 4.23: Forney compression testing machine

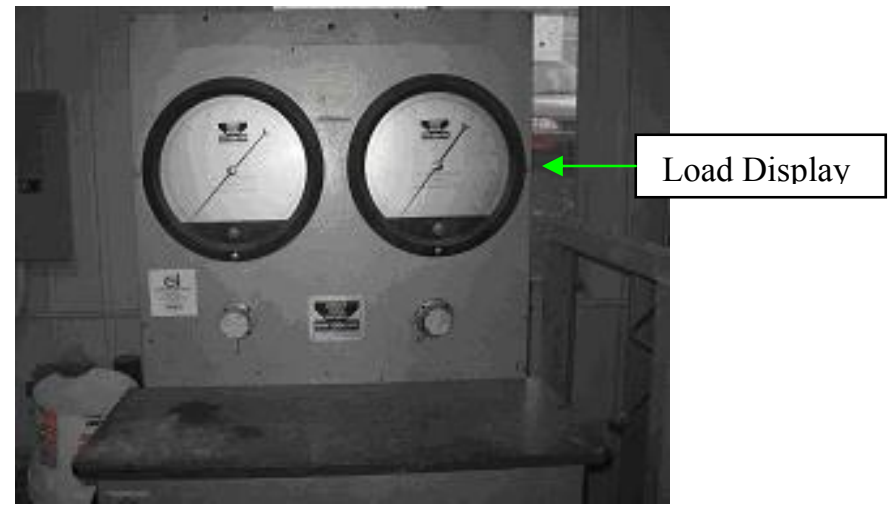

Figure 4.24: Analog readout of test

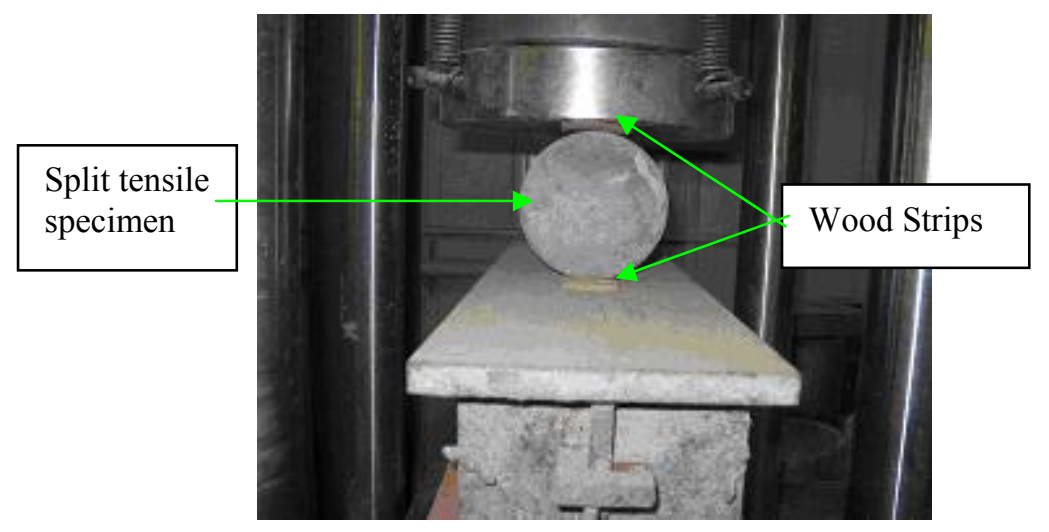


Figure 4.25: Split tensile testing 


\subsubsection{Additional tests: Flexure}

Based on the favorable results from the previous flexural tests (Section 4.2.3). LMC and CFLMC at $0.5 \%, 1.0 \%$ and $1.5 \%$ were tested. Three samples of each mix were tested. All specimens were tested after 3 days of moist curing and 25 days of air curing.

\subsubsection{Fracture Test}

Fracture mechanics is the field of solid mechanics that deals with the behavior of cracked bodies subjected to stresses and strains. When a brittle body breaks, its total surface area increases. F.C. Roesler [46] explains that there is energy associated with the new surface. This additional surface energy must be balanced by the work of external forces or by decrease of some form of energy in the system, for instance by a decrease of strain energy. Non linear fracture mechanics models have been developed to understand the nature of quasi-brittle materials such as concrete. The RILEM technical committee 50FMC of Concrete-Test Methods proposed a draft recommendation to measure the fracture energy $\mathrm{G}_{\mathrm{F}}$ using a three-point bend beam in 1985 [47]. This method was based on the fictitious crack model by Hillerborg et al. [48]. The beam size depends on the maximum of size of aggregates and RILEM suggested standard sizes of beams. The notch depth is equal to half the beam depth, and the notch width at the tip should be less than $10 \mathrm{~mm}$.
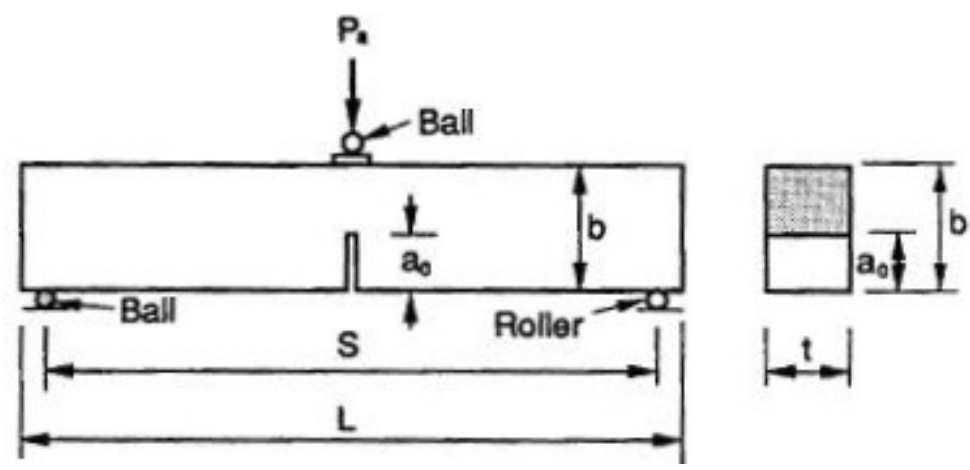

Figure 4.26: 3 point bend beam according to RILEM [47] 


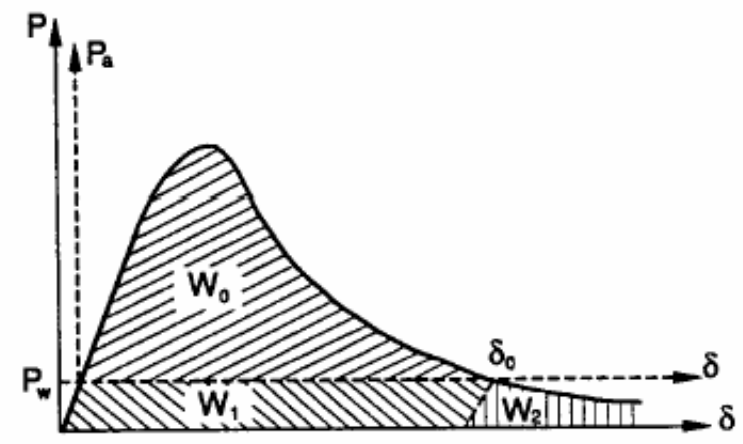

Figure 4.27: Load-displacement curve for evaluation of the fracture energy $G_{F}$ [47]

The total area under the load displacement curve ( $P-\delta$ curve) may be divided into three parts, $\mathrm{W}_{0}$ (area under applied load), $\mathrm{W}_{1}$ and $\mathrm{W}_{2}$ (areas due to beam self weight) and $\mathrm{W}_{1}=\mathrm{PW} \delta_{0}$. It has been demonstrated by Petersson [49] and Swartz and Yap [50] that the value of $\mathrm{W}_{2}$ is approximately equal to $\mathrm{W}_{1}$.

The total fracture energy $\mathrm{W}_{\mathrm{t}}$ is

$W_{t}=W_{0}+2 P_{w} \delta_{0}$ (Equation 4.4)

The fracture energy per unit projected area is calculated by $G_{F}=\frac{W_{t}}{\left(b-a_{0}\right) t}=\frac{W_{0}+2 P_{w} \delta_{0}}{\left(b-a_{0}\right) t}$

Due to material quantity constraints and requirements of being a 'comparative' study, smaller beam samples than those recommended by RILEM committee were used. It was ensured that all beam samples were subjected to the exact sample preparation conditions, curing and testing. Beam weights were not taken into consideration in calculation. Hence the simplified calculation of fracture toughness $\left(\mathrm{G}_{\mathrm{F}}\right)$ or the critical strain energy release rate is calculated as

$G_{F}=\frac{W_{0}}{\left(b-a_{0}\right) t}$

$\mathrm{W}_{0}=\mathrm{W}_{\mathrm{t}}=$ Total fracture energy 
Beam samples 3"x3"x12" (span length 9") were used for the test. The notch length was 1.5". The notch was sawn under wet conditions 1 day before the test. The test is performed with a constant rate deformation, which allows the maximum load to be reached in about 20 minutes after the start of the test. The critical or maximum load $\left(\mathrm{P}_{\mathrm{cr}}\right)$, total fracture energy $\left(\mathrm{W}_{0}\right)$ and the critical SERR or toughness $\left(\mathrm{G}_{\mathrm{F}}\right)$ were obtained from the graphs.

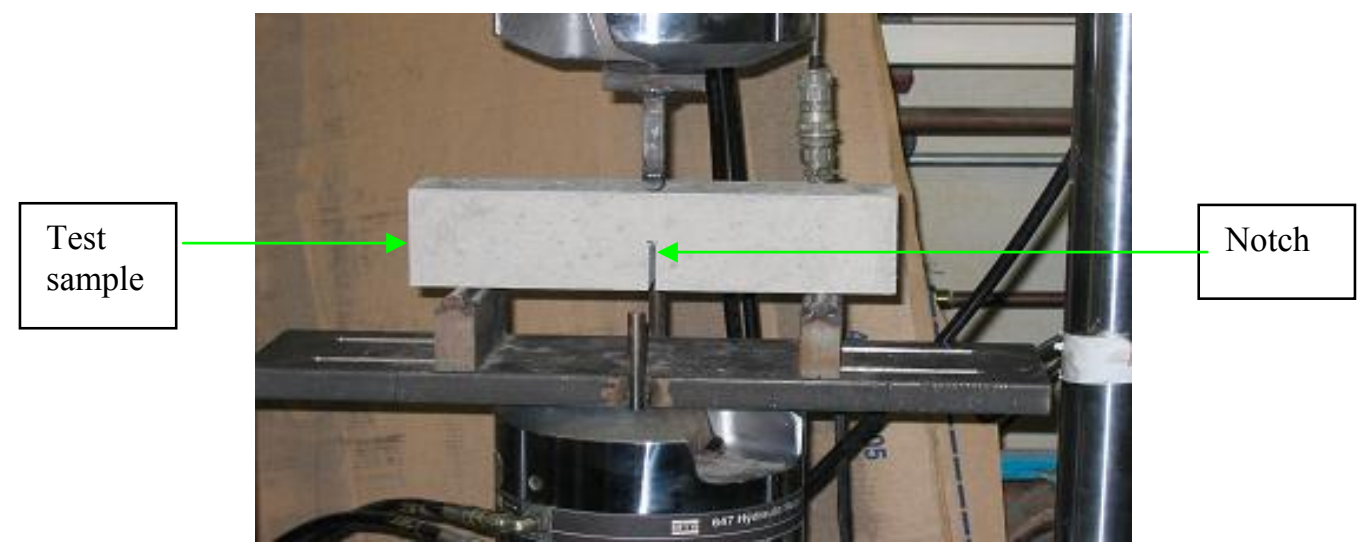

Figure 4.28: Three point loading for determination of fracture energy

\subsubsection{Split Composite Cylinder Test}

The tensile strength of the bond between the concrete substrate and overlay material could be determined using a specially cast composite cylinder. For this unique test, portland cement concrete cylinders 3"x 6" cylinders after over 60 days of curing, were sawn into half, polished with a grinding wheel and placed back into its original plastic mold. Overlay material was poured over the remaining half to form a complete $3 " \mathrm{x} 6$ " cylinder. This composite specimen was tested under conditions similar to the split tensile test.

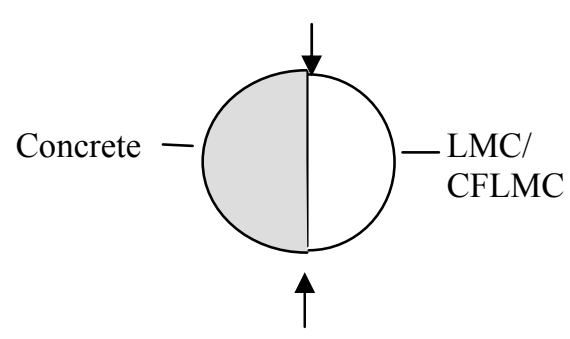

FRONT VIEW

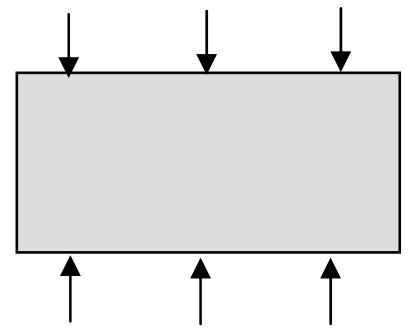

SIDE VIEW

Figure 4.29: Splitting tensile test of composite cylindrical specimen 


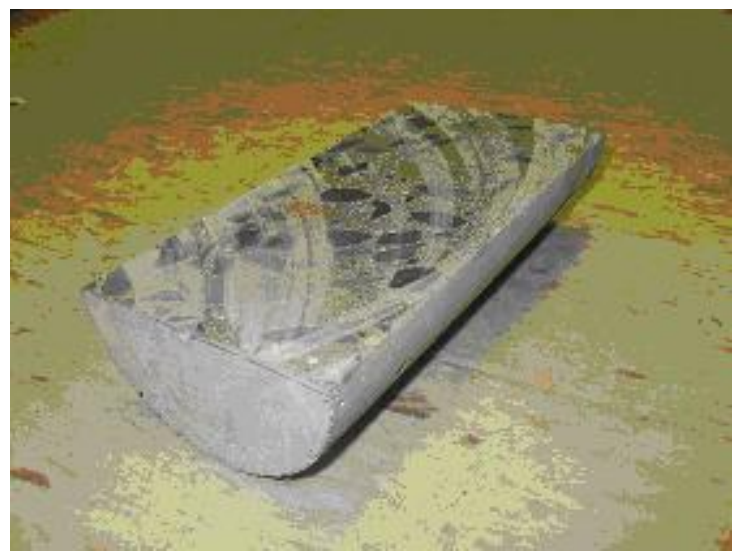

Figure 4.30: One $1 / 2$ sawed concrete cylinder

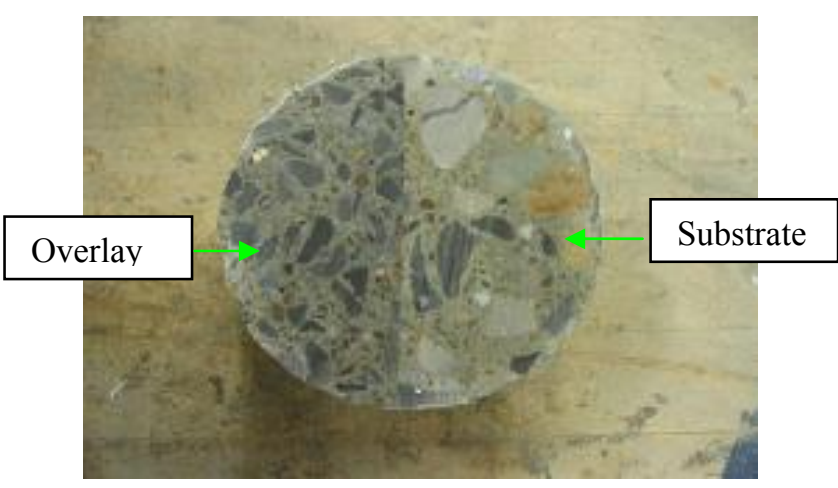

Figure 4.32: Composite cylinder

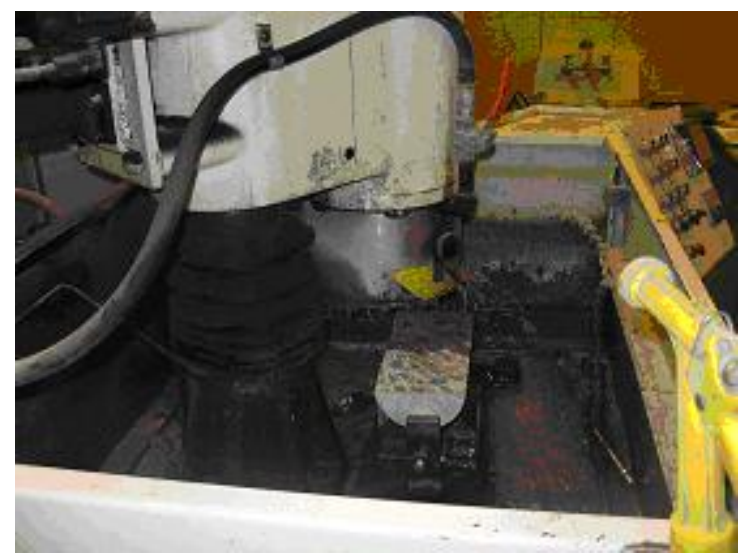

Figure 4.31: Grinding of face for smooth finish $x$

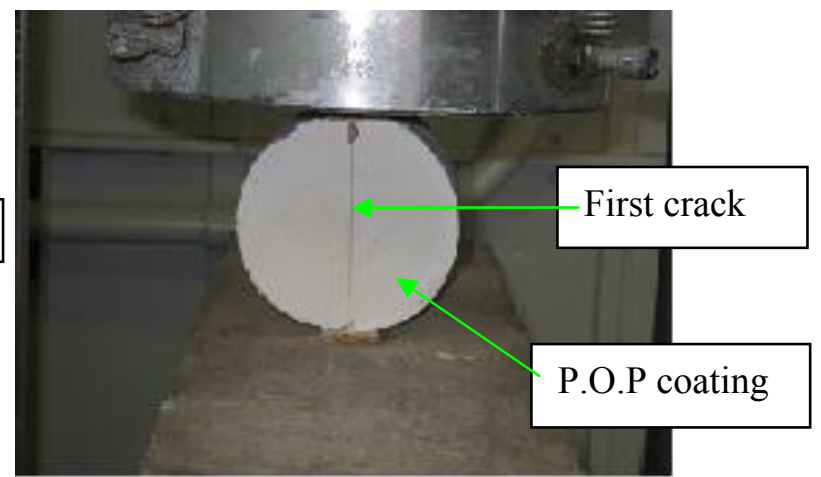

Figure 4.33: First crack formation at interface

The ends of the composite cylinder were coated with 'Plaster of Paris' (POP) to detect the load at first crack. This value of load should not be confused with the ultimate load at which the cylinder cracks. The load at first crack gives a more accurate value for the bond strength. 


\section{CHAPTER FIVE}

\section{RESULTS AND ANALYSIS}

\subsection{Introduction}

A detailed look into the results and discussion of each experiment is included in this chapter.

\subsection{Mixing Procedure}

The dry mix procedure (Section 3.7) was adopted to prepare carbon fiber reinforced latex modified concrete. The mixing procedure was controlled to ensure that there was uniform distribution of fibers within the cement matrix. A few fibers were selected randomly from the mix and measured to determine whether the fibers were abraded during mixing. All fibers maintained the original length of $0.5 \mathrm{in}$. and hence there was no change in the aspect ratio (length/diameter) of the fibers. This proved that mixing in the ordinary concrete mixer did not prove to be detrimental to the fibers. Scanning electron microscope (SEM) photographs from fractured specimens after testing showed that carbon fibers were dispersed quite evenly within the cement matrix.

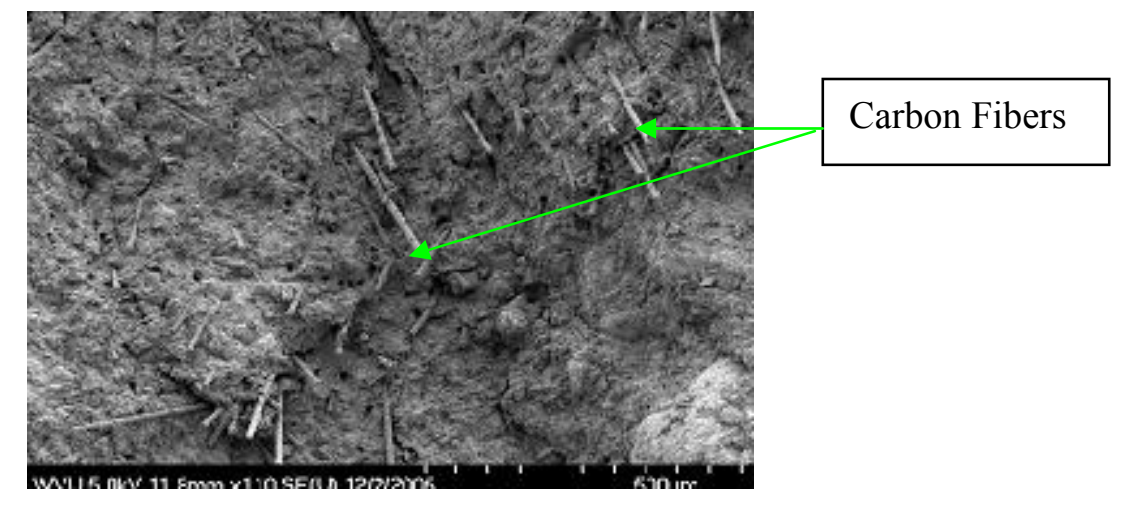

Figure 5.1: SEM photograph showing uniform fiber dispersion in concrete 


\subsection{Slump}

Slump is a measure of field workability of concrete. Carbon fibers reduces the fresh mix workability of concrete while latex polymer dispersions improves the fresh mix workability. The improvements in workability due to latex modification are attributed to surface-active agents in polymer dispersions [2]. The mix design of LMC is usually formulated to accommodate the loss of slump (2-3 inches approx) due to addition of fibers. Overlay applications on bridge decks require high slump concrete. In this study, the slump of LMC (8") and the slump of CFLMC (5") fall within the specifications required by ACI 548.4 [20], which is $3 "$ to $8 "$. No admixtures were used in this experiment to improve workability.

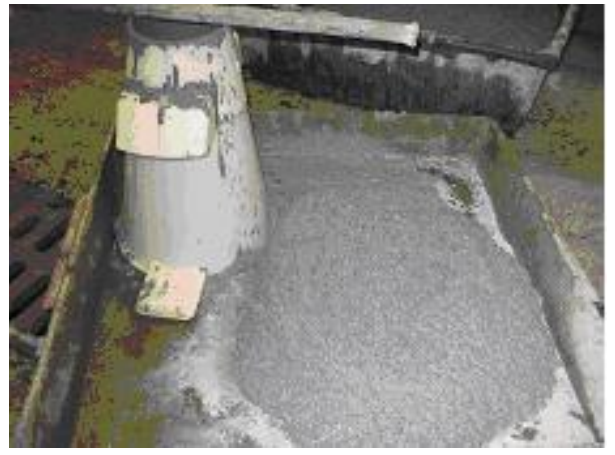

Figure 5.2: Slump of $\operatorname{LMC}\left(8^{\prime \prime}\right)$

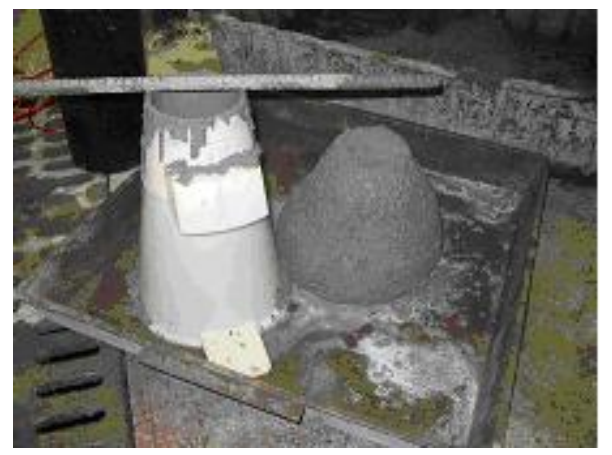

Figure 5.3: Slump of CFLMC (5") 


\subsection{Interfacial Shear Strength}

In this experiment, SEM photographs were based on examination of one sample. Fractured surface from a tensile specimen was studied. Fragments of latex-modified cement are observed to cover nearly half of the fiber surface. The carbon fibers also did not show any fracture (indicated by cement adhesion on the end surface of the fiber) (Figure 5.5). It indicates that the fibers have high strength to resist breakage. Failure was due to a combination of shear in the cement matrix in the vicinity of the fibers, and interfacial shear between the fiber and matrix. Latex helped to improve adhesion between the carbon fiber and the matrix. This adhesion helped to transfer loads from microcracks to the carbon fibers, thus improving ductility of the material.

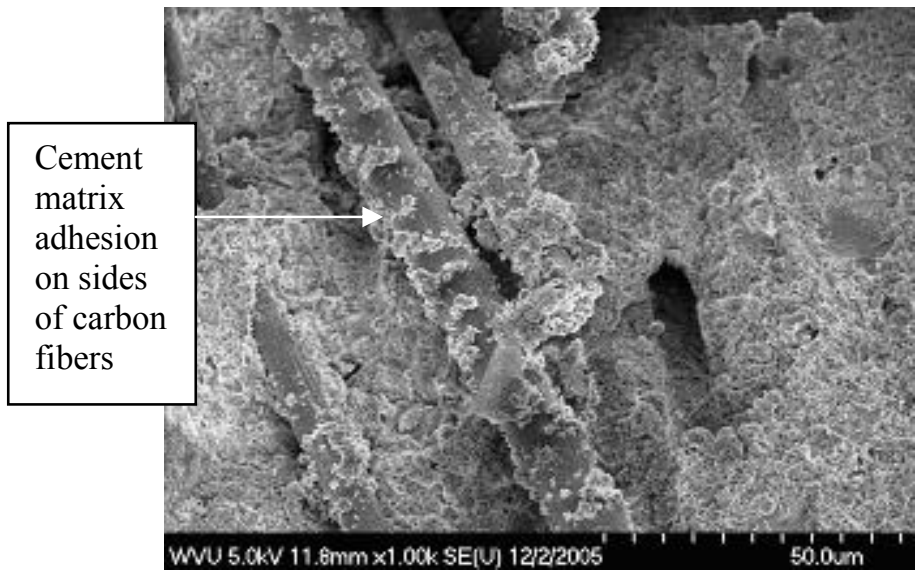

Figure 5.4 (a): Adhesion of matrix with fibers

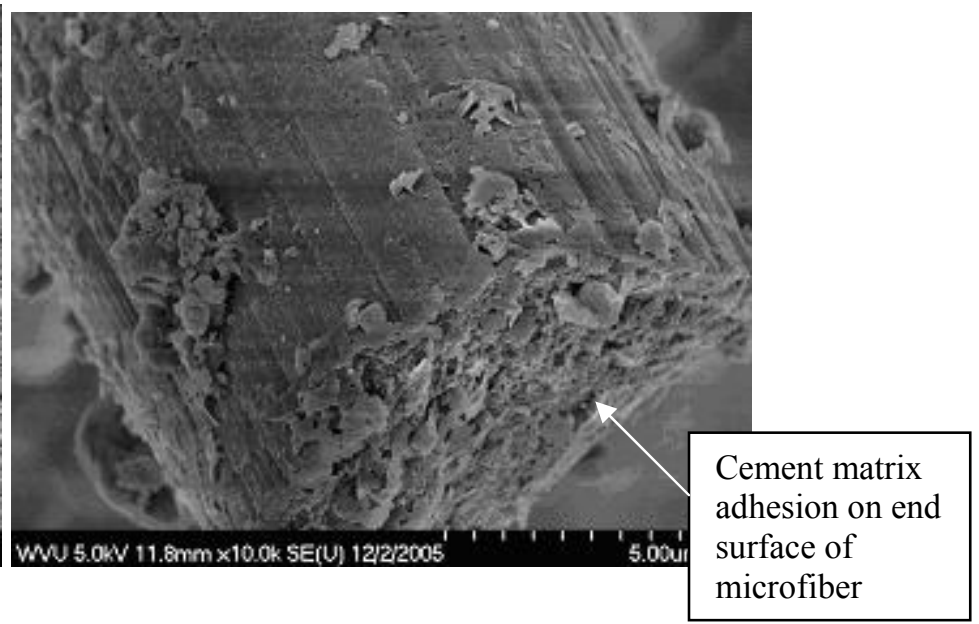

Figure 5.4 (b): Magnification of carbon fiber

Figure 5.4: SEM photographs of carbon fibers in cement matrix

Since there is no fiber fracture and judging from the shear failure in the matrix, it is possible to assume the parallel iso strain model [A.1] for the CFLMC composite. 


\subsection{Direct Tension Testing}

The individual results of the direct tension tests are shown in figure 5.5, where the lighter colored stress strain curves represent experimental results of individual tests, and the bolder curves represent the polynomial curve fit. The polynomial curve fit and the spread of data (shown using error bars) are plotted in figure 5.6. Conclusions are based on test results from 3 samples of each material type. CFLMC showed an average $26 \%$ increase in strain to failure over LMC, but does not show significant improvement in strength. Ductility denotes the property of CFLMC to accommodate greater strains without cracking. Tensile toughness, or the amount of energy required to cause fracture, is given by the area under the stress strain function. CFLMC showed an average increase of $45 \%$ in toughness.

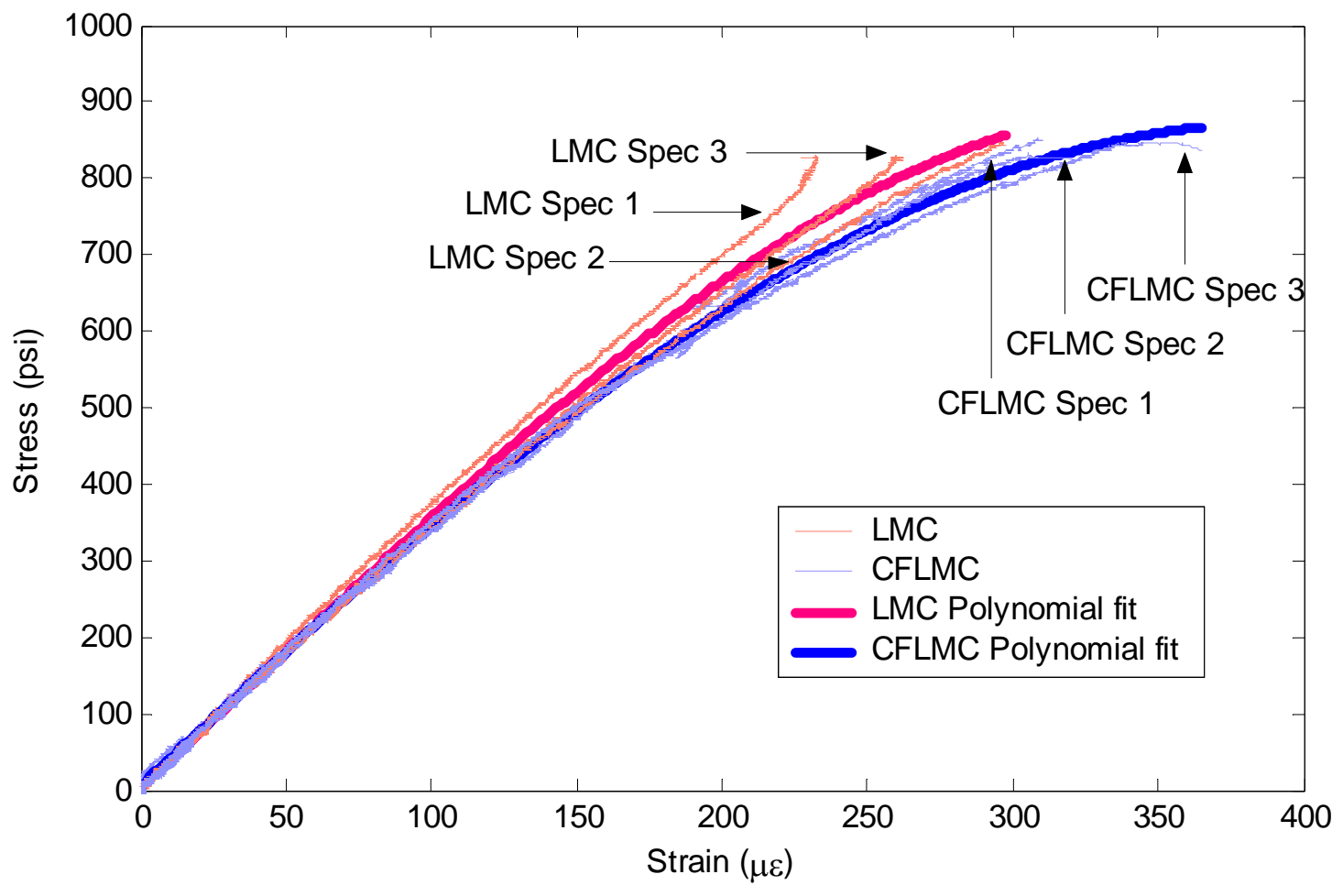

Figure 5.5: Tensile stress strain graph (experimental test results) 


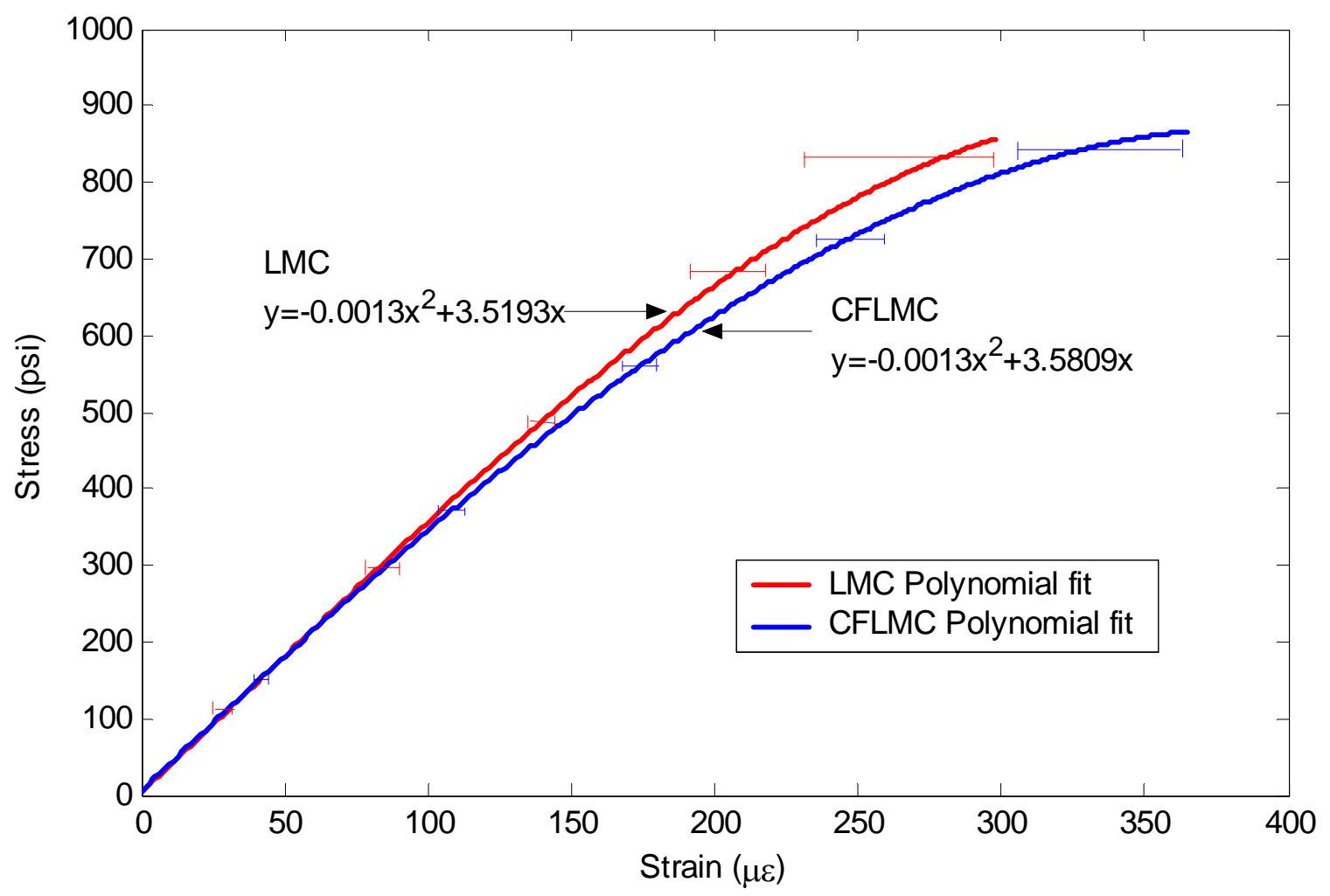

Figure 5.6: Tensile stress strain graph (Polynomial fit results)

Table 5.1: Results of direct tension tests

\begin{tabular}{|c|c|c|c|c|c|c|c|}
\hline Sample & $\begin{array}{c}\text { Load at } \\
\text { Failure } \\
\text { (lbs) }\end{array}$ & $\begin{array}{l}\text { Ultimate } \\
\text { Stress } \\
\text { (psi) }\end{array}$ & $\begin{array}{c}\text { Ultimate } \\
\text { Strain } \\
(\mu \varepsilon)\end{array}$ & $\begin{array}{l}\text { Toughness } \\
\text { (psi) }\end{array}$ & $\begin{array}{c}\text { Average } \\
\text { ultimate } \\
\text { stress } \\
\text { (psi) }\end{array}$ & $\begin{array}{c}\text { Average } \\
\text { ultimate } \\
\text { strain }(\mu \varepsilon)\end{array}$ & $\begin{array}{l}\text { Average } \\
\text { Toughness } \\
\text { (psi) }\end{array}$ \\
\hline $\begin{array}{l}\text { LMC } \\
\text { Spec 1 } \\
\text { Spec } 2 \\
\text { Spec } 3\end{array}$ & $\begin{array}{l}829 \\
847 \\
828\end{array}$ & $\begin{array}{l}829 \\
847 \\
828\end{array}$ & $\begin{array}{l}233 \\
298 \\
262\end{array}$ & $\begin{array}{l}0.093156 \\
0.140090 \\
0.111757\end{array}$ & 834.6 & 264.3 & 0.115001 \\
\hline $\begin{array}{l}\text { CFLMC } \\
\text { Spec } 1 \\
\text { Spec } 2 \\
\text { Spec } 3 \\
\end{array}$ & $\begin{array}{l}852 \\
825 \\
845\end{array}$ & $\begin{array}{l}852 \\
825 \\
845\end{array}$ & $\begin{array}{l}310 \\
322 \\
365\end{array}$ & $\begin{array}{l}0.150443 \\
0.192590 \\
0.156949\end{array}$ & 841 & 332.3 & 0.166661 \\
\hline
\end{tabular}

Figure 5.7 derived from the linear portion of figure 5.6 show the initial modulus of elasticity of LMC \& CFLMC to be similar. The modulus of elasticity of a concrete is largely controlled by the volume and the modulus of aggregates. [12]. Small additions of fibers would not be expected to greatly alter the modulus of elasticity of the composite. 


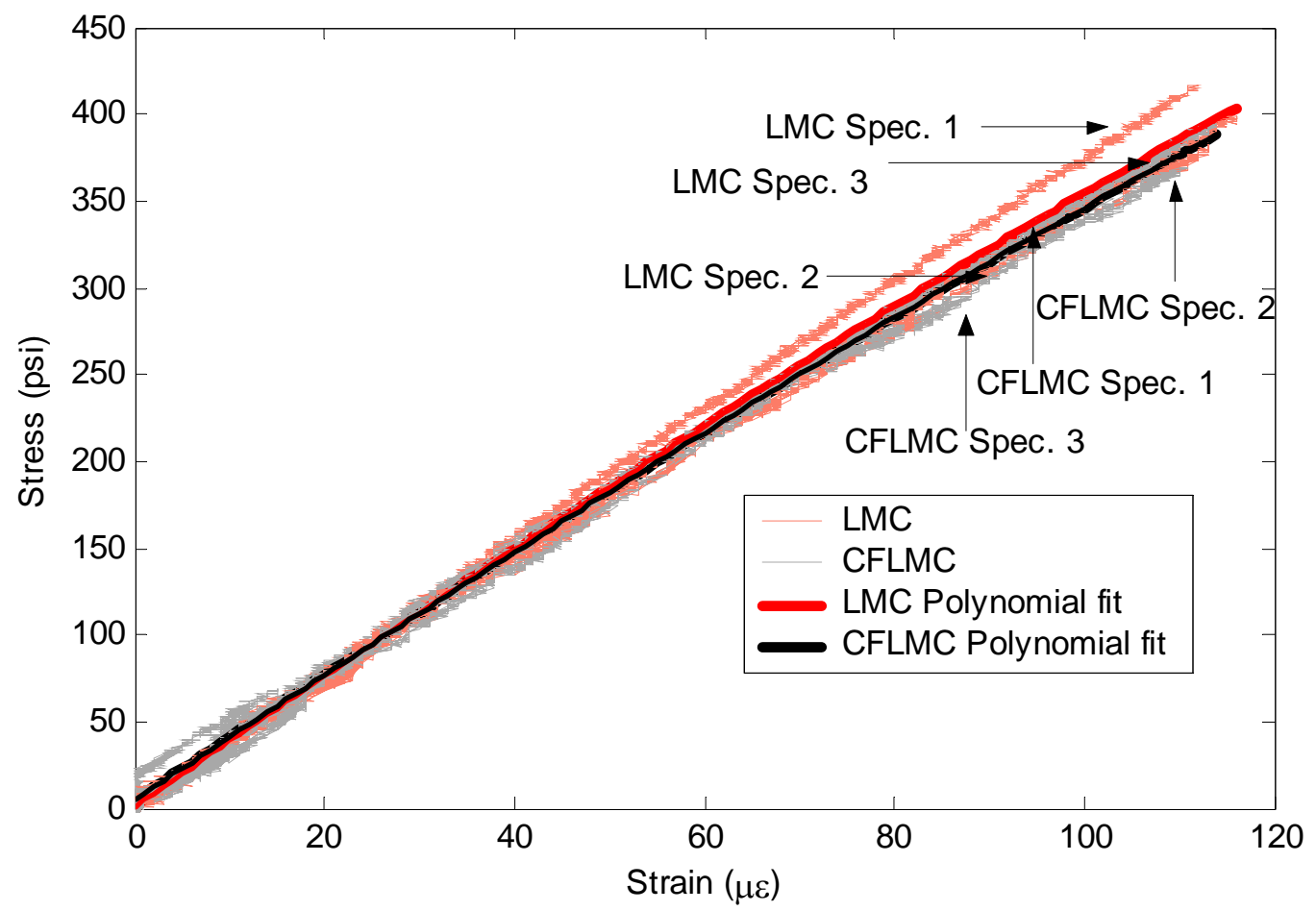

Figure 5.7: Plot of tensile modulus of elasticity (experimental test results)

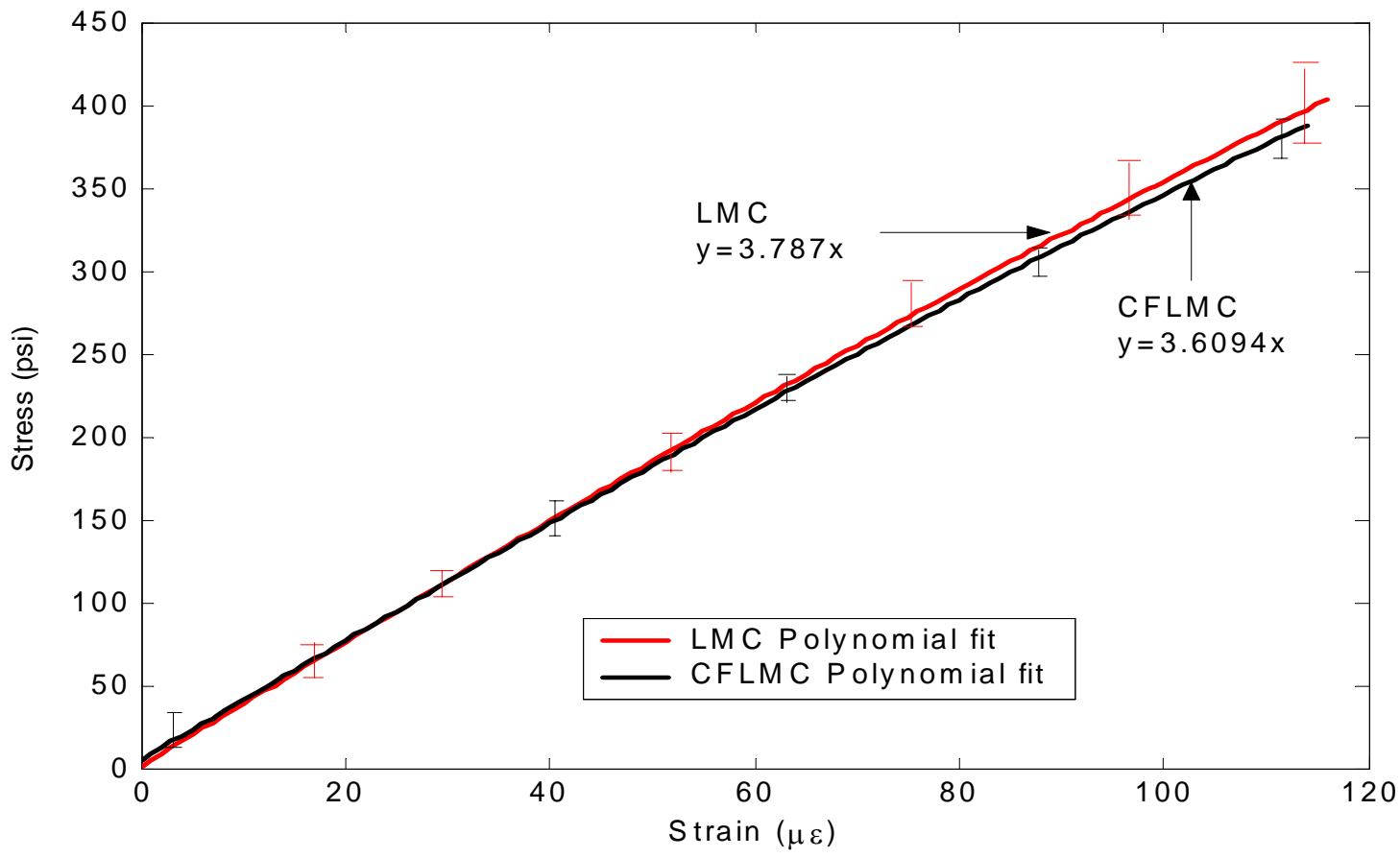

Figure 5.8: Plot of tensile modulus of elasticity (polynomial fit results) 
Dispersion in the results could be due to variablility in concrete specimens and eccentricities during loading. The additional loading capacity depends on the fiber diameter and volume fraction. Carbon fibers, being microfibers added at a very low volume fraction of $0.15 \%$ is not expected to increase the direct tensile strength of the material. The CFLMC matrix will fail at its normal failure stress of the LMC matrix. However, fiber reinforcement increases the strain to failure of the material. Improvements in ductility are more pronounced towards the failure region of the matrix, when the effect of the micro-fibers comes into action.

\subsubsection{Theoretical Prediction of Tensile Elastic Modulus}

From the parallel-isostrain model for fiber reinforced materials

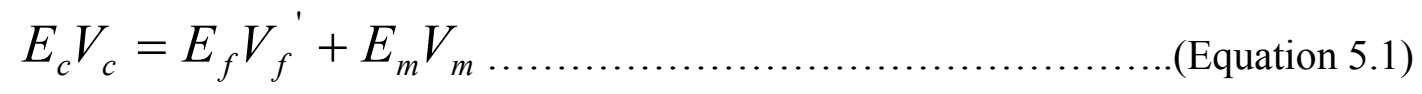

where

$V_{f}{ }^{\prime}=V_{f} \times \eta$

$E=$ Elastic Modulus

$V=$ Volume fraction

$\eta=$ Efficiency factor for 3D random fibers [12]

Suffixes

$f=$ fiber; $m=$ matrix; $c=$ composite

Substituting values

$V_{f}=0.0015, E_{f}=33 \times 10^{6} \mathrm{psi}, E_{m}=3.78 \times 10^{6} \mathrm{psi}, V_{m}=\left(1-V_{f}\right), V_{c}=V_{f}+V_{m}, \eta=1 / 5$

$E_{c}=3.79 \times 10^{6} \mathrm{psi}$

Theoretical equations prove that the low volume fraction of the carbon fibers do not cause a significant change in tensile modulus of elasticity.

\subsubsection{Theoretical Prediction of Tensile Strength}

From equations derived by Hannat D.J. for fiber reinforced concrete, [12] 
$\sigma_{m}=\frac{\sigma_{c}}{1+V_{f}^{\prime}(M-1)}$

Where

$V_{f}^{\prime}=V_{f} \times \eta$

$\sigma=$ Failure Stress

$M=$ Ratio of Modulus of elasticity $=E_{f} / E_{m}$

$V=$ Volume

$\eta=$ Efficiency factor for randomness of 3D fibers

\section{Suffixes}

$f=$ fiber; $m=$ matrix; $c=$ composite

Substituting

$V_{f}=0.0015, E_{f}=33 \times 10^{6} \mathrm{psi}, E_{m}=3.78 \times 10^{6} \mathrm{psi}, \eta=1 / 5$

$\sigma_{m}=\frac{\sigma_{c}}{1+\left(\frac{0.0015}{5}\right) \times\left(\frac{33 \times 10^{6}}{3.78 \times 10^{6}}-1\right)}=\frac{\sigma_{c}}{1.0023}$

The tensile strength of the LMC overlay is not influenced significantly by addition of carbon fibers at $0.15 \%$ volume fraction. 


\subsection{Four Point Loading}

Three samples of a particular mix were tested under four point loading (ASTM C 78 [44] and ASTM C 1018 [44]). Experimental curves of load versus displacement for individual tests are shown in Figure 5.10. The load displacement curve shows an increase in the ultimate flexural strength for CFLMC specimens. Flexural toughness is determined in terms of area under the load deflection curve for fiber reinforced concrete. From figure 5.9, CFLMC shows an average $25.4 \%$ increase in toughness over LMC. Due to the small percentage of fibers and the aspect ratio (length/diameter) of carbon fibers, CFLMC does not sustain loads in the post-crack region of the load deflection graphs.

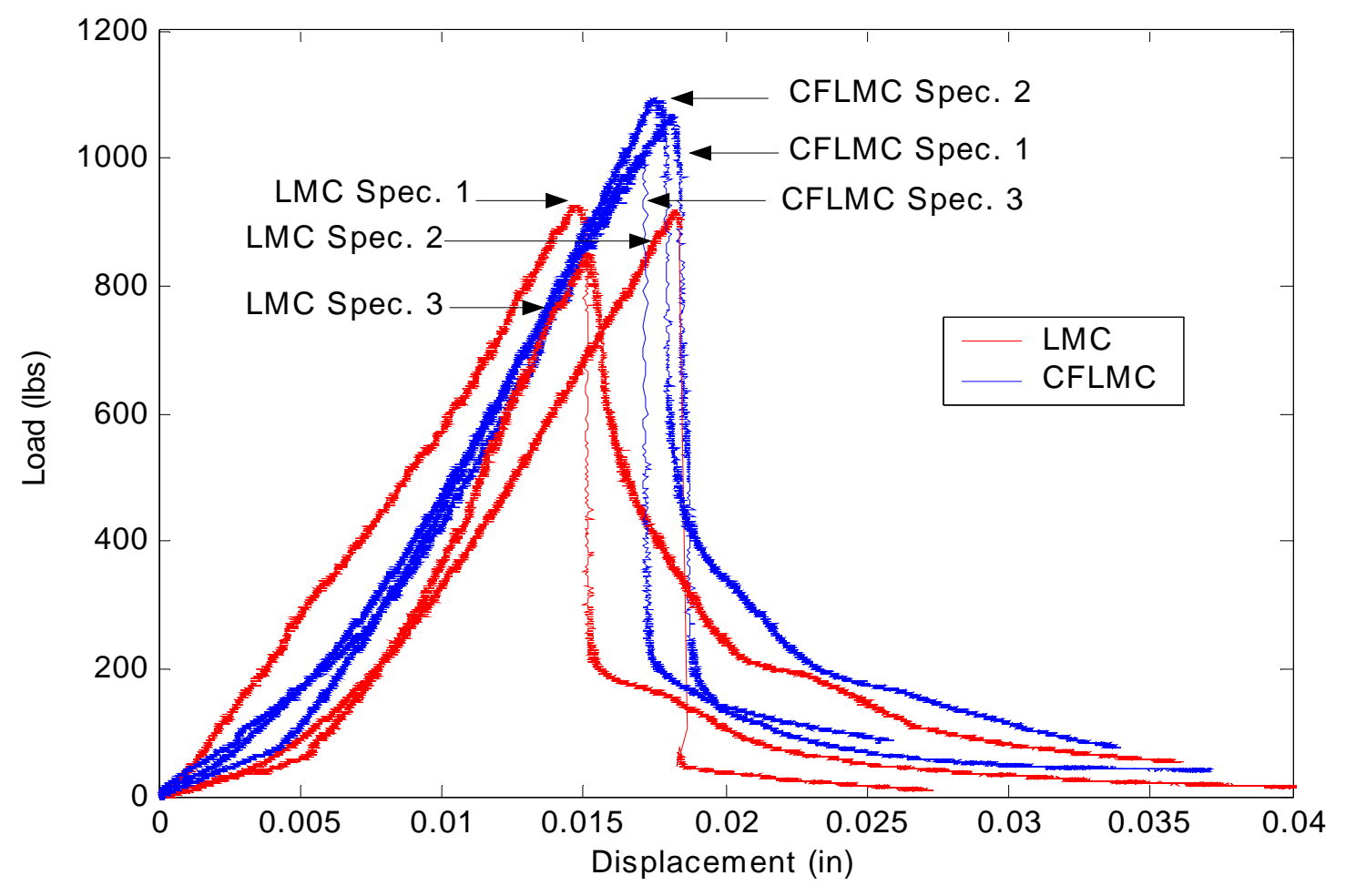

Figure 5.9: Load Vs Displacement graph for four point loading 


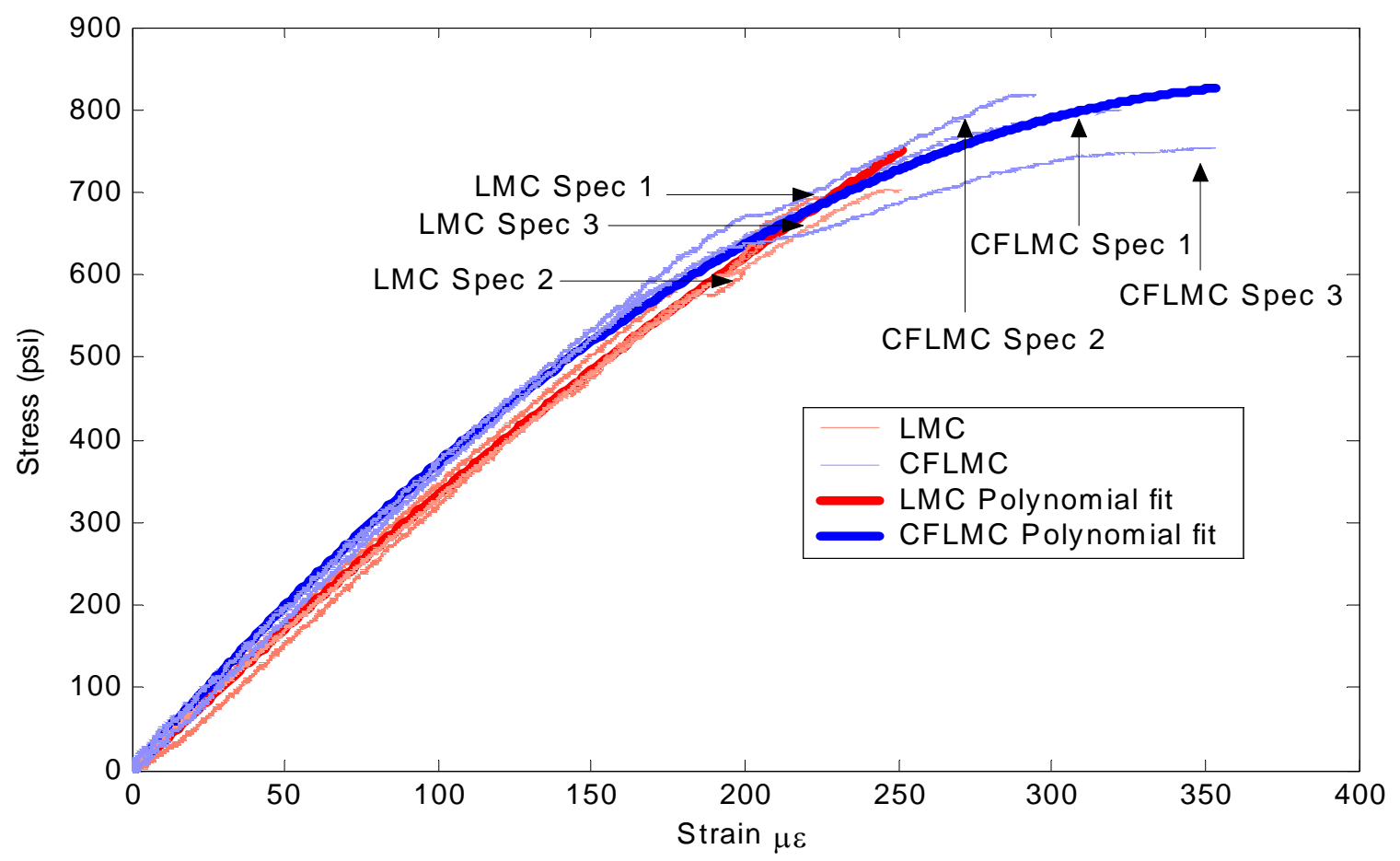

Figure 5.10: Stress Strain curve for four point loading (experimental test results)

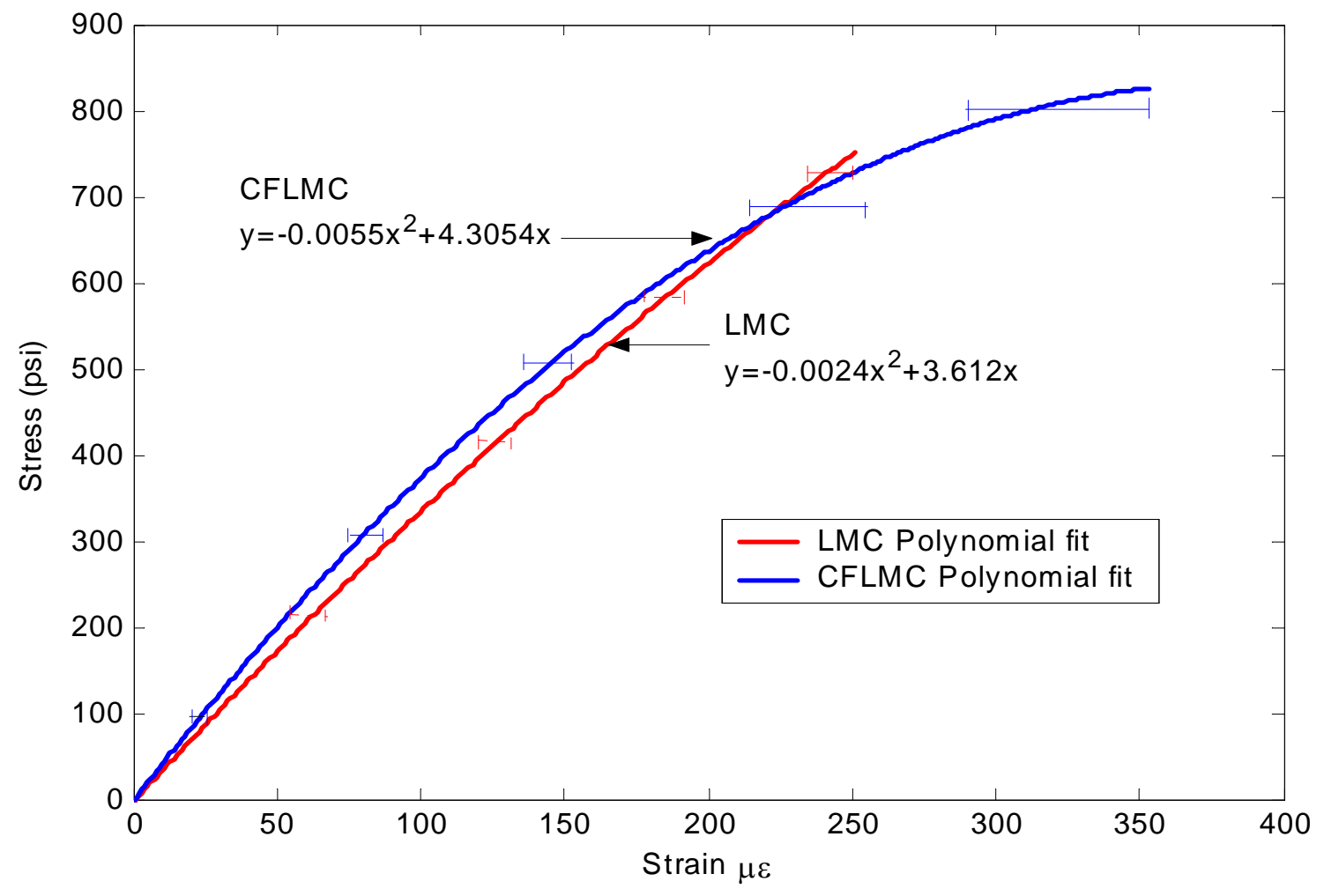

Figure 5.11: Stress Strain curve for four point loading (polynomial fit results) 
Figure 5.10 is a plot of the individual experimental stress strain curves for LMC \& CFLMC in a 4 point loading test. Figure 5.11 is a plot showing the polynomial fit and the dispersion of data for the two types of materials. The low percentage of fibers is effective enough to increase the average flexural strength and failure strain by $17 \%$ and $43 \%$ respectively. These improvements show that carbon fibers are very effective at preventing cracking at larger deformations of the material.

Table 5.2: Test results for four point loading

\begin{tabular}{|c|c|c|c|c|c|c|c|}
\hline Sample & $\begin{array}{c}\text { Load at } \\
\text { Failure } \\
\text { (lbs) }\end{array}$ & $\begin{array}{c}\text { Modulus of } \\
\text { rupture } \\
\text { (psi) }\end{array}$ & $\begin{array}{c}\text { Ultimate } \\
\text { Strain } \\
(\mu \varepsilon)\end{array}$ & $\begin{array}{c}\text { Toughness } \\
\text { (lbs.in) }\end{array}$ & $\begin{array}{c}\text { Average } \\
\text { Modulus } \\
\text { of } \\
\text { rupture } \\
\text { (psi) }\end{array}$ & $\begin{array}{c}\text { Average } \\
\text { ultimate } \\
\text { strain } \\
(\mu \varepsilon)\end{array}$ & $\begin{array}{c}\text { Average } \\
\text { Toughness } \\
\text { (lbs. in) }\end{array}$ \\
\hline LMC & & & & & & & \\
Spec. 1 & 925 & 694 & 225 & 8.34 & & \\
Spec. 2 & 850 & 638 & 206 & 8.34 & 678 & 227 & 7.78 \\
Spec. 3 & 936 & 702 & 251 & 6.66 & & & \\
\hline CFLMC & & & & & & & \\
Spec. 1 & 1066 & 800 & 323 & 9.86 & & \\
Spec. 2 & 1092 & 819 & 295 & 10.98 & 791 & 324 \\
Spec. 3 & 1004 & 753 & 353 & 8.46 & & \\
\hline
\end{tabular}

The upper limit for validity of the conventional beam theory is reached at the onset of cracking. Previous research [52] on flexural testing of fiber reinforced concrete have shown that there is slight upward shift of the neutral axis during loading. Greater strains are recorded in the tension zone of the beam in flexure, compared to the compression zone. This enlarges the tension zone of the specimen whereby the specimen is able to sustain greater tensile strains. Hence CFLMC shows greater ductility properties than LMC. At the same time, the compression zone of the specimen is also utilized during loading. This explains how a flexural specimen has greater ultimate strengths than a specimen of the same material in direct tension. 


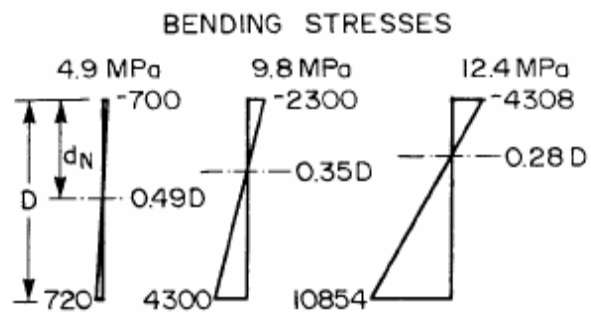

Figure 5.12: Change in strain distribution and shift of neutral axis for carbon fiberreinforced cement in flexure [51]

\subsection{Three Point Loading}

Results of testing flexure samples under three point loading helped to reinforce conclusions obtained for the four point loading. Three samples of each mixture i.e. LMC and CFLMC were testing in three point loading under same conditions of loading rate as the four point loading test. Stress strain curves for three point loading showed similar trends to the four point loading.

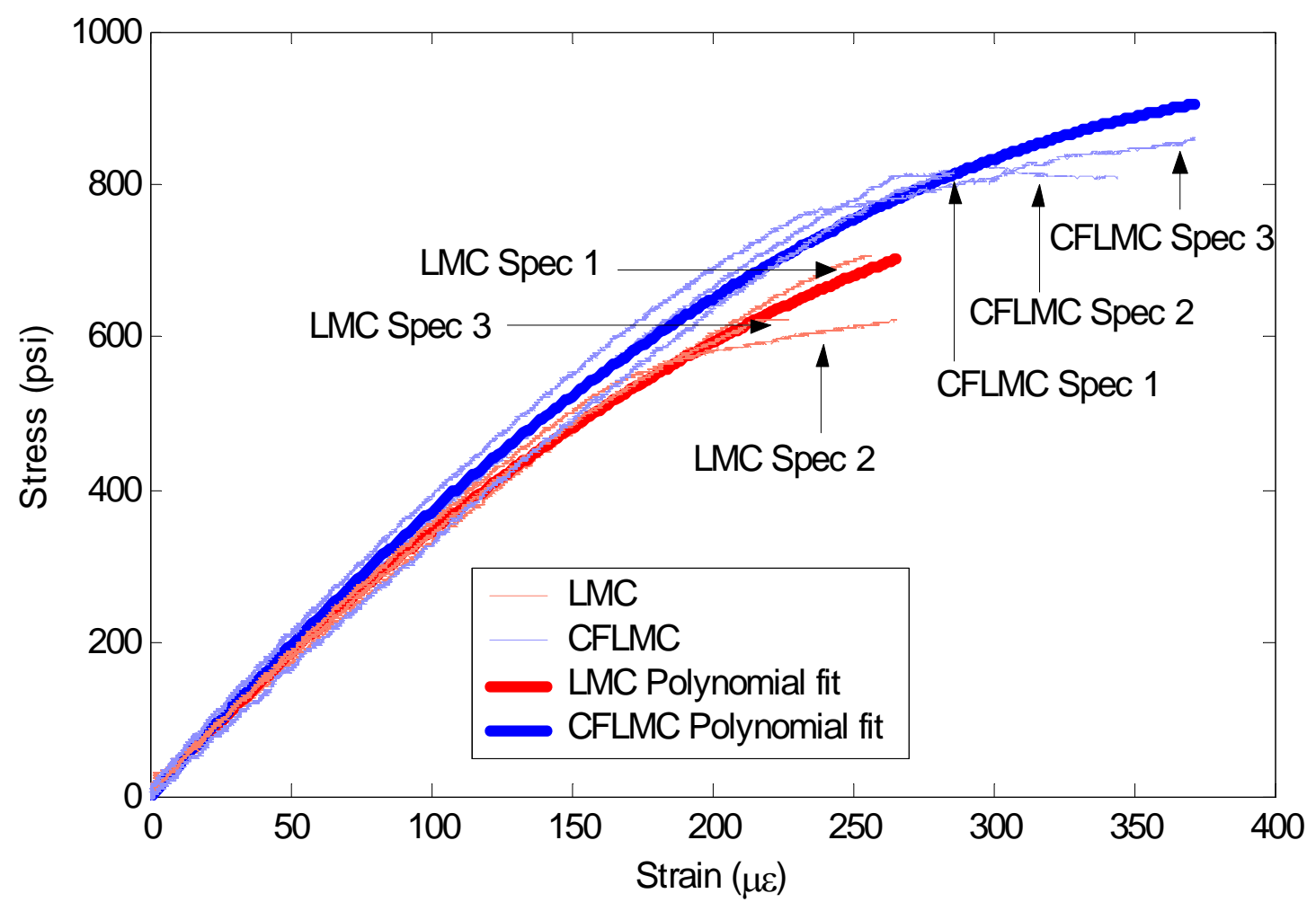

Figure 5.13: Stress Strain curve for three point loading (experimental test results) 


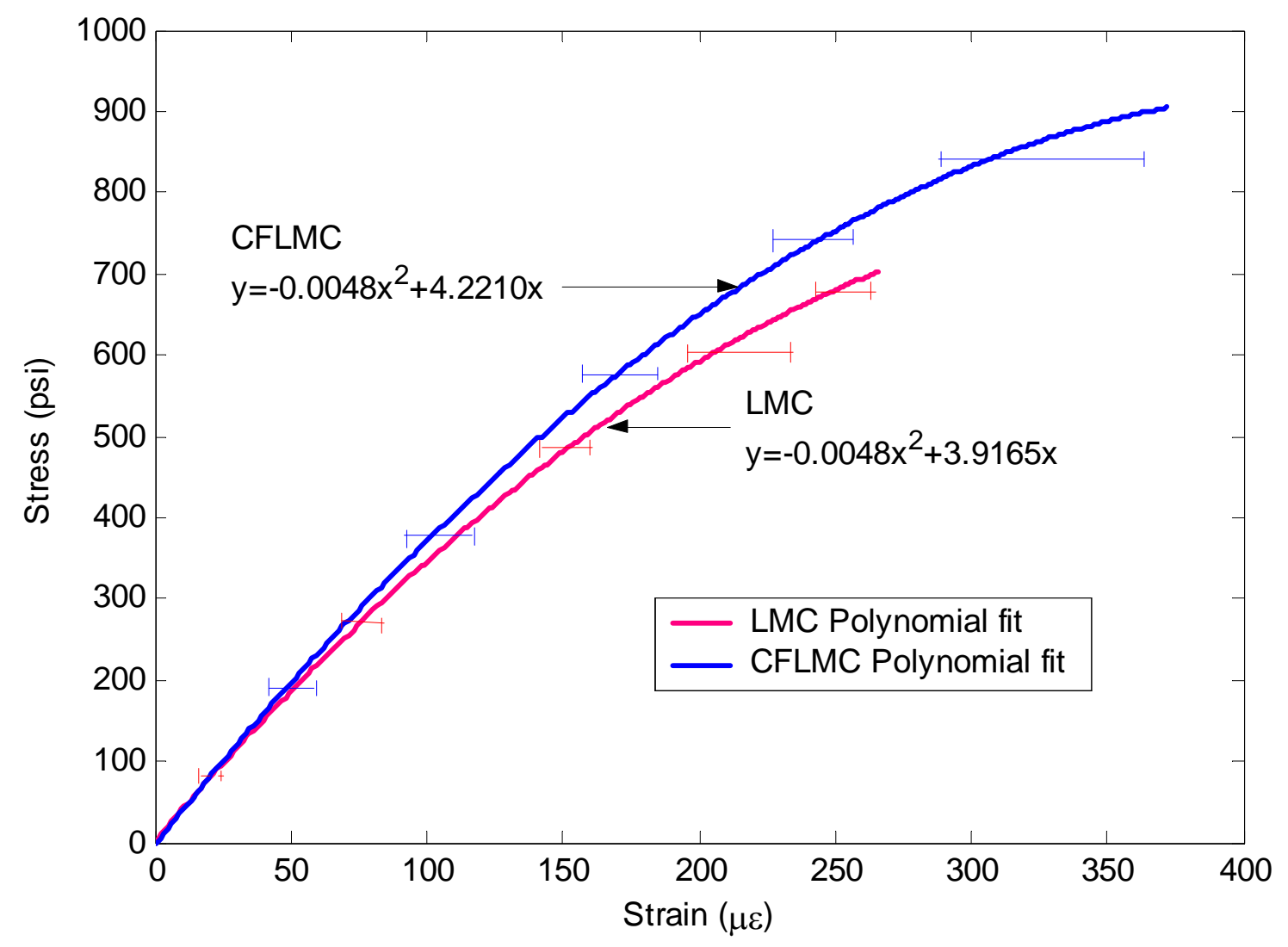

Figure 5.14: Stress Strain curve for three point loading (polynomial fit results)

Results showed an average $27.5 \%$ increase in modulus of rupture (ultimate flexural strength) and $33.6 \%$ increase in strain to failure.

Table 5.3: Test results for three point load test.

\begin{tabular}{|c|c|c|c|c|c|}
\hline $\begin{array}{c}\text { Sample } \\
\text { No. }\end{array}$ & $\begin{array}{c}\text { Load at } \\
\text { Failure } \\
(\mathbf{l b s})\end{array}$ & $\begin{array}{c}\text { Modulus } \\
\text { of } \\
\text { rupture } \\
(\mathbf{p s i})\end{array}$ & $\begin{array}{c}\text { Ultimate } \\
\text { Strain } \\
(\boldsymbol{\mu} \boldsymbol{\varepsilon})\end{array}$ & $\begin{array}{c}\text { Average } \\
\text { modulus of } \\
\text { rupture } \\
(\mathbf{p s i})\end{array}$ & $\begin{array}{c}\text { Average } \\
\text { ultimate } \\
\text { strain } \\
(\boldsymbol{\mu} \boldsymbol{)})\end{array}$ \\
\hline LMC & & & & & \\
Spec. 1 & 627 & 704 & 257 & & \\
Spec. 2 & 552 & 621 & 266 & 650 & 250 \\
Spec. 3 & 555 & 624 & 227 & & \\
\hline CFLMC & & & & & \\
Spec. 1 & 733 & 818 & 286 & & \\
Spec. 2 & 726 & 810 & 344 & 829 & \\
Spec. 3 & 765 & 860 & 371 & & \\
\hline
\end{tabular}




\subsection{Split Tensile Tests}

Results from the split tensile tests show that there was no significant change (about $7 \%$ increase only) of tensile strengths between LMC \& CFLMC. This trend was similar to the results obtained from direct tension testing.

Table 5.4: Test results for split tensile test

\begin{tabular}{|c|c|c|c|}
\hline Sample No. & $\begin{array}{c}\text { Load at } \\
\text { Failure } \\
\text { (lbs) }\end{array}$ & $\begin{array}{c}\text { Ultimate } \\
\text { Tensile } \\
\text { Strength (psi) }\end{array}$ & $\begin{array}{l}\text { Average } \\
\text { Tensile } \\
\text { Strength (psi) }\end{array}$ \\
\hline LMC & 25800 & 513 & 518 \\
& 28000 & 557 & \\
& 24300 & 484 & 555 \\
\hline CFLMC & 28500 & 567 & \\
& 30000 & 597 & \\
& 25200 & 502 & \\
\hline
\end{tabular}




\subsection{Further Experiments}

Based on the improved performance of CFLMC in flexure, it was decided to further investigate the properties of CFLMC at different volume fractions of carbon fibers. Increased carbon fiber percentage would cause reduction in workability and would cause difficulty in placement of the overlay on bridge decks. Workability issues due to increase fiber content can be overcome with use of suitable admixtures. These samples were tested after 28 days of curing. The different tests performed are

1. Four point loading (flexure)

2. Fracture Tests

3. Bond strength tests.

\subsubsection{Four Point Loading Tests (Flexure)}

Figure 5.15 represents the experimental stress strain curve for individual tests while figure 5.16 is a plot of the polynomial fit, along with the dispersion of data. The stress strain plots show a $20 \%$ average increase in modulus of rupture (MOR), and an 18\% average increase in strain to failure by addition of carbon fibers by $0.5 \%$ (by weight of cement) to LMC. Further increase of CF\% does not cause great improvements in flexural properties of LMC. The limit on increase of mechanical properties of CFLMC is due to the increase in air content due to workability issues of CFLMC. Thus, it is justified in using $0.7 \%$ carbon fibers to LMC in previous tests. 


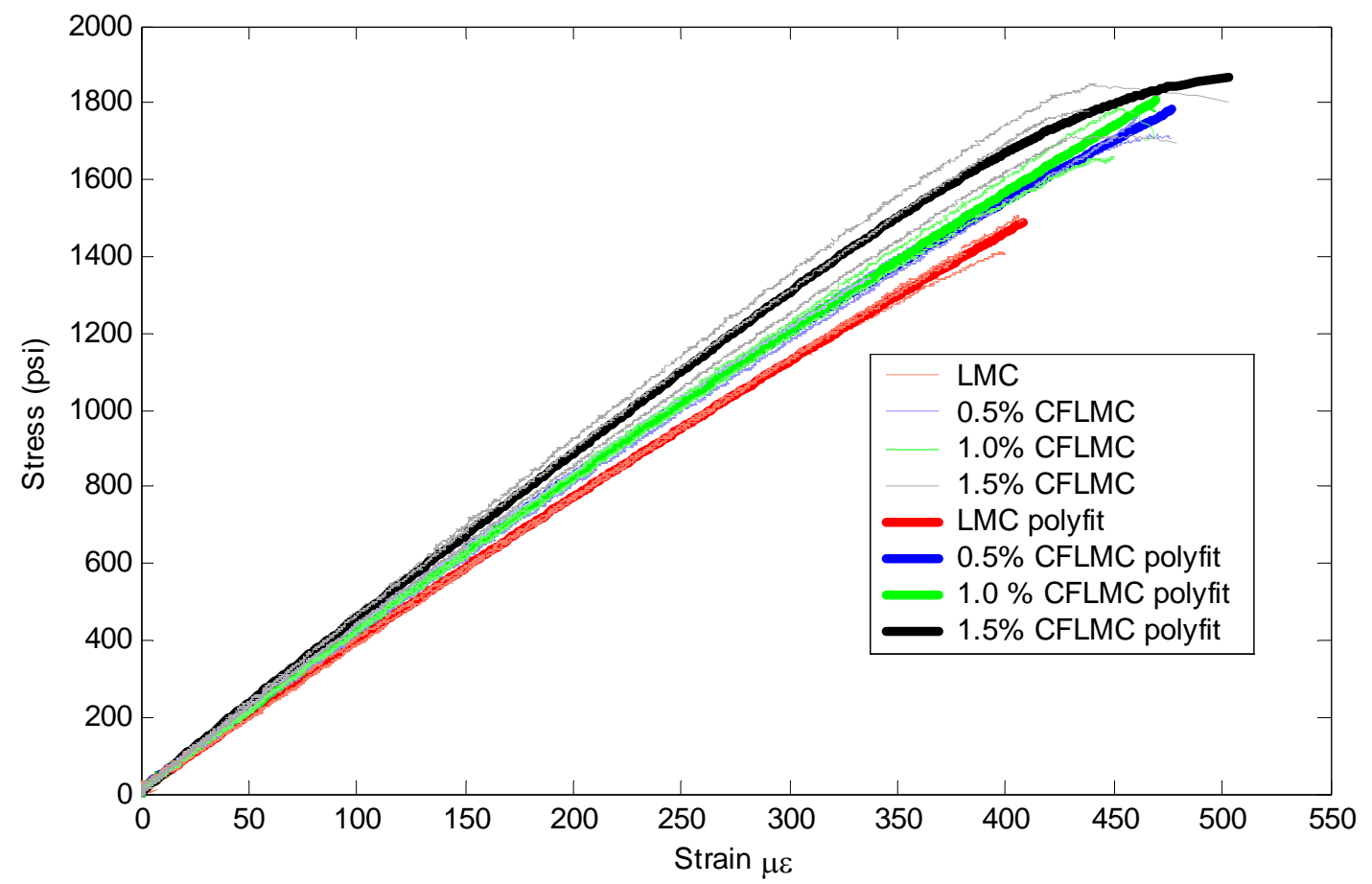

Figure 5.15: Stress vs. Strain plot for LMC \& CFLMC specimens in four point loading (experimental test results)

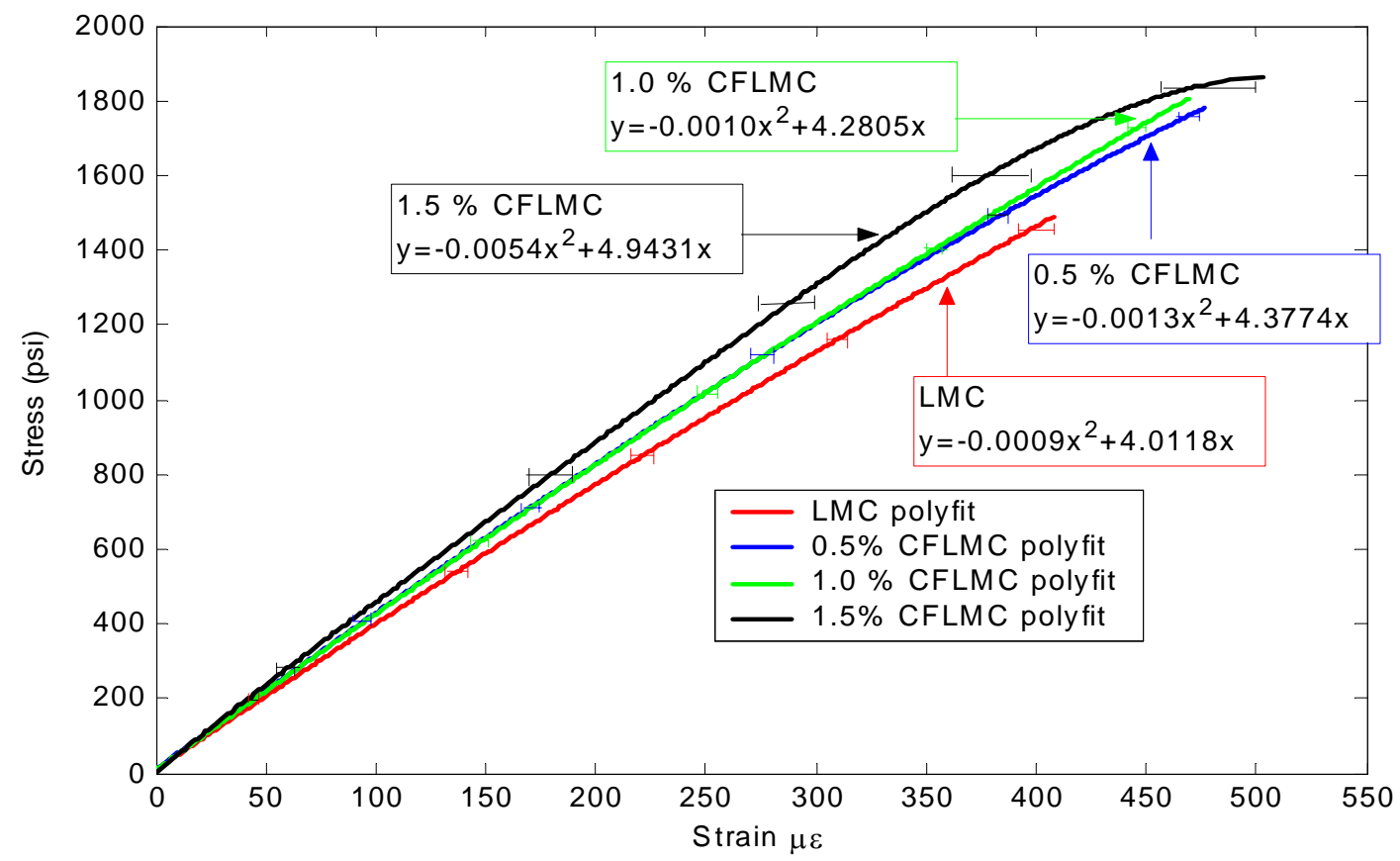

Figure 5.16: Stress vs. Strain plot for LMC \& CFLMC specimens in four point loading (polynomial fit results) 
Table 5.5: Test results for four point loading test for CF\% in $\mathrm{LMC}$

\begin{tabular}{|c|c|c|c|c|c|}
\hline Sample & $\begin{array}{c}\text { Load at } \\
\text { Failure } \\
(\mathbf{l b s})\end{array}$ & $\begin{array}{c}\text { Modulus of } \\
\text { rupture MOR } \\
(\mathbf{p s i})\end{array}$ & $\begin{array}{c}\text { Ultimate } \\
\text { Strain } \\
(\boldsymbol{\mu \varepsilon})\end{array}$ & $\begin{array}{c}\text { Average } \\
\text { MOR } \\
(\mathbf{p s i})\end{array}$ & $\begin{array}{c}\text { Average } \\
\text { ultimate } \\
\text { strain }(\boldsymbol{\mu \varepsilon})\end{array}$ \\
\hline LMC & 501 & 1502 & 408 & & \\
& 469 & 1407 & 382 & 1440.6 & 396.6 \\
& 471 & 1413 & 400 & & \\
\hline CFLMC & 587 & 1762 & 461 & & 469.6 \\
$0.5 \%$ & 570 & 1710 & 477 & 1730.3 & \\
& 573 & 1719 & 471 & & \\
\hline CFLMC & 596 & 1789 & 468 & & \\
$1.0 \%$ & 594 & 1782 & 469 & 1744.3 & 462.3 \\
& 554 & 1662 & 450 & & \\
\hline CFLMC & 616 & 1848 & 503 & & \\
$1.5 \%$ & 593 & 1779 & 439 & 1780.3 & 473.6 \\
& 571 & 1714 & 479 & & \\
\hline
\end{tabular}

\subsubsection{Fracture Test}

Fracture toughness is measured from the area under the graph for an experimental curve in a load displacement plot. The averaged load deflection curves (figure 5.18) from the fracture tests show increase in fracture energy with increasing carbon fiber percentages in LMC. CFLMC at $1 \%$ and $1.5 \%$ showed huge improvements in fracture toughness $(78.8$ $\%$ \& $123 \%$ respectively). It seems practical to design a mix in between $0.5 \%$ and $1 \%$, since workability was also issue to be considered. A quadratic fit of the fracture toughness for various carbon fiber percentages, was plotted in figure 5.19. It predicts the fracture toughness of CFLMC at $0.7 \%$ to be $1.35 \mathrm{lb} / \mathrm{in}$, which is an average improvement of $27 \%$, compared to LMC. Thus it is viable to design a mix at $0.7 \%$ for considerable improvement mechanical properties of LMC. 


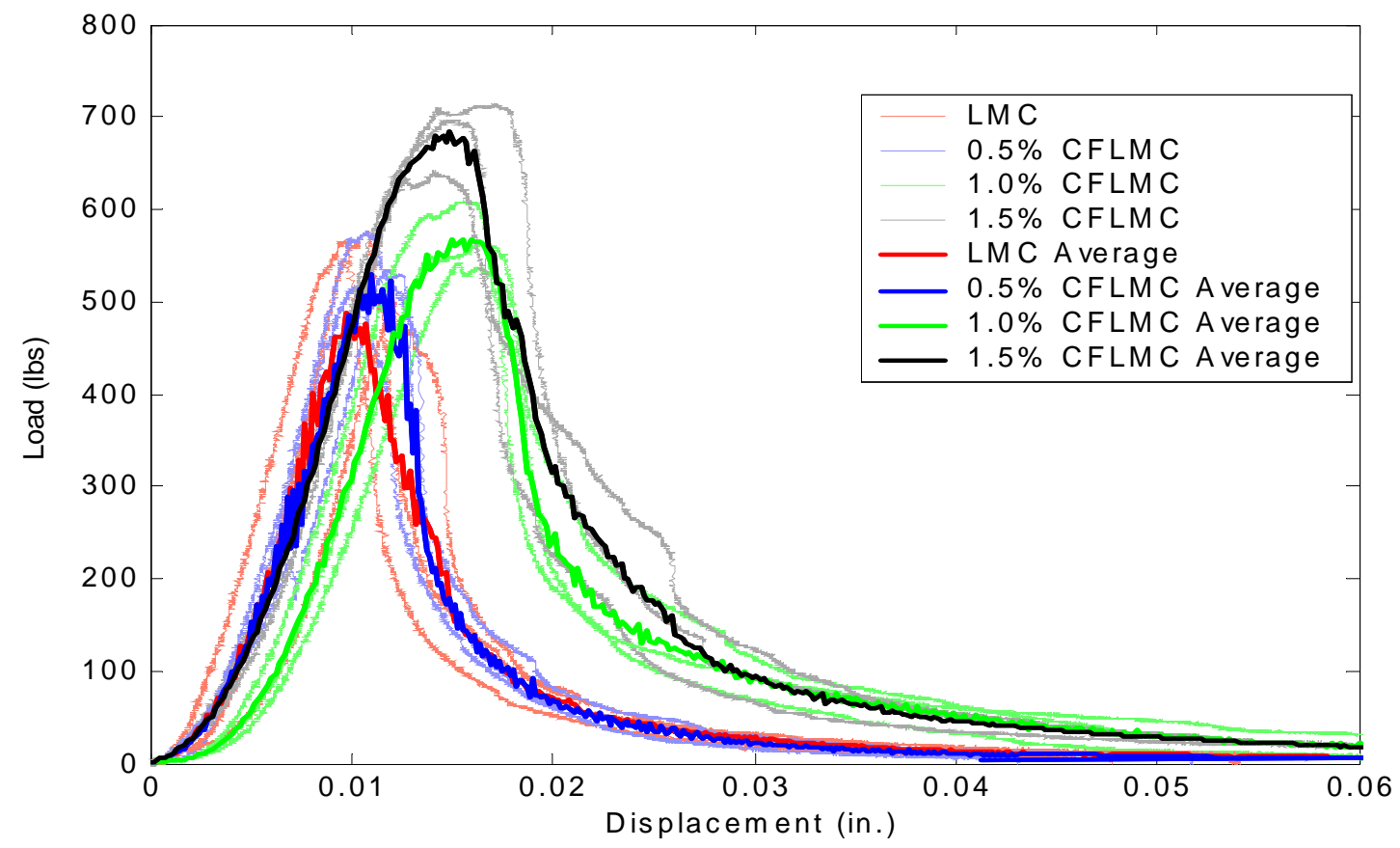

Figure 5.17: Load vs. Displacement in fracture test (experimental test results)

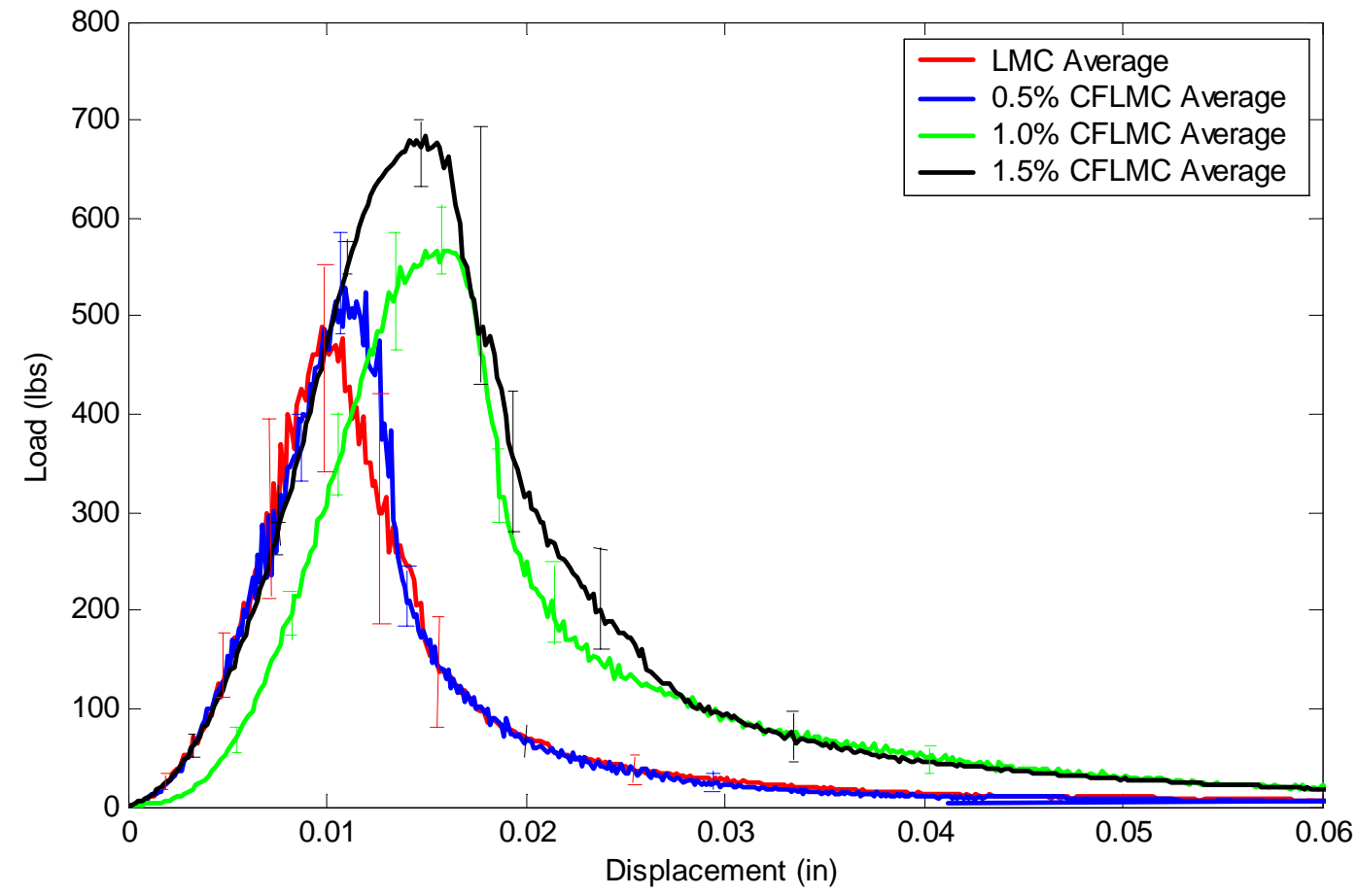

Figure 5.18: Load vs. Displacement in fracture test (average test results) 


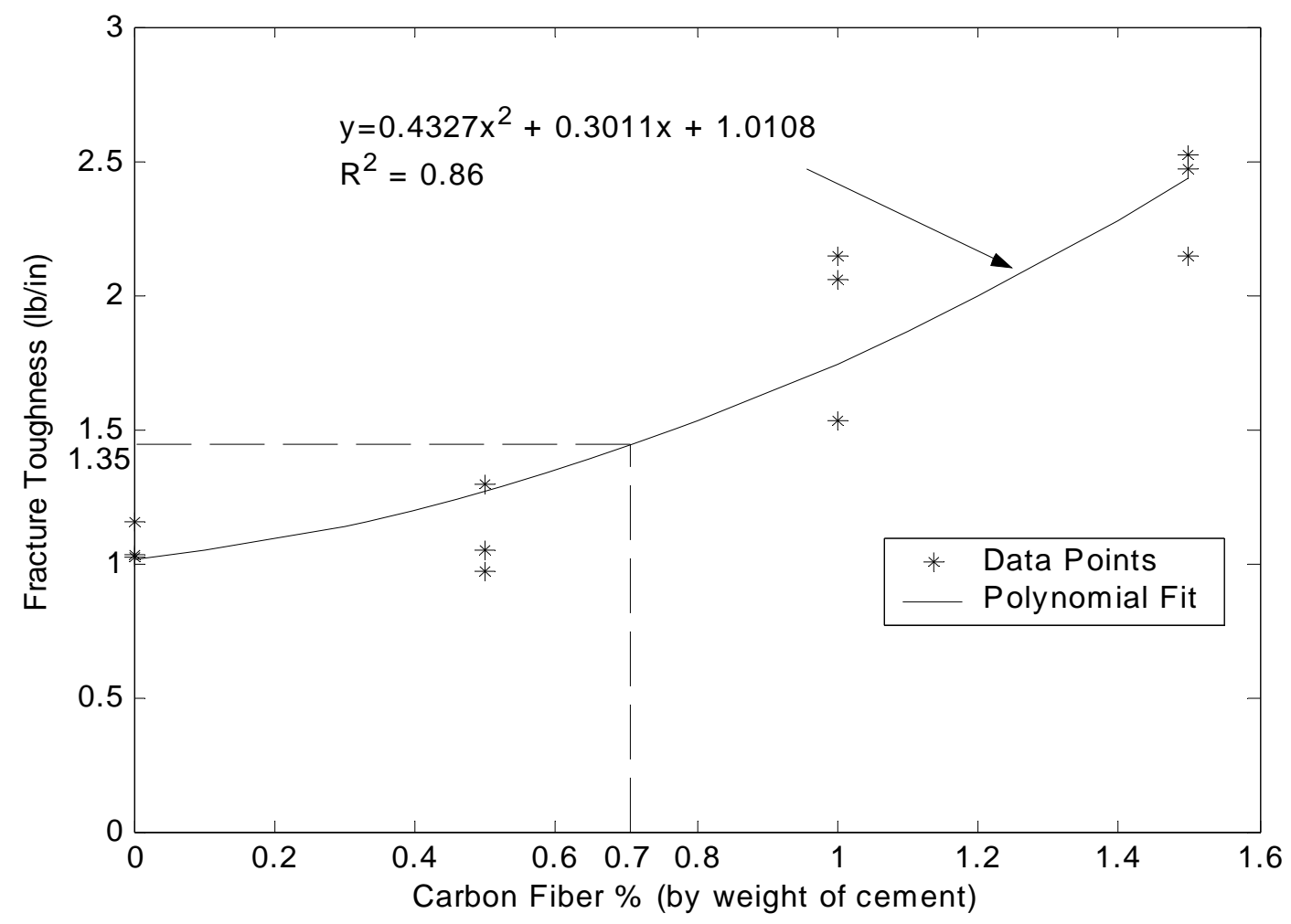

Figure 5.19: Fracture toughness vs. CF \% (by weight of cement)

Table 5.6: Test results for fracture test

\begin{tabular}{|c|c|c|c|c|c|c|}
\hline $\begin{array}{c}\text { Test } \\
\text { Sample }\end{array}$ & $\begin{array}{c}P_{\text {cr }} \\
\text { (lbs) }\end{array}$ & $\begin{array}{c}W_{0} \\
\text { (lb in) }\end{array}$ & $\begin{array}{c}\mathbf{G}_{\mathbf{F}} \\
(\mathbf{l b} / \mathbf{i n})\end{array}$ & $\begin{array}{c}\text { Avg } \\
\mathbf{P}_{\mathbf{c r}} \\
(\mathbf{l b s})\end{array}$ & $\begin{array}{c}\text { Avg } \\
\mathbf{W}_{\mathrm{t}} \\
(\mathrm{lb} / \mathbf{i n})\end{array}$ & $\begin{array}{c}\text { Average } \\
\mathbf{G}_{\mathbf{F}} \\
(\mathbf{l b} / \mathbf{i n})\end{array}$ \\
\hline \multirow{3}{*}{$\begin{array}{c}\mathrm{CF}- \\
0 \%\end{array}$} & 567 & 4.6223 & 1.027178 & \multirow{3}{*}{547.66} & \multirow{3}{*}{4.8} & \multirow{3}{*}{1.066} \\
\hline & 577 & 5.1961 & 1.154689 & & & \\
\hline & 499 & 4.5842 & 1.018711 & & & \\
\hline \multirow{3}{*}{$\begin{array}{l}\text { CF - } \\
0.5 \%\end{array}$} & 517 & 4.698 & 1.044 & \multirow{3}{*}{542.66} & \multirow{3}{*}{4.956} & \multirow{3}{*}{1.101} \\
\hline & 535 & 4.3580 & 0.968444 & & & \\
\hline & 576 & 5.8133 & 1.291844 & & & \\
\hline \multirow{3}{*}{$\begin{array}{c}\mathrm{CF}- \\
1 \%\end{array}$} & 542 & 6.9042 & 1.534267 & \multirow{3}{*}{572} & \multirow{3}{*}{8.607} & \multirow{3}{*}{1.912} \\
\hline & 565 & 9.2732 & 2.060711 & & & \\
\hline & 609 & 9.6446 & 2.143244 & & & \\
\hline \multirow{3}{*}{$\begin{array}{l}\text { CF - } \\
1.5 \%\end{array}$} & 697 & 9.6617 & 2.147044 & \multirow{3}{*}{684} & \multirow{3}{*}{10.709} & \multirow{3}{*}{2.379} \\
\hline & 714 & 11.3641 & 2.525356 & & & \\
\hline & 641 & 11.1038 & 2.467511 & & & \\
\hline
\end{tabular}




\subsubsection{Split Tensile Test on Composite Cylinders}

The split tensile results show a decrease in bond strength of CFLMC to the concrete substrate, compared to LMC.

Table 5.7: Test results of split tensile test for bond strength

\begin{tabular}{|c|c|c|c|}
\hline Sample & $\begin{array}{c}\text { Load } \\
\text { (lbs) }\end{array}$ & $\begin{array}{c}\text { Tensile } \\
\text { Strength } \\
\text { (psi) }\end{array}$ & $\begin{array}{c}\text { Average } \\
\text { Tensile } \\
\text { strength (psi) }\end{array}$ \\
\hline \multirow[t]{3}{*}{ LMC } & 9600 & 191.08 & \multirow{3}{*}{211.6507} \\
\hline & 12100 & 240.84 & \\
\hline & 10200 & 203.0255 & \\
\hline \multirow[t]{3}{*}{ CF $0.5 \%$} & 10100 & 201.035 & \multirow{3}{*}{202.362} \\
\hline & 9100 & 181.1306 & \\
\hline & 11300 & 224.9204 & \\
\hline \multirow[t]{3}{*}{ CF $1.0 \%$} & 8300 & 165.207 & \multirow{3}{*}{183.78} \\
\hline & 8900 & 177.149 & \\
\hline & 10500 & 208.9968 & \\
\hline \multirow[t]{3}{*}{ CF $1.5 \%$} & 9100 & 181.1306 & \multirow{3}{*}{185.11} \\
\hline & 8700 & 173.1688 & \\
\hline & 10100 & 201.035 & \\
\hline
\end{tabular}

Greater the carbon fiber percentage, the lower the workability of the mix and lower the ability of the mix to wet and adhere to the substrate. Hence higher percentages of carbon fibers in the mix may cause a loss of bond strength between the substrate and overlay.

Hence it is concluded that CFLMC with high percentages of carbon fibers may show improved mechanical properties but the gains does not substantiate its usage in field applications. Hence these experiments further justify a percentage of $0.7 \%$ as ideal for practical field purposes of CFLMC. 


\section{CHAPTER SIX \\ CONCLUSIONS}

\subsection{Introduction}

This experimental study investigated CFLMC from the viewpoint of mixing and mechanical properties for bridge deck overlay applications. The following conclusions were derived from this research.

\subsection{Practicability of CF in Concrete}

In this study, dry mixing of carbon fibers with cement enabled uniform dispersion of the carbon micro-fibers in concrete based on microscopic examination of a fractured surface of a random specimen.. A volume fraction of $0.15 \%$ carbon fibers showed improvement in mechanical properties of LMC.

\subsection{Complimentary roles of LMC and Carbon Fibers in Concrete.}

This study showed that there is a mutual benefit due to interactions between latex and carbon fibers. Styrene butadiene latex helped in improved adhesion of the cement matrix with the carbon fibers. Failure was mainly due to a combination of shearing of the matrix in the vicinity of the fiber, and interfacial shear between the fiber and matrix. This was observed from SEM photographs from a single random sample. Latex also helped in fiber dispersion. Improved adhesion and dispersion enabled carbon fibers to be a more effective reinforcing material for concrete.

\subsection{Effect of Carbon Fibers on the Mechanical Properties of LMC}

A comparison of LMC and CFLMC at $0.7 \%$ (by weight of concrete) has brought out the following results. All conclusions are based on average of testing 3 samples of each type of material. 


\subsubsection{Improvements due to Carbon Fibers}

1. In direct tension, CFLMC showed a $26 \%$ average increase in strain to failure (ductility) compared to LMC. It also showed a corresponding average increase of $45 \%$ in toughness. Improvements in ductility have the potential to reduce cracking in overlays.

2. Besides a $17 \%$ increase in ultimate flexural strength, the stress strain curves show increase in strain to failure or ductility ( $43 \%$ average).

3. Fracture tests predict the fracture toughness of CFLMC at $0.15 \%$ volume fraction to have an average improvement of $27 \%$, compared to LMC.

\subsubsection{Neutral Effects of Carbon Fibers}

1. There is no significant change in the tensile modulus of elasticity or tensile strength of LMC by addition of carbon fibers.

\subsubsection{Disadvantages of CFLMC}

1. Reduction in slump and workability is expected in the manufacture of CFLMC. The mix design of LMC is usually formulated to accommodate the loss of slump (2-3 inches approx) due to addition of fibers.

2. Decrease in bond strength with increasing the carbon fiber percentage in LMC. It is necessary to keep carbon fiber percentages at low levels in overlay applications. However, improved surface texturing, grout methods, and use of water reducing admixtures can overcome this problem.

\subsection{Tensile Testing of Concrete.}

A method of tensile testing of concrete was developed during the course of this research. Specimens were dog-bone shaped and special attention was taken for specimen preparation and specimen gripping. 


\subsection{Future Recommendations}

Additional research into CFLMC can be investigated to enhance its properties. These include

1. Effects of admixtures to overcome the disadvantages of CFLMC. These may include water reducing admixtures for improved workability.

2. Effect of increased fiber lengths on the properties of LMC in tension and flexure

3. Improved overlaying practices to ensure better bonding between overlay and substrate to reduce delamination. 


\section{REFERENCES}

1. ACI, BRE, Concrete society, ICRI, "Concrete Repair Manual" - 2nd Edition

2. WVDOH, "Standard specifications for roads and bridges- Supplemental Specifications" 2000 edition, Section 679 - Overlaying of Portland Cement Concrete Bridge Decks.

3. ACI 548.3R-95, "State-of-the-Art Report on Polymer-Modified Concrete".

4. Peier W.H, "Adhesion testing of Polymer Modified Cement Mortars", Adhesion between polymers and concrete symposium proceedings organized by RILEM Technical Committee 52, Aix-en-Provence, France, pp 730-740, September 1619,1986

5. Cresson, L., British patent 191, 474 Jan 12, 1923

6. Dow Chemical Co., "A handbook on Portland Cement Concrete and Mortar containing Styrene/Butadiene Latex," Midland, Mich., (1985)

7. Jaenicke, J.,Knoop, Miedel, H., and Schweitzer, O., US Patent 2,311,233, Feb. 16, 1943, assigned to American Lurgi Corp.

8. R. Critchley, and Bond, A.E; British patent 369, 561, Mar 17, 1932.

9. Rodwell, A.G., German Patent 680, 312, Aug 29, 1939.

10. Zayat K, Bayasi Z., "Effect of Latex on the Mechanical Properties of Carbon Fiber Reinforced Cement", ACI Materials Journal, Title no. 93-M20, March April 1996, pp 178-181

11. Colin D.J," Fiber-Reinforced cements and concretes" Taylor \& Francis Group, 1st edition ,November 1, 2000

12. Hannat D.J., "Fiber cements and fiber concretes", John Wiley and sons

13. Soroushian P, Aouadi F, Nagi M, "Latex modified carbon fiber reinforced mortar", ACI materials journal Jan Feb 1991, pp 11-18

14. Ohama Y., "Handbook of Polymer-Modified Concrete and Mortars - Properties and Process Technology" Noyes Publications NJ, USA, Courtesy of the Hoechst Gosei Co., Ltd. (1995)

15. Lefebure, V., British Patent 217, 279, June 5, 1924

16. Cooke, G.B., US Patent 2,227533, Jan 7, 1941, assigned to Crown Cork and seal Co., Inc.

17. Geist, J.M.; Amagna, S.V.; and Mellor, B.B.,'Improved Portland Cement Mortars with Polyvinyl Acetate Emulsions," Industrial and Engineering Chemistry, V. 45, No 4, (1953), pp 759-767

18. Luo. S," Evaluations of Concrete Overlays for Bridge Deck Applications", Thesis, WVU, Department of Civil and Environmental Engineering, (2002).

19. Steele, G. W. and Judy, J. M., "Polymer-modified concretes in bridge deck overlay systems", ASTM Special Technical Publication, n 629, 1977, p 110-115.

20. ACI 548.4-93, "Standard Specification for Latex-Modified Concrete (LMC) Overlays" (Reapproved 1998)

21. ACI 544.1R-96, "State-of-the-Art Report on Fiber Reinforced Concrete" (Reapproved 2002).

22. Naaman, A.E,'Fiber Reinforcement for Concrete," Concrete International:Design and Construction, Vol 7, No. 3, Mar 1985, pp. 21-25. 
23. Romualdi, J.P., and Batson G.B., "Mechanics of Crack Arrest in Concrete," J. Eng. Mech. Div., ASCE, Vol. 89, No. EM3, June 1963, pp. 147-168.

24. Biryukovich, K.L., and Yu, D.L., " Glass Fiber Reinforced Cement”, translated by G.L. Cairns, CERA Translation No 12, Civil Eng. Research Association London, (1965), pp 41

25. RILEM Technical Committee 19-FRC," Fiber Concrete Materials", Materials and Structures, Test Res, Vol 10, No. 56, 1977, pp. 103-120.

26. Sakai H., Takahashu K., Mitsui Y., Ando T., Awata M., and Hoshijima T., (1994), Fiber Reinforced Concrete developments and Innovations, ACI Special Publication SP-142 pp 121-140

27. Daniel J.I., Shah S.P., (editors), "Thin-Section Fiber Reinforced Concrete and Ferrocement" SP-124, ACI, Detroit, pp. 441, (1990)

28. Peiffer. G. and Soukatchoff, P., (1994), Special Concretes - Workability and Mixing, RILEM Proceedings 24, E \& FN Spon, pp. 89-97

29. Bayasi, Z.,"Properties and Applications of Carbon Fiber Reinforced Cement Composites," Proceedings, Symposium on Advancements in Concrete Materials, Bradley University, Mar. 1989, pp, 4.1-4.35

30. Zheng Q. and Chung D.D.L., "Carbon Fiber Reinforced Cement Composites Improved by Using Chemical Agents", Cement Concrete Research. 19, 25-41 (1989).

31. Ohama, Y., "Principle of latex modification and some typical properties of LMC," ACI Journal, Proceedings V.84, No. 6, Nov-Dec 1987, pp. 511-518.

32. Fukuchi T., Ohama, Y., Hashimoto H., and Sugiyama M., "Properties of Steel Fiber Polymer-Modified Concrete," The Society of Materials Science, Kyoto, Japan, 1978, pp 163-165

33. Sundara, Raja Iyengar, K. T., Nagaraj T.S., and Kameswara Rao, B., "Superplasticised Natural Rubber Latex-Modified Steel Fiber reinforced Concretes," Proceedings, RILEM International Symposium on Fiber Reinforced Concrete, London, England, 1986, 7 pp.

34. Yang X., and Chung D. D. L., "Latex-Modified Cement Mortar Reinforced by Short Carbon Fibers", Composites 23(6), pp. 453-460 (1992).

35. Tlili A., "Development, Characterization, and Fundamental Investigation of Latex-Modified Steel Fiber Reinforced Concrete", PhD Dissertation, Dept. of Civil \& Environmental Engineering, Michigan State University, (1993).

36. Zayat K, Bayasi Z., "Effect of Latex on the Mechanical Properties of Carbon Fiber Reinforced Cement", ACI Materials Journal, Title no. 93-M20, March April 1996, pp 178-181

37. Chen P.W., Chung D.D.L, "A Comparative Study of Concretes Reinforced with Carbon, Polyethylene and Steel Fibers and Their Improvement by Latex Addition", ACI Mater. J. 93(2), (1996), pp 129-133

38. Fu X, Lu W., and Chung D.D.L., "Improving the Bond Strength between Carbon Fiber and Cement by Fiber Surface Treatment and Polymer Addition to Cement Mix", Cement Concrete Research 26(7), (1996), pp 1007-1012.

39. Chen P.W, Fu X, and Chung D.D.L, "Microstructural and Mechanical Effects of Latex, Methylcellulose and Silica Fume on Carbon Fiber Reinforced Cement", ACI Mater. J. 94(2), 147-155 (1997) 
40. Zeng Q. S, and Chung D.D.L., "Improving the Abrasion Resistance of Mortar by Adding Latex and Carbon Fibers", Cement Concrete Research. 27(8), pp. 11491153 (1997)

41. Cao J and Chung D.D.L., "Improving the Dispersion of Steel Fibers in Cement Mortar by the Addition of Silane", Cement Concrete. Research. 31(2), 309-311 (2001).

42. Chung D.D.L., "Dispersion of Short Fibers in Cement", J. Mater. Civil Engg.17(4), (2005), pp 379-383

43. Ramey, G.E, and Strickland, M," An Experimental Evaluation of Rapid Setting Material Used in the repair of Concrete Bridges and Pavements," FHWA Report

44. ASTM standards

- ASTM C33 -03 Standard Specification for Concrete Aggregates

- ASTM C39/C39M-05 Standard Test Method for Compressive Strength of Cylindrical Concrete Specimens

- ASTM C78-02 Standard Test Method for Flexural Strength of Concrete (Using Simple Beam with Third-Point Loading)

- ASTM C94/C94M-05 Standard Specification for Ready-Mixed Concrete

- ASTM C143/C143M-05a Standard Test Method for Slump of Hydraulic Cement Concrete

- ASTM C150-05 Standard Specification for Portland Cement

- ASTM C293-02 Standard Test Method for Flexural Strength of Concrete (Using Simple Beam With Center-Point Loading)

- ASTM C496/C496M-04 Standard Test Method for Splitting Tensile Strength of Cylindrical Concrete Specimens

- ASTM C1018-97 Standard Test Method for Flexural Toughness and FirstCrack Strength of Fiber-Reinforced Concrete (Using Beam With Third-Point Loading)

- ASTM C1245-93 "Standard Test Method for Determining Bond Strength Between Hardened Roller Compacted Concrete and Other Hardened Cementitious Mixtures Point Load Test".

45. Geissert G. D., Li S., Frantz G.C., Stephens J.E.,’Splitting Prism Test Method to Evaluate Concrete-to-Concrete Bond Strength", ACI Materials Journal Vol. 93, No. 3, May 1999, pp 359-366.

46. Roesler F.C, "Brittle Fractures Near Equilibrium," Proc. Phys. Soc. Lond. B69 981 (1956).

47. RILEM Committee on Fracture Mechanics of Concrete - Test Methods, "Determination of the Fracture Energy of Mortar and Concrete by means of Three-Point Bend Tests on Notched Beams," Materials and Structures, Vol. 18, No. 106, pp, 285-290, (1985)

48. Hillerborg, A.," Existing Methods to Determine and Evaluate Fracture Toughness of Aggregate Materials: RILEM Recommendation on Concrete," in Fracture Toughness and Fracture Energy, Test Methods for Concrete and Rock, edited by Mihashi H., et al., Balkema, Rotterdam, 1989, pp, 145-151

49. Petersson, P. E., "Crack Growth and development of Fracture Zones in Plain Concrete and Similar Materials," Report TVBM-1006, Division of Building Materials, Lund Institute of Technology, 1981. 
50. Swartz, S.E., and Yap, S.T., "The Influence of Dead Load on Fracture Energy Measurements Using the RILEM Method," Materials and Structures, Vol. 21, 1988, pp. 410-415

51. Akihama S., Suenaga T. and Banno T., International Journal of Cement Composites, Vol. 8, No 1, (1986), pp 21-33 


\section{APPENDIX}

\section{A.1 - PARALLEL ISO-STRAIN MODEL}

The following theory is given in most textbooks on composites [12]. The simplified theory is based on the following assumptions

1) The fibers are aligned in the direction of stress

2) There are equal strains in the fiber and matrix before cracking

3) The Poisson's ratio in fiber and matrix $=0$

Load is shared by fiber and matrix

$F=F_{f}+F_{m}$

Equilibrium

$\sigma A=\sigma_{f} A_{f}+\sigma_{m} A_{m}$

Compatibility

$\varepsilon=\varepsilon_{f}=\varepsilon_{m}$

Constitutive Relationship

$\sigma=E \varepsilon$

Substituting (4) in (2)

$E \varepsilon A=E_{f} \varepsilon_{f} A_{f}+E_{m} \varepsilon_{m} A_{m}$

From (3), Eqn. (5) yields

$E A=E_{f} A_{f}+E_{m} A_{m}$

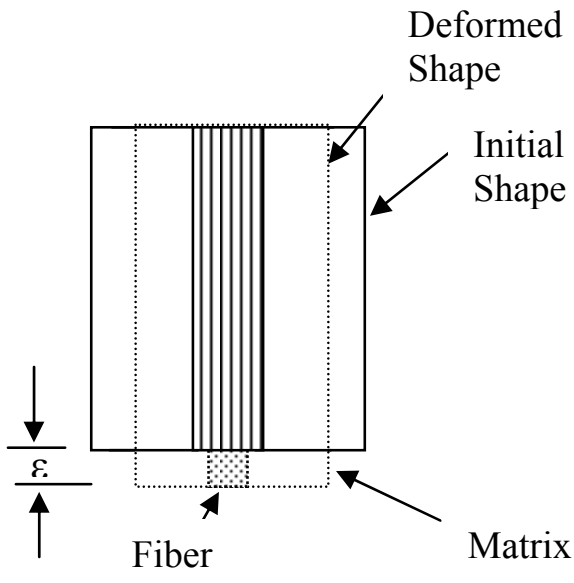

Figure A.1: Fiber

Matrix Model

Substituting A by $\mathrm{V}$

$E V=E_{f} V_{f}+E_{m} V_{m}$

where

$\mathrm{E}=$ Modulus of Elasticity

$\mathrm{V}=$ Volume

$\mathrm{A}=$ Cross sectional Area

$\sigma=$ Stress

$\varepsilon=$ Strain

$\mathrm{F}=\mathrm{Load}$

Suffix

$\mathrm{f}=$ Fiber

$\mathrm{m}=$ Matrix 


\section{A.2 LATEX MODIFIED CONCRETE MIX PROPORTIONS}

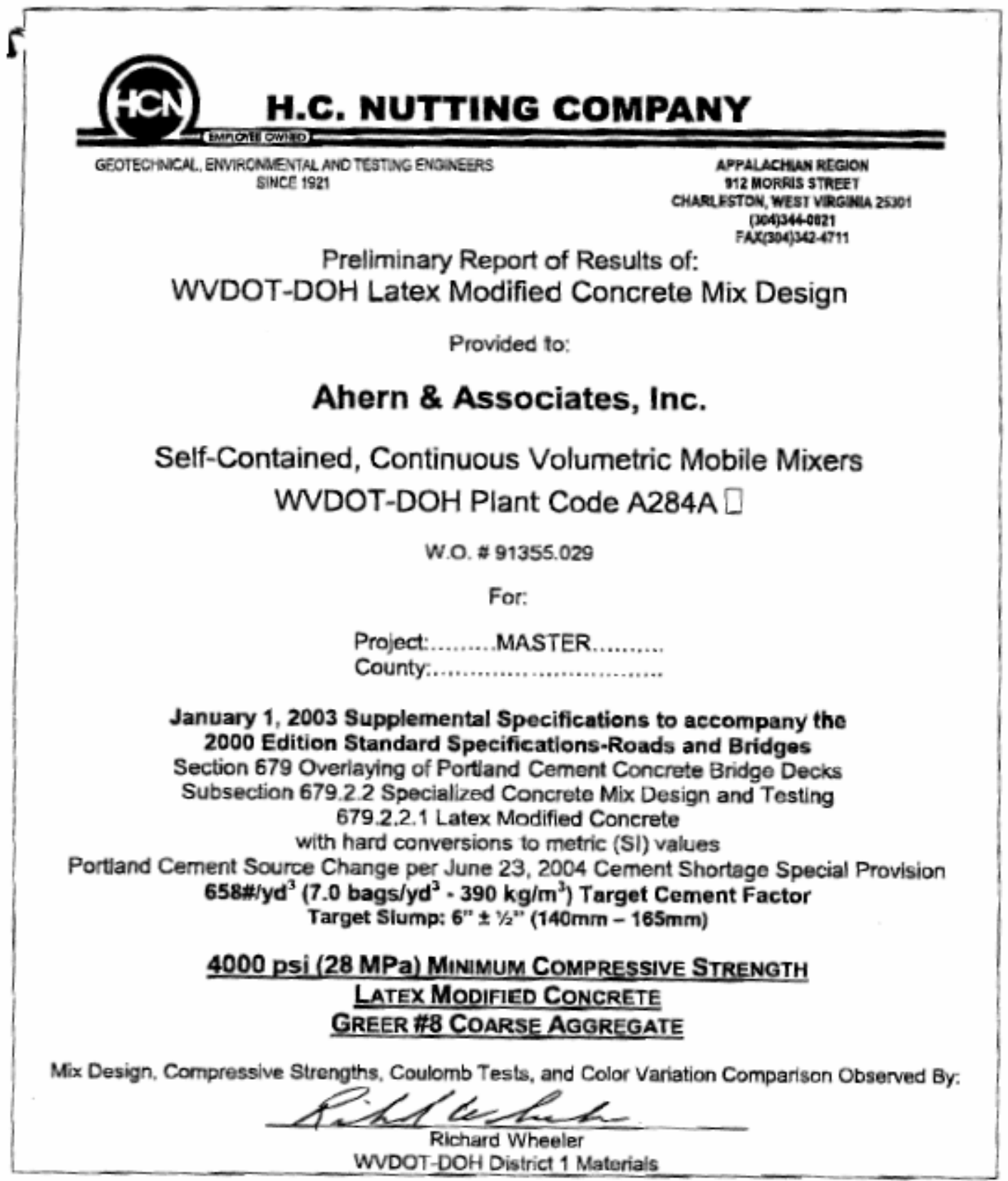


SUMMARY: Ahern \& Associates, Inc. - W. O. $\$ 91355.029$ - LMC Lab Trial Mixtures

Gravimetric Nominal Proportions per Cubic Yard $\left(27.00 \mathrm{ft}^{3}\right)$

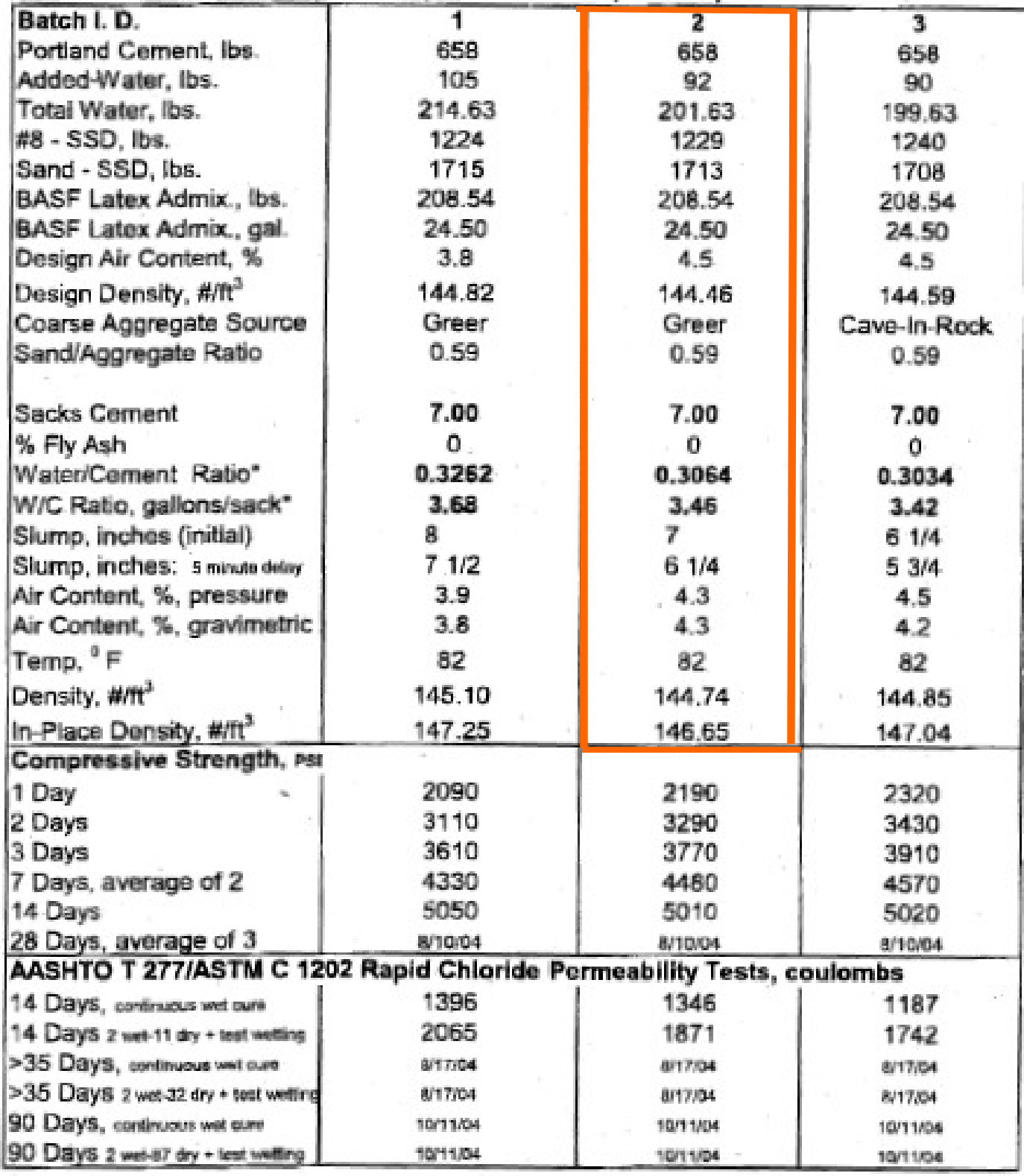

"Inclusive of free water on the aggregates, water in the latox admixture, and added water<smiles>[AsH2][AsH2]</smiles> 


\section{A.3 - CARBON FIBER SPECIFICATIONS}

SGL CARBON GROUP

Product Specification

\begin{tabular}{|c|c|c|c|c|c|c|c|c|c|c|c|c|c|c|c|c|}
\hline 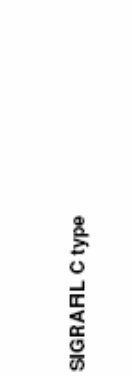 & 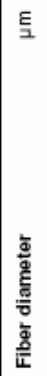 & $\tilde{\sigma}_{0}^{\tilde{\sigma}}$ & $\begin{array}{l}\frac{7}{\frac{7}{6}} \\
\frac{8}{8} \\
\frac{8}{2}\end{array}$ & $\frac{8}{0}$ & 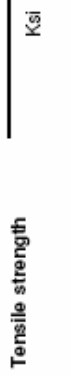 & $\frac{00}{0}$ & $\frac{\pi}{2}$ & 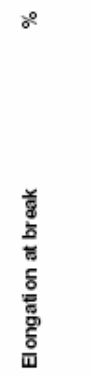 & 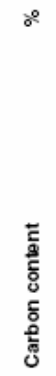 & 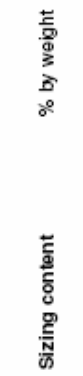 & 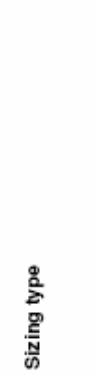 & 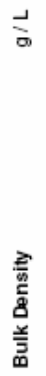 & $\underline{\mathrm{E}}$ & 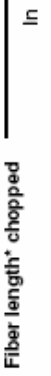 & ్ㅗㄹ & $\stackrel{c}{\bar{c}}$ \\
\hline \multicolumn{17}{|c|}{ Electromagnetic shielding - glues, resin systems, paper manufacturing (cont'd): } \\
\hline C25 S006 GLY & 7.5 & 1.80 & 112 & 3.6 & 520 & 225 & 33 & $1.4-1.8$ & $>95$ & $1.5-6.5$ & Glycerine & - & 6 & 0.2 & 16 & 630 \\
\hline C25 S000 GLY & 7.5 & 1.80 & 112 & 3.6 & 520 & 225 & 33 & $1.4-1.8$ & $>95$ & $1.5-6.5$ & Glyce rine & - & 9 & 0.4 & 16 & 630 \\
\hline C25 S012 GLY & 7.5 & 1.80 & 112 & 3.6 & 520 & 225 & 33 & $1.4-1.8$ & $>95$ & $1.5-6.5$ & Glyce rine & - & 12 & 0.5 & 16 & 630 \\
\hline \multicolumn{17}{|c|}{ Other applications - fuel cells, cement reinforcement, chemical resistance: } \\
\hline C10 S003 GLY & 7.5 & 1.75 & 112 & 2.8 & 410 & 200 & 29 & $1.2-1.3$ & $>95$ & $1.5-6.5$ & Glycerine & - & 3 & 0.1 & 18 & 710 \\
\hline C10 S006 GLY & 7.5 & 1.75 & 112 & 2.8 & 410 & 200 & 29 & $1.2-1.3$ & $>95$ & $1.5-6.5$ & Glycerine & - & 6 & 0.2 & 18 & 710 \\
\hline C25 S003 GLY & 7.5 & 1.80 & 112 & 3.6 & 520 & 225 & 33 & $1.4-1.8$ & $>95$ & $1.5-6.5$ & Glycerine & - & 3 & 0.1 & 16 & 630 \\
\hline C25 S006 GLY & 7.5 & 1.80 & 112 & 3.6 & 520 & 225 & 33 & $1.4-1.8$ & $>95$ & $1.5-6.5$ & Glycerine & - & 6 & 0.2 & 16 & 630 \\
\hline C25 S000 GLY & 7.5 & 1.80 & 112 & 3.6 & 520 & 225 & 33 & $1.4-1.8$ & $>95$ & $1.5-6.5$ & Glycerine & - & 9 & 0.4 & 16 & 630 \\
\hline C25 S012 GLY & 7.5 & 1.80 & 112 & 3.6 & 520 & 225 & 33 & $1.4-1.8$ & $>95$ & $1.5-6.5$ & Glycerine & - & 12 & 0.5 & 16 & 630 \\
\hline $\mathrm{C} 30 \mathrm{~S} 003 \mathrm{GLY}$ & 7.0 & 1.82 & 113 & 3.8 & 550 & 240 & 34 & $1.2-1.6$ & $>95$ & $1.5-6.5$ & Glycerine & - & 3 & 0.1 & 13 & 510 \\
\hline C30 S006 GLY & 7.0 & 1.82 & 113 & 3.8 & 550 & 240 & 34 & $1.2-1.6$ & $>95$ & $1.5-6.5$ & Glycerine & - & 6 & 0.2 & 13 & 510 \\
\hline $\mathrm{C} 30 \mathrm{~S} 000 \mathrm{GLY}$ & 7.0 & 1.82 & 113 & 3.8 & 550 & 240 & 34 & $1.2-1.6$ & $>95$ & $1.5-6.5$ & Glycerine & - & 9 & 0.4 & 13 & 510 \\
\hline C30 \$012 GLY & 7.0 & 1.82 & 113 & 3.8 & 550 & 240 & 34 & $1.2-1.6$ & $>95$ & $1.5-6.5$ & Glycerine & - & 12 & 0.5 & 13 & 510 \\
\hline
\end{tabular}

Packaging units
\begin{tabular}{|l|c|c|c|c|}
\hline SIGRAFIL C Type & Packaging & $\begin{array}{c}\text { Items per } \\
\text { carton }\end{array}$ & $\begin{array}{c}\text { Net weight per } \\
\text { PE bag }\end{array}$ & Net weight per carton \\
\hline $\begin{array}{l}\text { C25 S003/6 PUT } \\
\text { C25 S003/6 APS }\end{array}$ & $\begin{array}{c}\text { PE bags in cartons on non- } \\
\text { retumable pallets }\end{array}$ & 8 & $12.5 \mathrm{~kg} / 27.6 \mathrm{lb}$ & $100 \mathrm{~kg} / 220 \mathrm{lb}$ \\
\hline C25 S001 EPY & $\begin{array}{c}\text { PE bags in cartons on non- } \\
\text { returnable pallets }\end{array}$ & 4 & $10 \mathrm{~kg} / 22 \mathrm{lb}$ & $40 \mathrm{~kg} / 3 \mathrm{lb}$ \\
\hline $\begin{array}{l}\text { C10 S003/6 GLY } \\
\text { C25 S003/6/9/12 EPY } \\
\text { C25 S003/6/9/12 GLY } \\
\text { C30 S003/6/9/12 GLY }\end{array}$ & $\begin{array}{c}\text { PE bags in cartons on non- } \\
\text { returnable pallets }\end{array}$ & 8 & $10 \mathrm{~kg} / 22 \mathrm{lb}$ & $20 \mathrm{~kg} / 176 \mathrm{lb}$ \\
\hline
\end{tabular}

- Registered trademark of SGL Carbon Group companies

This information is based on our present state of knowladge and is

intended to provide general notes on our products and their uses. It

should therefore not be construed as guaranteeing specific

properties of the products described or their suitability for a

perticular application. Any existing industrial property rights must

"General Conditions of Sale".

$08 / 2004$

http://www.sglcarbon.com/sgl_t/fibers/pdf/sigrafil_c_e.pdf 


\section{Greer Limestone Company}

P.O. Box 1900, The Greer Mansion, 598 Canyon Road, Morgantown, WV 26507-1900

Phone: (304) 296-1751 Fax; (304) 594-3567

www.greerindustries.com

\section{Greer Limestone Company}

Chemical Analysis

$$
\begin{aligned}
& \mathrm{CaO}=44 \% \\
& \mathrm{MgO}=1.5 \% \\
& \mathrm{CaCo} 3=80 \% \\
& \mathrm{MgCo} 3=3.50 \% \\
& \mathrm{CaCo} 3 \text { Equivalent }=85 \%
\end{aligned}
$$


A.4 - SPECIFICATION FOR COARSE AGGREGATE -11

GREER LIMESTONE COMPANY

out e $7 / 18 / 05$

Ave.

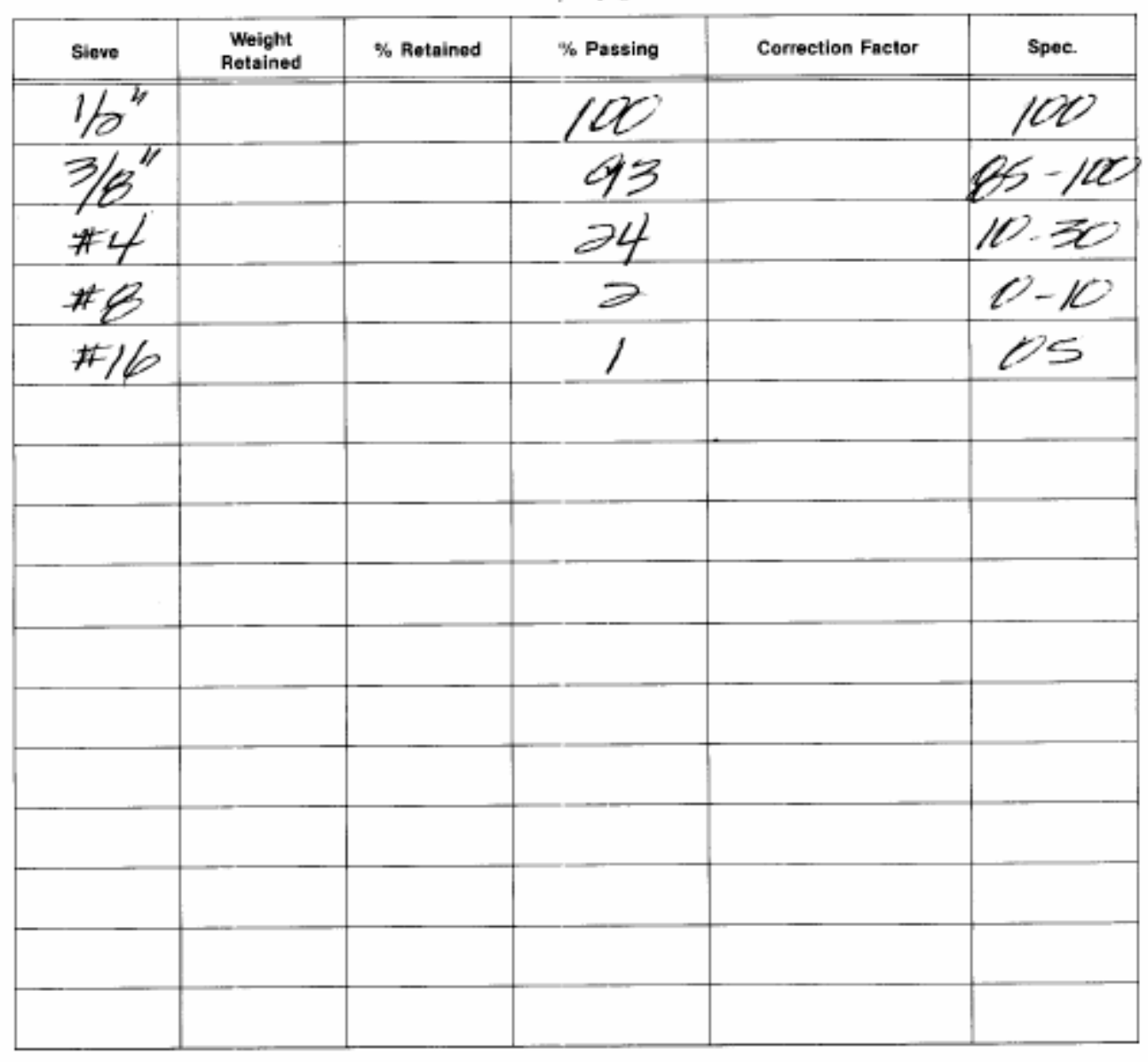

ABSORPtION, $8 \%$

Tested by

Sample from

93 


\section{A.5 - SPECIFICATION FOR SAND}

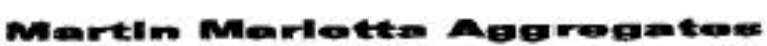

MATERIAL DATA SHEET

\section{APPLE GROVE PLANT}

\section{COARSE SAND}

\begin{tabular}{|c|c|c|}
\hline STEVISIRE & PERCENT PASSENG & $\begin{array}{l}\text { SPECERCATION } \\
\text { WV } 702.6\end{array}$ \\
\hline$"$ & & \\
\hline $31 / 5^{4}$ & & \\
\hline $3^{2}$ & & \\
\hline 25 & & \\
\hline$\overline{2}^{2}$ & & \\
\hline $1 \mathrm{~K}^{\prime \prime}$ & & \\
\hline$T^{2}$ & & \\
\hline$x^{2}$ & & \\
\hline 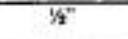 & & \\
\hline $3 \pi^{n}$ & 100 & 100 \\
\hline 14 & 96 & $95=100$ \\
\hline 28 & 79 & $80-100$ \\
\hline a 16 & 64 & $45-80$ \\
\hline 30 & 52 & \\
\hline 440 & 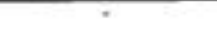 & $=$ \\
\hline 150 & 21 & $76-36$ \\
\hline 100 & 4 & $2=10$ \\
\hline 6200 & 1.1 & \\
\hline$F M$ & 2.833 & \\
\hline$A \cdot B A R$ & 6,112 & $5.7-6.5$ \\
\hline
\end{tabular}

\begin{tabular}{|c|c|c|}
\hline & & SPEC. \\
\hline $\begin{array}{l}\text { Unit Weight } \\
\text { (Loose) }\end{array}$ & $99 \mathrm{lb} / \mathrm{ft} 3$ & $=$ \\
\hline $\begin{array}{l}\text { Unit Weight } \\
\text { (Dry Rodded) }\end{array}$ & $111 \mathrm{lb} / \mathrm{ft} 3$ & $=$ \\
\hline $\begin{array}{l}\text { Bulk Specifie Gravity } \\
\text { (Dry) }\end{array}$ & 2.60 & - \\
\hline $\begin{array}{l}\text { Bulk Specifie Gravity } \\
\text { (SSD) }\end{array}$ & 2.64 & - \\
\hline $\begin{array}{c}\text { Bulk Specific Gravity } \\
\text { (Apparent) }\end{array}$ & 2.71 & - \\
\hline $\begin{array}{c}\text { Absorption } \\
\text { Percent }\end{array}$ & $1.6 \%$ & - \\
\hline $\begin{array}{c}\text { Los Angies } \\
\text { Abrasion }\end{array}$ & - & 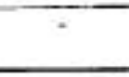 \\
\hline+ & & \\
\hline $\begin{array}{l}\text { Sodium Sulfate } \\
\text { Soundness }\end{array}$ & $\begin{array}{c}7.3 \% \\
\text { loss }\end{array}$ & $10 \% \mathrm{Max}$ \\
\hline Un-compacted Voids & 41 & - \\
\hline Sand Equivalent & 93 & $\cdot$ \\
\hline Percent Crushed Parricles & - & 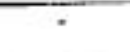 \\
\hline
\end{tabular}

\begin{tabular}{|c|c|c|c|c|c|c|c|}
\hline \multicolumn{8}{|c|}{$\begin{array}{l}\text { Deleterious Report } \\
\text { WVDOT Last Five Years }\end{array}$} \\
\hline & $\begin{array}{l}\text { Sodium } \\
\text { Sulfate }\end{array}$ & $\begin{array}{l}\text { Los Angles } \\
\text { Abrasion }\end{array}$ & $\begin{array}{l}\text { Deleterious } \\
\text { Shale }\end{array}$ & $\begin{array}{c}\text { Coal \& } \\
\text { Light Weights }\end{array}$ & $\begin{array}{l}\text { Friable } \\
\text { Particies }\end{array}$ & $\begin{array}{l}\text { Thin \& } \\
\text { Elongated }\end{array}$ & $\begin{array}{c}\text { Organic } \\
\text { Impurities }\end{array}$ \\
\hline 2002 & 3.3 & + & - & 0.0 & 0.0 & - & 3 \\
\hline 2001 & 1.0 & - & - & 0.1 & 0.1 & - & 2 \\
\hline 2000 & 4.4 & - & - & 0.1 & 0.0 & $=$ & 2 \\
\hline 1999 & 0.7 & $=$ & - & 0.4 & 0.0 & $=$ & 2 \\
\hline 1998 & 1.4 & - & - & 0.2 & 0.2 & $=$ & 1 \\
\hline
\end{tabular}




\section{A.6 - SPECIFICATION FOR LATEX}

\section{CERTIFICATE OF ANALYSIS COLOR RESOURCES IITERRATIOWAL P.O.ISAMPLE ORDRRf1390816683 DEL./2091079179}

$\begin{array}{ll}\text { Lot Number: } & \underline{\mathrm{GA2XS88702}} \\ \text { Date of Manufacture: } & \underline{\text { Octolegr 20, 2002 }} \\ \text { Solids, \% by weight: } & \underline{47.3 \%} \\ \text { WoighVGallon, lbs.: } & \underline{8.5 \mathrm{lbs} / \mathrm{gal}} \\ \mathrm{pH}: & \underline{9.8} \\ \text { Viscosity, cps.: } & \underline{24 \mathrm{cps}} \\ \text { Particle Size, nm: } & \underline{232 \mathrm{~nm}} \\ \text { Coagulum, ppm.: } & 1 \mathrm{ppm} \\ \text { Special Instructions: } & \\ \end{array}$

Styrofan ${ }^{\bullet} 1186$

APPROveo BY: Molinda Lumsford TITLE: Quality Control Technician

This report cortilies that the enalytical values reflect direct analysis of a sample of the shipment. This repert does not relieve the purchaser from examining the product upon dellvery and gives no assurance of sultablity of the product for any releve the purchaser trom ara any questions about these values or this report, please contact Mr. Douglas M. Meredith, particular purpose. If you have any questlons about these values or this report, please contact Mr. Douglas M. Meredich, 370 Franklort Road, Monaca, PA, USA 15051. 


\section{A.7 - WIRE RESISTANCE STRAIN GAGE - N2A-06-20CBW-120}

VISHAY.

20CBW

Vishay Micro-Measurements

\section{General Purpose Strain Gages - Linear Pattern}

\begin{tabular}{|c|c|c|c|c|c|c|}
\hline \multicolumn{7}{|c|}{ GAGE PATTERN DATA } \\
\hline & pin & & \multicolumn{2}{|c|}{$\begin{array}{l}\text { GAGE } \\
\text { DESIGNATION } \\
\text { See Note } 1\end{array}$} & $\begin{array}{l}\text { RESISTANCE } \\
\text { (OHMS) } \\
\text { See Note } 2\end{array}$ & $\begin{array}{l}\text { OPTIONS } \\
\text { AVAILABLE }\end{array}$ \\
\hline & & & \multicolumn{2}{|c|}{ N2A-XX-20CBW-120 } & $120 \pm 0.2 \%$ & W, E, L, LE, P \\
\hline & & & \multicolumn{2}{|c|}{$\begin{array}{l}\text { NZA-XX-ZOCBW-350 } \\
\text { EA-XX-20CBW-120 } \\
\text { WA-XX-20CBW-120 } \\
\text { WK-XX-20CBW-350 } \\
\text { EP-XX-20CBW-120 } \\
\text { SA-XX-20CBW-120 } \\
\text { SK-XX-20CBW-350 }\end{array}$} & $\begin{array}{l}350 \pm 0.2 \% \\
120 \pm 0.2 \% \\
350 \pm 0.4 \% \\
120 \pm 0.4 \% \\
350 \pm 0.2 \% \\
120 \pm 0.4 \% \\
350 \pm 0.4 \%\end{array}$ & $\begin{array}{l}W, E, L, L E, P \\
W, E, L, L E, P \\
W^{*}\end{array}$ \\
\hline & War & & \multicolumn{4}{|c|}{$\begin{array}{l}\text { DESCRIPTION } \\
\text { For use on concrete and for strain integration on large } \\
\text { specimens. }\end{array}$} \\
\hline GAGE & NSIONS & \multicolumn{2}{|c|}{$\begin{aligned} E S & =\text { Each Section } \\
S & =\text { Section }(S 1=\operatorname{Sec} 1)\end{aligned}$} & \multicolumn{2}{|c|}{$\begin{aligned} \mathrm{CP} & =\text { Complete Pattem } \\
\mathrm{M} & =\text { Matrix }\end{aligned}$} & \begin{tabular}{|c|} 
inch \\
millimeter \\
\end{tabular} \\
\hline Gage Length & Overall Length & Grid Width & Overall Width & Matr & ix Length & latrix Width \\
\hline 2.000 & 2.250 & 0.188 & 0.188 & & 2.46 & 0.32 \\
\hline 50.80 & 57.15 & 4.78 & 4.78 & & 62.5 & 8.1 \\
\hline
\end{tabular}

\begin{tabular}{l}
\hline \multicolumn{1}{|c|}{ SAGE Gage Series data sheet for complete specifications. } \\
\begin{tabular}{|c|l|c|l|}
\hline Series & \multicolumn{1}{|c|}{ Description } & Strain Range & \multicolumn{1}{|c|}{ Temperature Range } \\
\hline N2A & Constantan foil gages with a thin, laminated, polyimide-film backing. & $\pm 3 \%$ & $-100^{\circ}$ to $+200^{\circ} \mathrm{F}\left[-75^{\circ}\right.$ to $\left.+95^{\circ} \mathrm{C}\right]$ \\
\hline EA & Constantan foil in combination with a tough, flexible, polyimide backing. & $\pm 5 \%$ & $-100^{\circ}$ to $+350^{\circ} \mathrm{F}\left[-75^{\circ}\right.$ to $\left.+175^{\circ} \mathrm{C}\right]$ \\
\hline WA & Fully encapsulated constantan gages with high endurance leadwires. & $\pm 2 \%$ & $-100^{\circ}$ to $+400^{\circ} \mathrm{F}\left[-75^{\circ}\right.$ to $\left.+205^{\circ} \mathrm{C}\right]$ \\
\hline WK & Fully encapsulated K-alloy gages with high-endurance leadwires. & $\pm 1.5 \%$ & $-452^{\circ}$ to $+550^{\circ} \mathrm{F}\left[-269^{\circ}\right.$ to $\left.+230^{\circ} \mathrm{C}\right]$ \\
\hline EP & Annealed constantan foil with tough, high-elongation polyimide backing. & $\pm 20 \%$ & $-100^{\circ}$ to $+400^{\circ} \mathrm{F}\left[-75^{\circ}\right.$ to $\left.+205^{\circ} \mathrm{C}\right]$ \\
\hline SA & Fully encapsulated constantan gages with solder dots. & $\pm 2 \%$ & $-100^{\circ}$ to $+400^{\circ} \mathrm{F}\left[-75^{\circ}\right.$ to $\left.+205^{\circ} \mathrm{C}\right]$ \\
\hline SK & Fully encapsulated K-alloy gages with solder dots. & $\pm 1.5 \%$ & $-452^{\circ}$ to $+450^{\circ} \mathrm{F}\left[-269^{\circ}\right.$ to $\left.+230^{\circ} \mathrm{C}\right]$ \\
\hline & & \\
\end{tabular}
\end{tabular}

Note 1: Insert desired S-T-C number in spaces marked XX.

Note 2: Tolerance is increased when Option W, E, SE, LE, or $\mathrm{P}$ is specified.

tOptions available but not normally recommended. See Optional Features data sheet for details. 


\section{A.8 - LOCTITE SPEEDBONDER H8000 ADHESIVE}

\section{LOGTITE}

\section{Product Description Sheet}

1001 Trout Brook Crossing

Telephone: (860) 571-5100

Speedbonder® Product $\mathrm{H} 8000$

Industrial Products, May 2002

\section{Description}

Loctite $\circledast$ Speedbonder $\mathrm{H} 8000$ is a non-sag, two component, room temperature curing, 10:1 mix ratio, methacrylate adhesive system. $\mathrm{H} 800 \mathrm{O}$ is designed to have fast fixture time and excellent bond strength on multiple substrates including metals and composites. The product also has high elongation and excellent cold temperature impact strength. This adhesive forms resilient bonds and maintains its strength over a wide range of temperatures.

Recommended Substrates: Steel, Aluminum, Stainless Steel, FRP, Xenoy, RTM, Gelcoat, and ABS

\section{Features}

Non-sagging gaps filled to $1 / 2$ inch

Superior impact and peel strength

Little or no surface preparation

Offers excellent tolerance to off-ratio mixing

Rapid room temperature cure

$100 \%$ reactive

Excellent environmental resistance

\begin{tabular}{|l|c|}
\hline Typical Cured Properties & Typical Value \\
\hline Tensile Strength, psi, ASTM D 638 & 2300 to 2500 \\
\hline Elongation, \%, ASTM D 638 & 50 to 100 \\
\hline Young's Modulus (psi) & 70,000 to 90,000 \\
\hline Shear Strength @ $180^{\circ} \mathrm{F}$ psi. ASTM D 1002 & 1900 to 2100 \\
\hline
\end{tabular}

\begin{tabular}{|c|c|c|c|}
\hline Typical Uncured Properties & Part A & Part B & Mixed \\
\hline OpenTime@ $90^{\circ} \mathrm{F}$. mins & - & - & 10 to 15 \\
\hline Open Time@ @ 40 F, mins & & & 60 to 75 \\
\hline Exotherm Time@ @ 70F,mins & - & - & 18 to 25 \\
\hline $\begin{array}{l}\text { Fixture Time,3 Kg weight, @ } \\
70^{\circ} \mathrm{F} \text {.mins }\end{array}$ & & & 15 to 20 \\
\hline Color & yellow & Blue & Green \\
\hline $\begin{array}{l}\text { Viscosity, cP Brookfield HBT } \\
\text { Spindle } \# 6,10 \mathrm{Rpm}\end{array}$ & $\begin{array}{c}160,000 \\
\text { to } \\
220,000\end{array}$ & $\begin{array}{c}40,000 \\
\text { to } \\
70,000\end{array}$ & - \\
\hline Specific Gravity & 0.94 & 1.15 & 0.96 \\
\hline Weight per Gallon, Lbs & 783 & 9.58 & - \\
\hline \multicolumn{4}{|l|}{ Mix Ratio } \\
\hline By weight & 8.17 & 1 & - \\
\hline By volume & 10 & 1 & - \\
\hline
\end{tabular}

\begin{tabular}{|l|c|}
\hline \multicolumn{2}{|l|}{ Typical Cured Properties } \\
\hline Shear Strength, psi, ASTM D1002 @ 70 ${ }^{\circ} \mathrm{F}$ & Typical Value \\
\hline Aluminum & 3000 to 3500 \\
\hline Steel & 3000 to 3500 \\
\hline Stainless Steel & 2800 to 3100 \\
\hline FRP & $>1200$ to 1600 \\
\hline Gelcoat & $>1000$ to 1500 \\
\hline
\end{tabular}

\section{Typical Cured Properties}

\begin{tabular}{|l|l}
\hline Etched Aluminum & 1100 to 1300 \\
\hline & 800 to 1000
\end{tabular}

\begin{tabular}{l|l}
\hline Ground Steel & 1000 to 1200 \\
\hline
\end{tabular}

\begin{tabular}{|c|c|c|}
\hline Side Impact Strength, $\mathrm{kJ} / \mathrm{m}^{2}$, GM9751P tes & \multicolumn{2}{|c|}{ Typical value } \\
\hline & @70 $70^{\circ} \mathrm{F}$ & @- $40^{\circ} \mathrm{F}$ \\
\hline Aluminum & $>42$ & $>42$ \\
\hline FRP & $>15$ & 16 \\
\hline Ground Steel & 24 & 30 \\
\hline T-Peel, pli, ASTM D1876 & \multicolumn{2}{|c|}{ Typical Value } \\
\hline Steel & \multicolumn{2}{|c|}{35 to 45} \\
\hline Aluminum & \multicolumn{2}{|c|}{50 to 60} \\
\hline
\end{tabular}

GENERAL INFORMATION

This product is not recommended for use in pure oxygen and/or oxygen rich systems and should not be selected as a sealant for chlorine or other strong oxidizing materials.

For safe handling information on this product, consult the Material Safety Data Sheet, (MSDS).

Handling and Application

Mixing: It is highly recommended that either meter mix equipment or cartridges with static mix nozzles be used to properly ratio and dispense the adhesive. For optimum mixing, the Loctite static mixer, Item 985545 is recommended. Once mixed, H8000 should achieve a uniform green color. Heat buildup during and after mixing is normal. To reduce the likelihood of exothermic reaction or excessive heat buildup, mix less than 100 grams at a time. Mixing smaller amounts will minimize heat buildup.

Applying: Bonding surfaces should be clean, dry, and free of contamination. Extensive surface preparation is not required for $\mathrm{H} 800 \mathrm{O}$, and good bonds can be formed on most substrates after a solvent wipe. To assure maximum bond strength, surfaces must be mated within the adhesive's open time. Use enough material to completely fill the joint when parts are clamped.

Curing: Parts should remain undisturbed during the interval of time between the material's open time and fixture time. After the fixture time is achieved the material has reached handling strength. Temperature below $55^{\circ} \mathrm{F}$ will slow the cure; above $85^{\circ} \mathrm{F}$ will accelerate cure rate.

Clean Up: It is important to clean up excess adhesive from work area and application equipment before it hardens. Denatured alcohol and many common industrial solvents are suitable for removing uncured adhesive. H8000 is flammable. Keep containers tightly closed after use. Keep away from heat, sparks, and open flame.

Storage

Speedbonder adhesives should be stored in unopened containers in a dry location at $40^{\circ} \mathrm{F}+/-5 \mathrm{~F}$. For further specific shelf life information, contact your local Technical Service Center. 


\section{A.9 - LVDT - LINEAR VARIABLE DISPLACEMENT TRANSDUCERS}

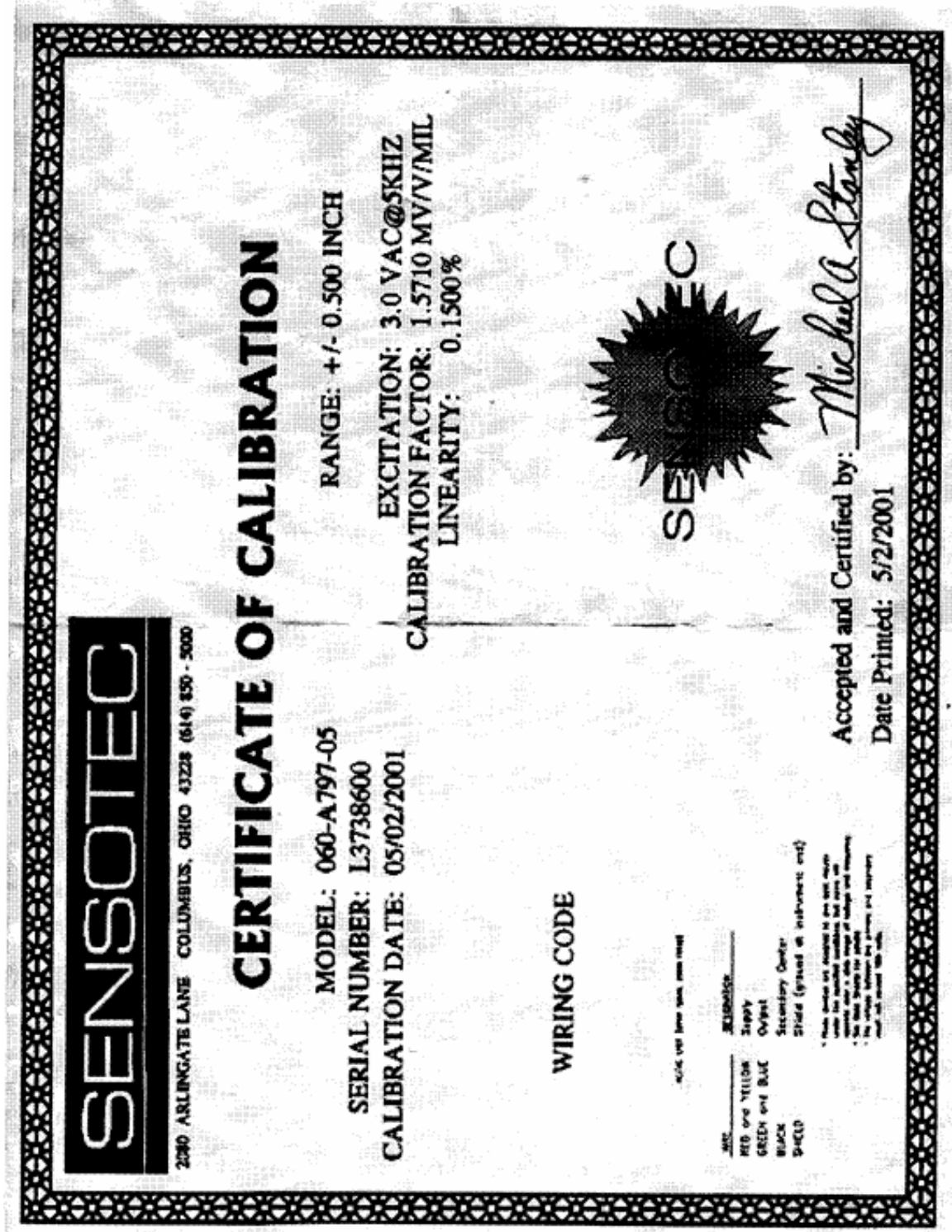




\section{A.10 - SYSTEM 5000 MODEL 5100 SCANNER}

\section{Description}

The Model 5100 Scanner is sized for standard 19-in (483-mm) instrumentation racks. Cabinets are available for various system configurations for bench-top or field use.

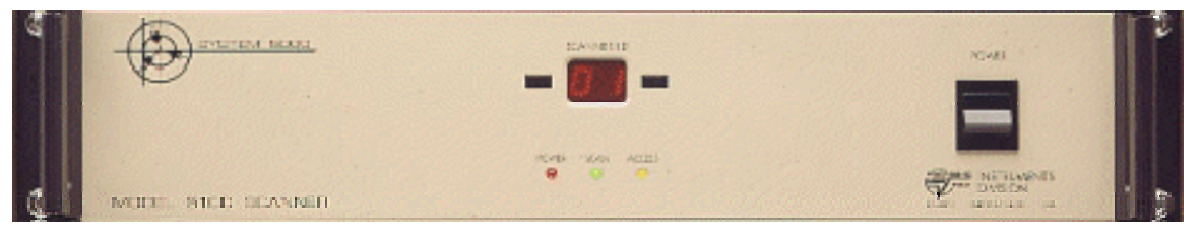

Model 5100 Scanner Front Panel

Sensor connections are quickly made to the cards at the rear of each scanner in System 5000. Strain gage cards include built-in bridge completion for quarter and half bridges, and a constant voltage power supply for $0,0.5,1,2,5$, and $10 \mathrm{~V}$ dc bridge excitation.

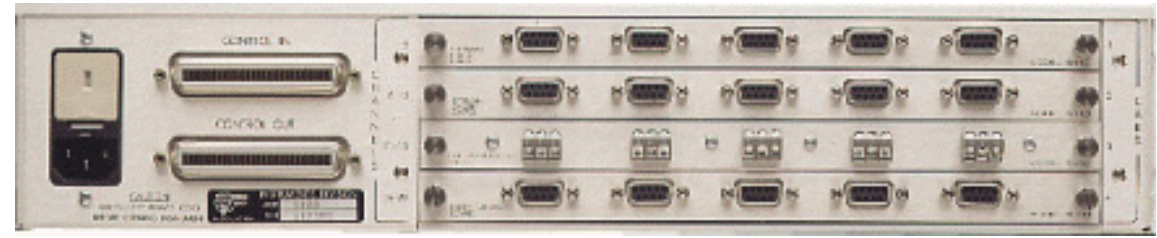

Model 5100 Scanner Rear Panel

Since each Model 5100 Scanner can function independently, your System 5000 components can be easily configured for each test requirement. A 100-channel system, for example, can be used as five independent 20-channel systems simply by purchasing additional software/interface hardware installations.

\section{Specifications}

\section{Inputs:}

Accepts up to four cards (five channels per card and up to 20 channels per scanner).

\section{A/D CONVERTER:}

16-bit (15-bit plus sign) successive approximation converter. Usable resolution is typically 15 bits. $40 \mu_{\mathrm{S}}$ total conversion time per reading.

\section{SCAN RATE:}

$1 \mathrm{~ms}$ per scan. Fifty complete scans per second typical usage. Concurrent scanning for all scanners.

Input channels in each single scanner are scanned sequentially at 0.04-ms intervals and 
stored in random access memory within a 1-ms window.

OPERATIONAL ENVIRONMENT:

Temperature : $-10^{\circ}$ to $+50^{\circ} \mathrm{C}$.

Humidity : Up to $90 \% \mathrm{RH}$, non-condensing.

Size

$3.5 \mathrm{H} \times 19 \mathrm{~W} \times 16 \mathrm{D}$ in $(89 \times 483 \times 381 \mathrm{~mm})$

Weight

$16 \mathrm{lb}(7.25 \mathrm{~kg})$

Power

115 or $230 \mathrm{~V}$ ac user-selectable; $\pm 10 \%$ of setting; $50 / 60 \mathrm{~Hz}$; $140 \mathrm{~W}$ max.

http://www.vishay.com/brands/measurements_group/guide/inst/5000/5100.htm 


\section{A.11 - MTS 810 HYDRAULIC TESTING MACHINE}

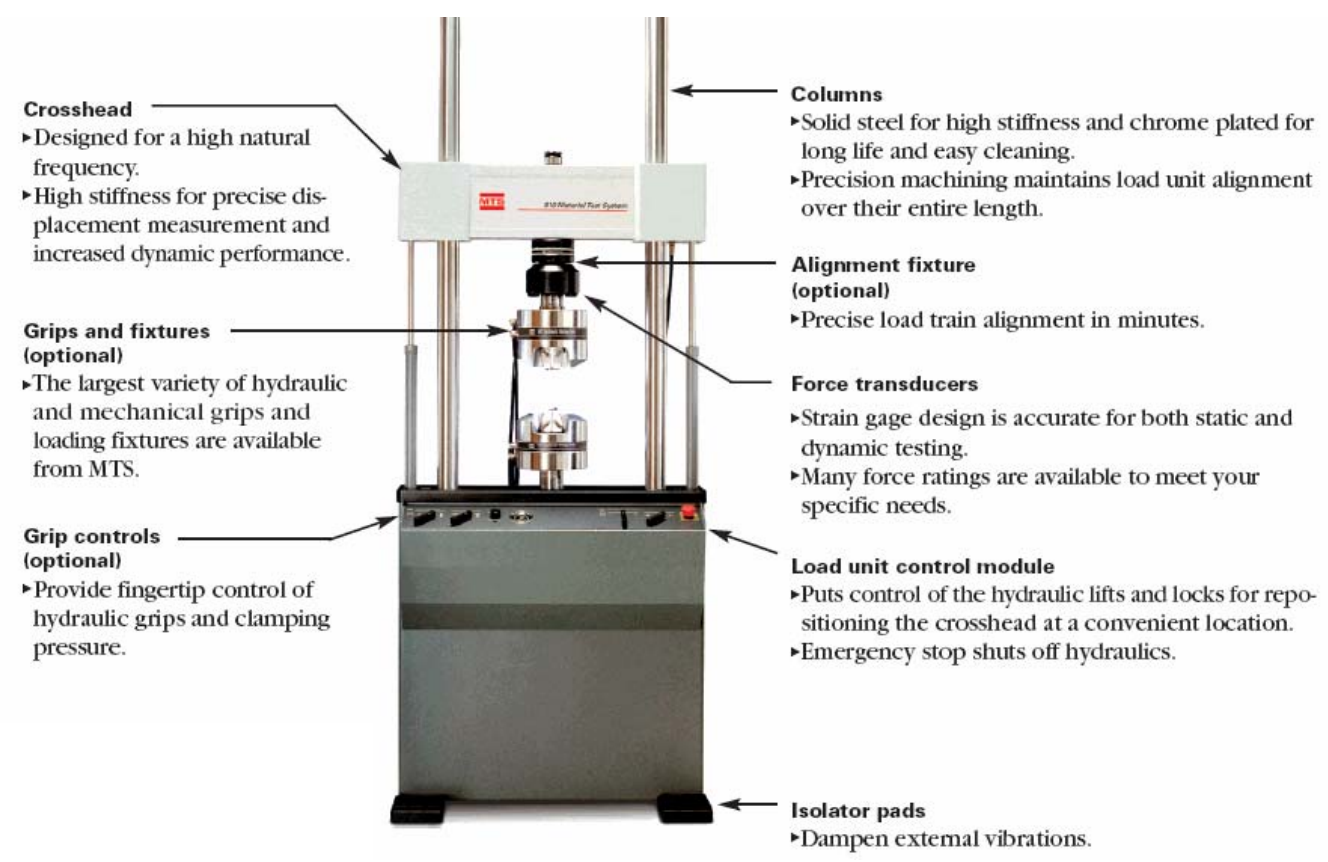

\section{Basic Specifications}

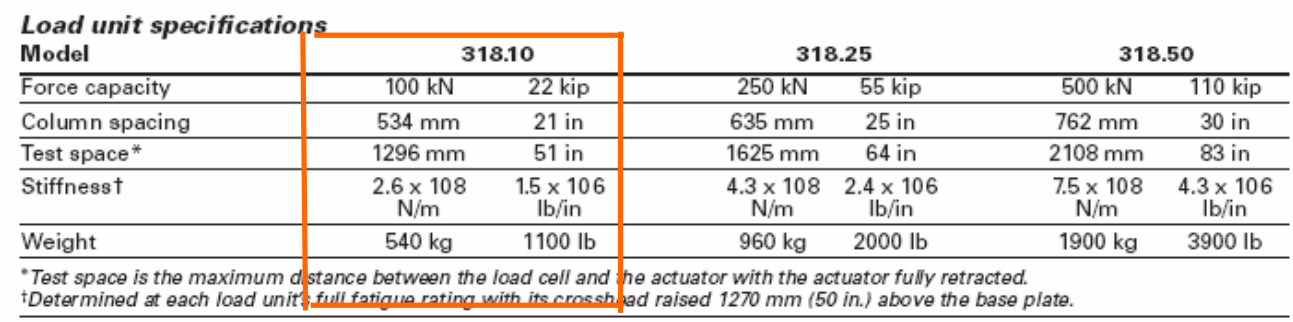

Hydraulic power supply specifications

\begin{tabular}{|c|c|c|c|c|c|c|c|c|c|}
\hline \multirow{2}{*}{$\frac{\text { Model }}{\text { Flow rate }}$} & \multicolumn{2}{|c|}{505.07} & \multicolumn{3}{|c|}{505.11} & \multicolumn{2}{|c|}{505.20} & \multicolumn{2}{|c|}{505.30} \\
\hline & Ipm & gpm & & $\mathrm{Ipm}$ & gpm & Ipm & gpm & $\mathrm{Ipm}$ & gpm \\
\hline At $50 \mathrm{~Hz}$ & 22.7 & 6 & & 41.6 & 11 & 62.5 & 16.5 & 100.7 & 26.6 \\
\hline At $60 \mathrm{~Hz}$ & 26.5 & 7 & & 41.6 & 11 & 75 & 20 & 113 & 30 \\
\hline \multicolumn{10}{|c|}{ Servovalve specifications } \\
\hline Model & & & 252.21 & & 252.22 & 252.23 & & 252.24 & 252.55 \\
\hline Flow ratin & $\mathrm{pm)}$ & & $4.0(1.0)$ & & $9.5(2.5)$ & $19(5.0)$ & & $37(10)$ & $56(15)$ \\
\hline \multicolumn{10}{|c|}{ Hydraulic actuator manifold specifications } \\
\hline \multicolumn{3}{|c|}{ Model } & \multicolumn{3}{|c|}{298.10} & \multicolumn{2}{|l|}{298.11} & \multicolumn{2}{|c|}{298.12} \\
\hline \multicolumn{3}{|c|}{ Station pressure control } & \multicolumn{3}{|c|}{ none } & \multicolumn{2}{|c|}{ off/high } & \multicolumn{2}{|c|}{ off/low/high } \\
\hline \multicolumn{3}{|c|}{ Accumulators } & \multicolumn{3}{|c|}{$\begin{array}{c}1 \text { liter ( } 1 \mathrm{qt} \text { ) pressure } \\
\text { and return }\end{array}$} & \multicolumn{2}{|c|}{$\begin{array}{c}1 \text { liter ( } 1 \mathrm{qt} \text { ) pressure } \\
\text { and return }\end{array}$} & \multicolumn{2}{|c|}{$\begin{array}{c}1 \text { liter (1 qt) pressure } \\
\text { and return }\end{array}$} \\
\hline
\end{tabular}

http://www.mts.com/stellent/groups/public/documents/library/dev_002083.pdf 


\section{A.12 - GRIPS FOR MTS 810 HYDRAULIC TEST MACHINE - 1}

Griffin Testing Products

P.O Box 146

Seneca, SC 29679

Tel: 1800-793-4743

www.Griffgrips.com

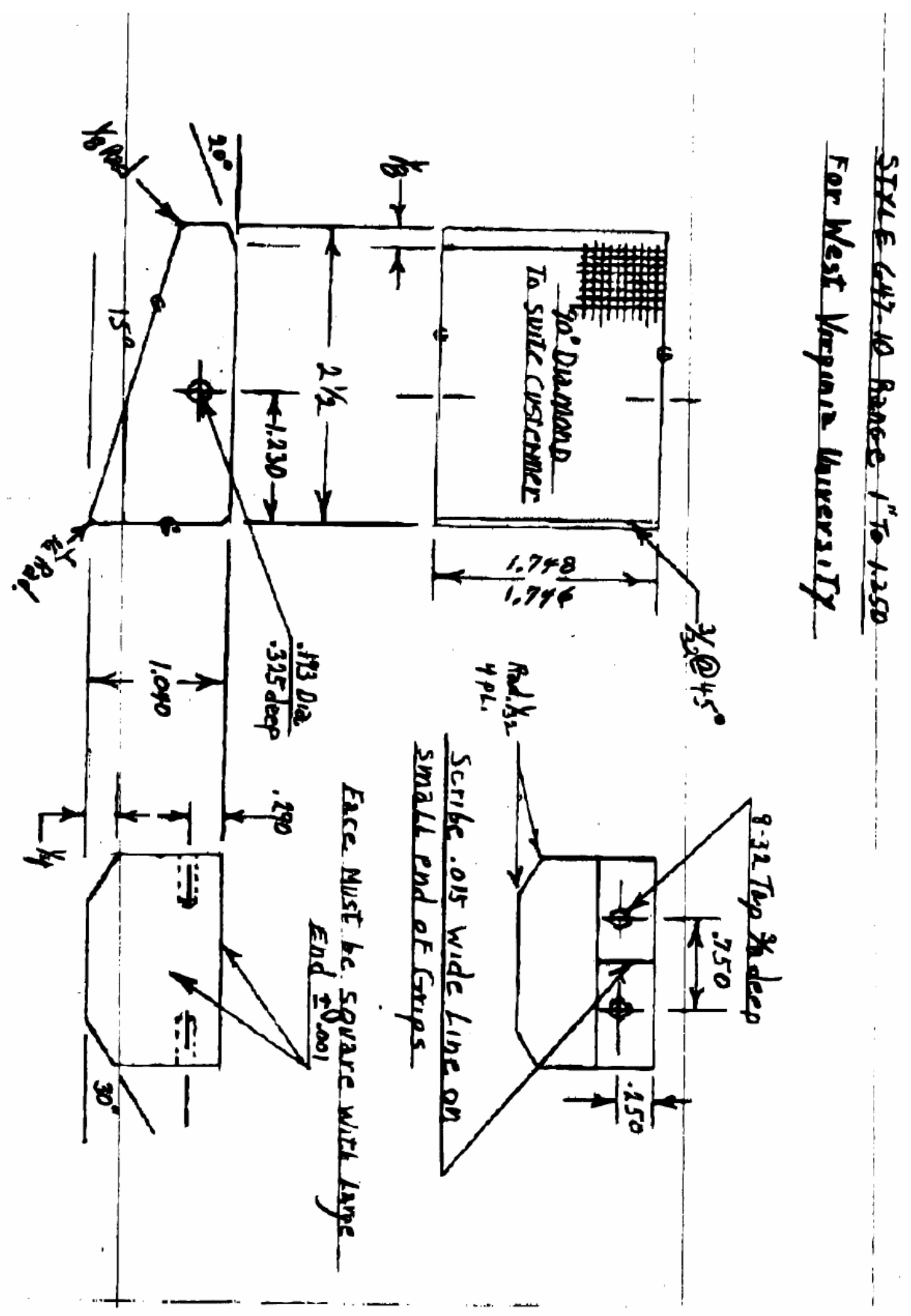




\section{A. 12 - GRIPS FOR MTS 810 HYDRAULIC TEST MACHINE - 11}

\section{Regional Office}

Griffin Testing Products, In

501 Bank Street

Derry, PA 15627

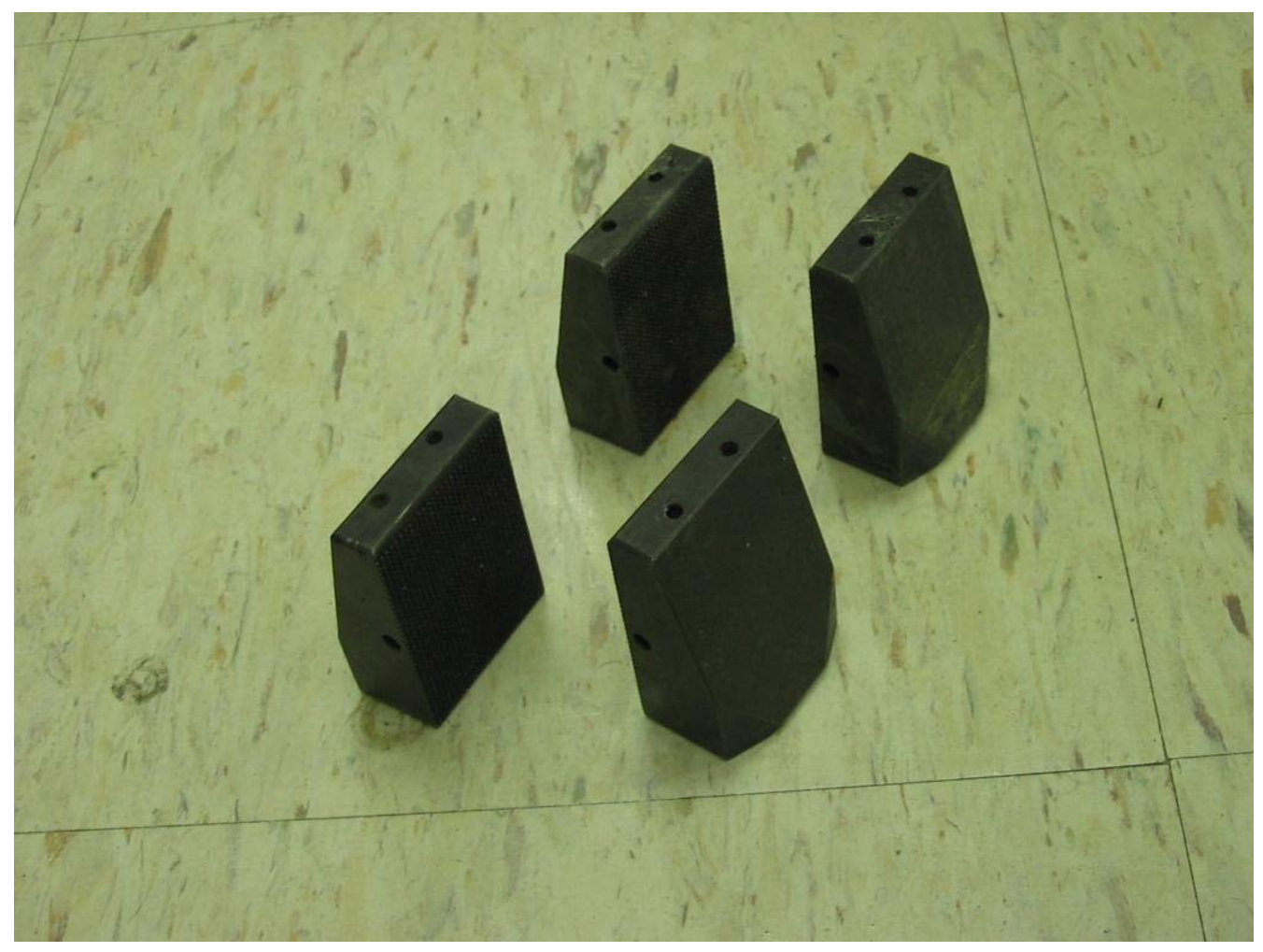

Grips for MTS 810 